\title{
Drying and Oxidation of Surface-Disposed Paste Tailings
}

\author{
by
}

\section{Rachel Bryan}

B.Sc. in Biochemistry

University of Guelph

\author{
A thesis submitted to the \\ Faculty of Graduate Studies and Research \\ in partial fulfillment of the requirements \\ for the degree of \\ Master of Applied Science \\ Ottawa-Carleton Institute of Civil and Environmental Engineering \\ Carleton University \\ Ottawa, Ontario, Canada \\ December, 2008
}

(C) Copyright

2008, Rachel Bryan 


$\begin{array}{ll}\begin{array}{l}\text { Library and } \\ \text { Archives Canada }\end{array} & \begin{array}{l}\text { Bibliothèque et } \\ \text { Archives Canada }\end{array} \\ \begin{array}{l}\text { Published Heritage } \\ \text { Branch }\end{array} & \begin{array}{l}\text { Direction du } \\ \text { Patrimoine de l'édition }\end{array} \\ \begin{array}{l}\text { 395 Wellington Street } \\ \text { Ottawa ON K1A 0N4 } \\ \text { Canada }\end{array} & \begin{array}{l}\text { O95, rue Wellington } \\ \text { Ottawa ON K1A 0N4 } \\ \text { Canada }\end{array}\end{array}$

Your file Votre référence ISBN: 978-0-494-47508-9

Our file Notre référence

ISBN: 978-0-494-47508-9

NOTICE:

The author has granted a nonexclusive license allowing Library and Archives Canada to reproduce, publish, archive, preserve, conserve, communicate to the public by telecommunication or on the Internet, loan, distribute and sell theses worldwide, for commercial or noncommercial purposes, in microform, paper, electronic and/or any other formats.

The author retains copyright ownership and moral rights in this thesis. Neither the thesis nor substantial extracts from it may be printed or otherwise reproduced without the author's permission.
AVIS:

L'auteur a accordé une licence non exclusive permettant à la Bibliothèque et Archives Canada de reproduire, publier, archiver, sauvegarder, conserver, transmettre au public par télécommunication ou par l'Internet, prêter, distribuer et vendre des thèses partout dans le monde, à des fins commerciales ou autres, sur support microforme, papier, électronique et/ou autres formats.

L'auteur conserve la propriété du droit d'auteur et des droits moraux qui protège cette thèse. $\mathrm{Ni}$ la thèse ni des extraits substantiels de celle-ci ne doivent être imprimés ou autrement reproduits sans son autorisation.
In compliance with the Canadian

Privacy Act some supporting forms may have been removed from this thesis.

While these forms may be included in the document page count, their removal does not represent any loss of content from the thesis.
Conformément à la loi canadienne sur la protection de la vie privée, quelques formulaires secondaires ont été enlevés de cette thèse.

Bien que ces formulaires aient inclus dans la pagination, il n'y aura aucun contenu manquant.

\section{Canada}




\section{Abstract}

Surface deposition of paste tailings has been used at the Bulyanhulu Gold Mine in Tanzania since 2001, but little is known about sulphide mineral oxidation in the paste storage facility. The rate of pyrite oxidation in a freshly deposited layer of paste depends on the rate of oxygen diffusion and the reaction kinetics. A coupled soil-atmosphere evaporation model (SoilCover) and a 1-D diffusive transport model (POLLUTE) were used to predict the extent of drying, oxygen ingress and sulphide consumption in layers of paste tailings. The results of the models agreed well with experimental results from small-scale and column laboratory tests, regardless of crack formation. The models were then used to develop a conservative estimate of pyrite oxidation at Bulyanhulu. Based on the results of the laboratory testing program and model simulations, it was concluded that acid drainage conditions could occur in the Bulyanhulu tailings storage facility. 


\section{Acknowledgements}

First and foremost I would like to thank my supervisors Dr. Paul Simms and Dr. Rens Verburg. Dr. Simms was always available on campus to answer questions and give direction during my research, for which I am very grateful. Dr. Verburg's experience working with acid-generating paste tailings was a great asset. His insightful suggestions on the experimental design and analysis were much appreciated and he was always available for consultation if needed. I am grateful to both Dr. Simms and Dr. Verburg for reading numerous drafts of my thesis and providing their comments and suggestions.

I would also like to thank a number of other people who contributed in various ways to this research: Dr. Ulrich Mayer for the help with MIN3P, Bereket Fisseha for the hours and hours of time spent in the lab, Peter Jones for his time and expertise in light and electron microscopy, Ron Hartree for help with the XRD analysis, Stan Conley for the technical assistance in setting up the data collection system, Marie Tudoret Chow for the help with the IC analysis, Dr. Fred Michel for providing the pore water squeezers and Dr. Paul Van Geel for providing the large tank and the column. 


\section{Table of Contents}

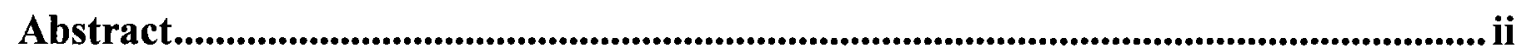

Acknowledgements ...............................................................................................................................iii

Table of Contents ........................................................................................................................... iv

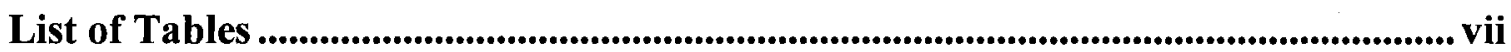

List of Figures.................................................................................................................................. viii

List of Appendices..................................................................................................................... xi

List of Acronyms ............................................................................................................................ xii

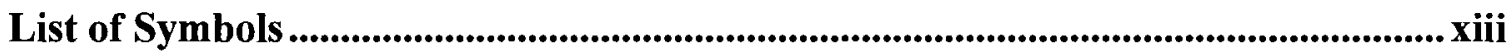

Chapter 1: Introduction .............................................................................................................. 1

1.1 Conventional vs. Paste Tailings Disposal ........................................................ 1

$1.2 \quad$ Study Objectives ....................................................................................... 3

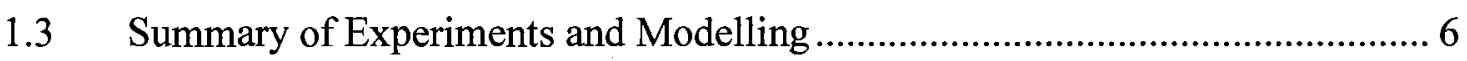

Chapter 2: Literature Review...................................................................................................... 8

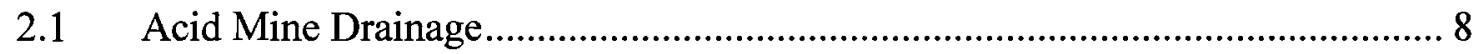

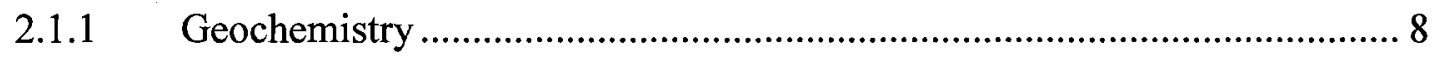

2.1.2 Treatments for Acid Mine Drainage .................................................. 13

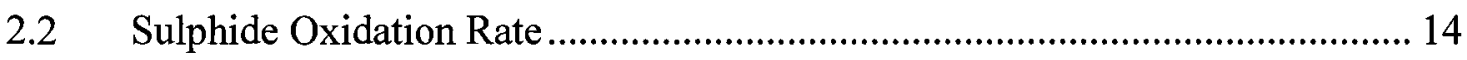

2.2.1 Mass Transfer through the Pore Space ………......................................... 15

2.2.2 Diffusion to the Active Grain Surface ...................................................... 18

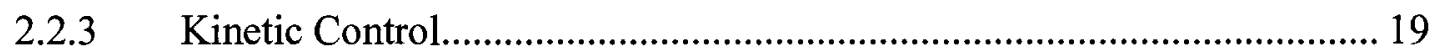

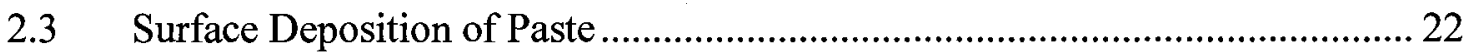

2.3.1 Paste Technology Basics....................................................................... 23 
2.3.2 Acid Drainage Potential of Paste Tailings .................................................. 25

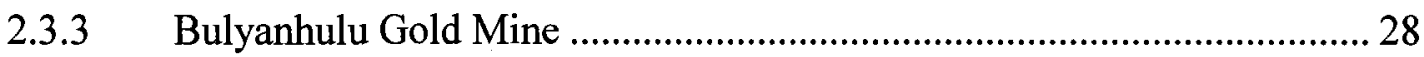

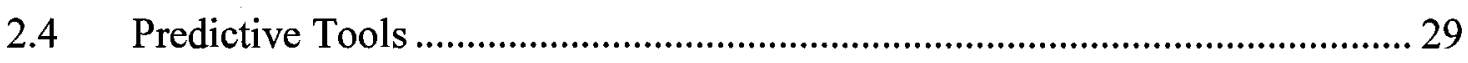

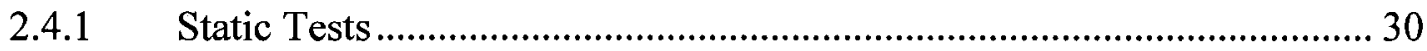

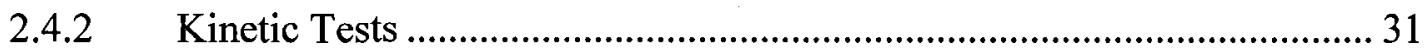

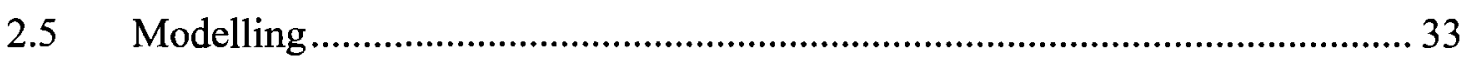

2.5.1 Background ........................................................................................ 33

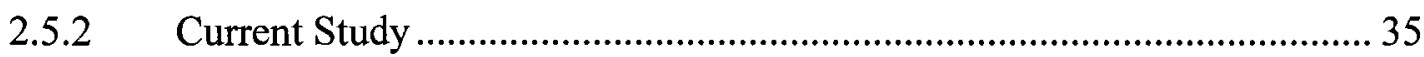

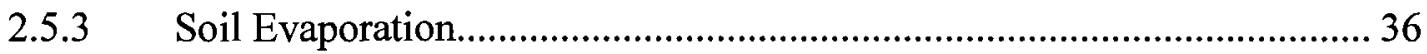

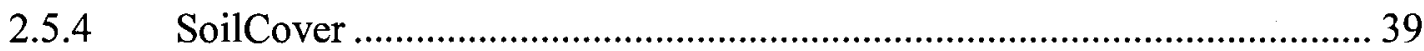

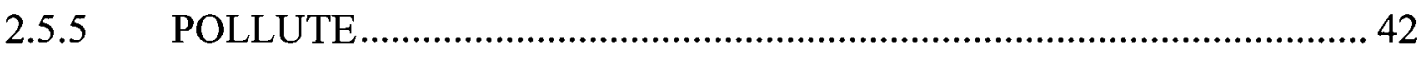

Chapter 3: Initial Tailings Characterization............................................................................... 44

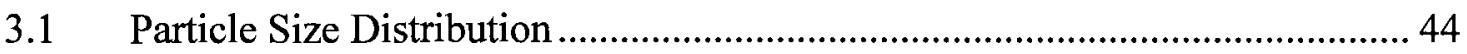

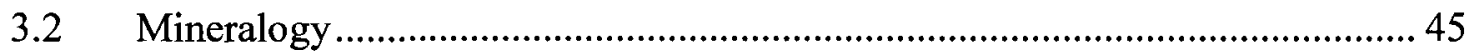

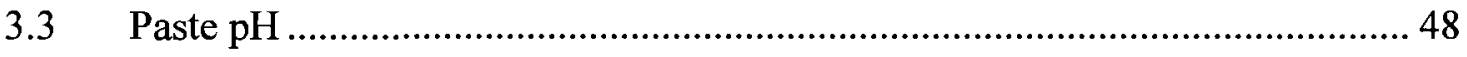

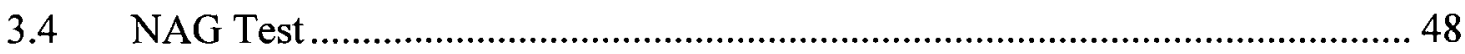

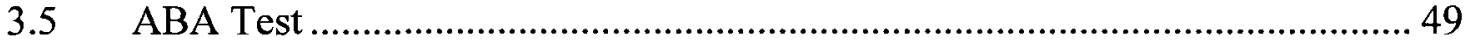

3.6 Grain Analysis and Long-Term Rewetting Test...............................................50

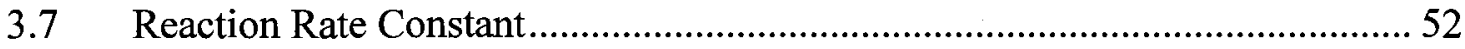

Chapter 4: Small-Scale Test...................................................................................... 55

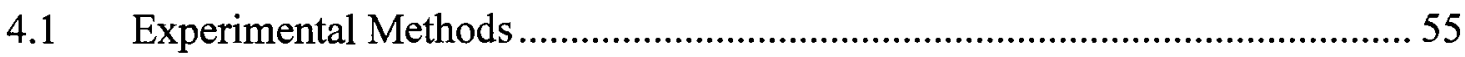

4.2 Modelling Methods.................................................................................... 58

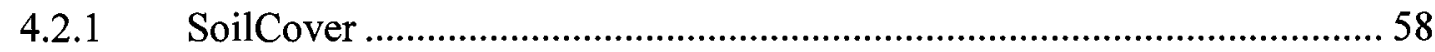




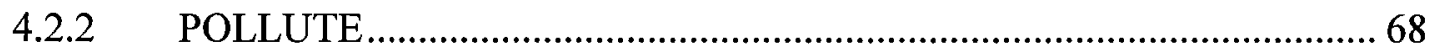

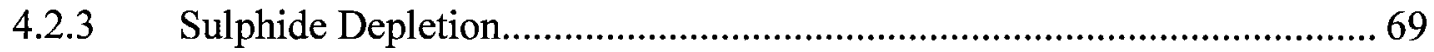

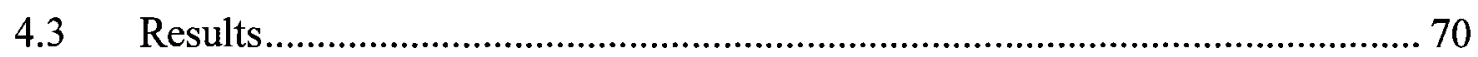

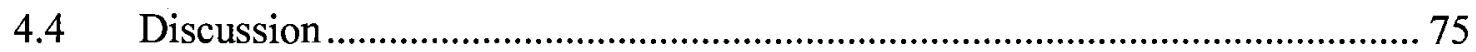

Chapter 5: Large-Scale Test ......................................................................................................... 79

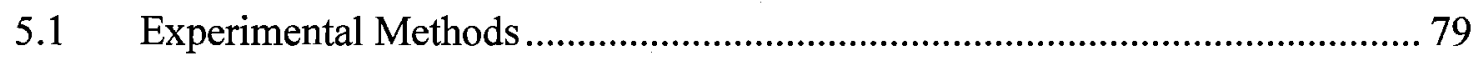

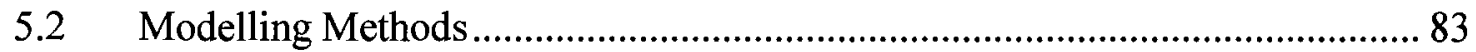

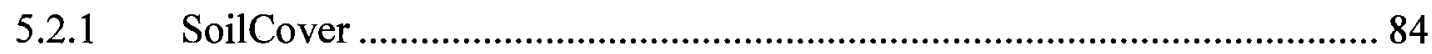

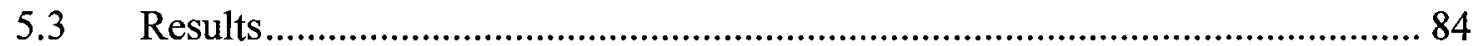

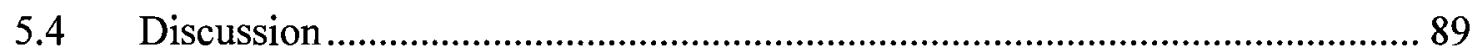

Chapter 6: Column Tests .......................................................................................................... 91

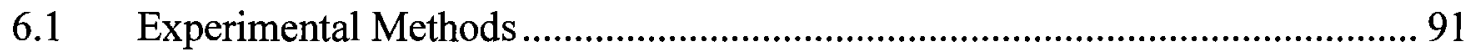

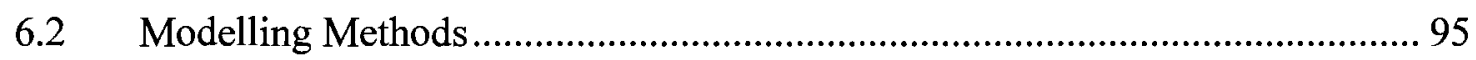

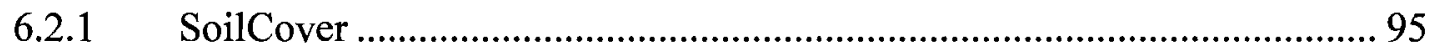

6.2.2 Sulphide Depletion............................................................................... 96

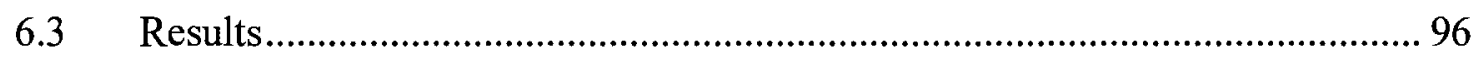

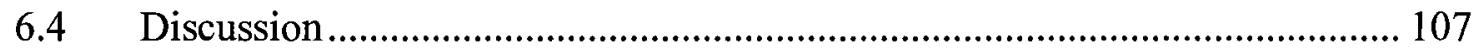

Chapter 7: Application to Bulyanhulu...................................................................... 111

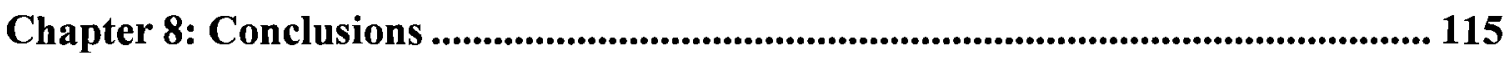

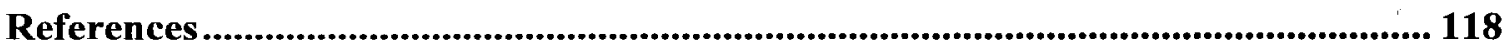




\section{List of Tables}

Table 2.1 Description of the iron-sulphide alteration index .......................................33

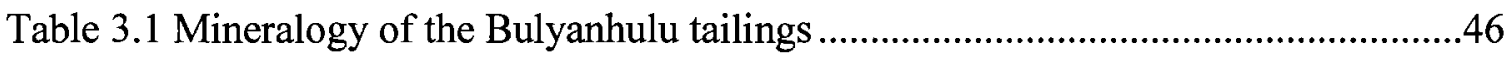

Table 3.2 Sulphate and metal/metalloid concentrations in the solid phase of the

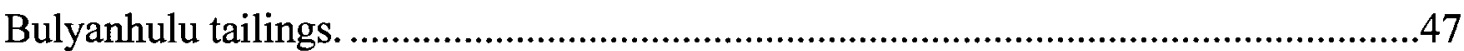

Table 3.3 Sulphide depletion during the long-term rewetting test.................................52

Table 4.1 Matric suction sensor locations in the small-scale test ..................................56

Table 4.2 Summary of the vertical shrinkage and change in void ratio during the

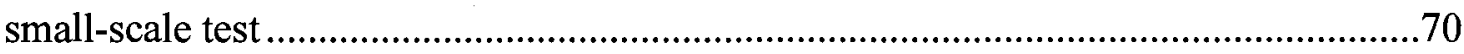

Table 4.3 Mean absolute error values between measured and modelled sulphide

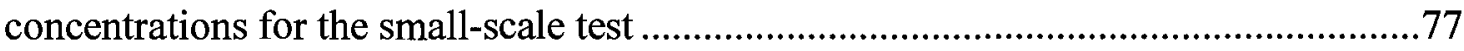

Table 5.1 Matric suction sensor locations in the large-scale test.................................81

Table 5.2 Change in tailings volume and surface area during the large-scale test ...........85

Table 6.1 Matric suction sensor locations in the column tests ....................................93

Table 6.2 Comparison of pore water quality before and after the column tests .............107

Table 6.3 Mean absolute error values between measured and modelled sulphide concentrations for the column tests................................................................ 108 


\section{List of Figures}

Figure 2.1 Effective diffusion coefficient of oxygen as a function of soil saturation .......17

Figure 2.2 Tailings storage facility at the Bulyanhulu Gold Mine in Tanzania ................29

Figure 2.3 Flow chart of sulphide oxidation modelling...................................................36

Figure 2.4 Relative humidity at the soil surface as a function of total suction...................38

Figure 3.1 Particle size distribution of the Bulyanhulu tailings..........................................45

Figure 3.2 Unoxidized tailings grains viewed under reflected light ...................................51

Figure 3.3 Determination of the first-order reaction rate constant for pyrite oxidation

by oxygen based on sulphide depletion over a 150-day rewetting test...........................53

Figure 4.1 Schematic diagram showing the setup for the small-scale test .........................55

Figure 4.2 Soil-water characteristic curve for the Bulyanhulu tailings ..............................61

Figure 4.3 Shrinkage curve due to self-weight consolidation........................................63

Figure 4.4 Shrinkage curve due to matric suction .............................................................64

Figure 4.5 Effect of volume change on prediction of the relative hydraulic

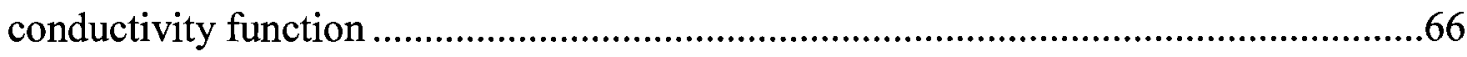

Figure 4.6 Effect of $K_{r}$ and mesh size on evaporation rate and suction profile

predictions using SoilCover .......................................................................................67

Figure 4.7 Measured and modelled evaporation during the small-scale test......................71

Figure 4.8 Measured and modelled matric suctions during the small-scale test ................72

Figure 4.9 POLLUTE-modelled oxygen concentration profile during the small-scale

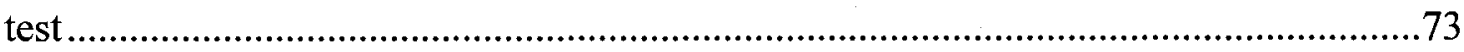

Figure 4.10 Sulphide depletion during the small-scale test ..............................................74 
Figure 4.11 Sensitivity of modelled sulphide depletion to particle diameter

Figure 5.1 Photos of the large-scale test setup........................................................

Figure 5.2 Schematic diagram showing the setup for the large-scale test .....................82

Figure 5.3 Photos of salt precipitation and cracking during the large-scale test ..............86

Figure 5.4 Measured and modelled evaporation during the large-scale test...................87

Figure 5.5 Measured and modelled matric suctions during the large-scale test...............88

Figure 5.6 Electrical conductivity and osmotic suction of tailings pore water during

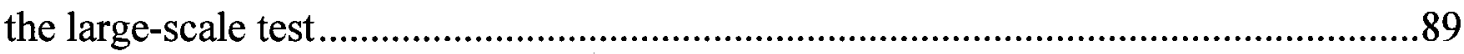

Figure 6.1 Photo of the column test setup..........................................................92

Figure 6.2 Schematic diagram showing the setup for the column tests........................94

Figure 6.3 Change in void ratio, degree of saturation and normalized surface area

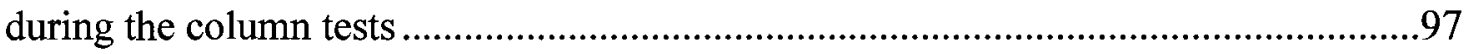

Figure 6.4 Measured and modelled evaporation during the column tests ........................99

Figure 6.5 Measured and modelled matric suctions during the Cracked Column test ....100

Figure 6.6 Measured and modelled matric suctions during the Sealed Column test.......101

Figure 6.7 Measured and modelled gaseous oxygen concentrations during the column

tests

Figure 6.8 Measured and modelled sulphide concentration in the solid phase at the

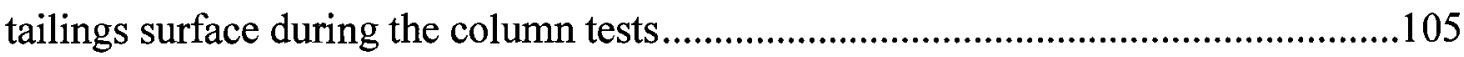

Figure 6.9 Measured and modelled sulphide concentration in the solid phase with

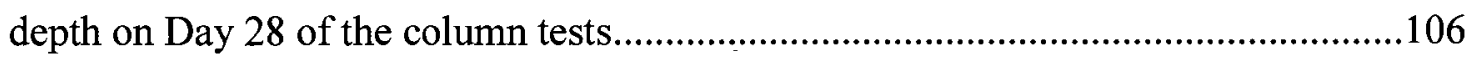

Figure 7.1 Evaporation during a 5-layer, 150-day simulation of paste deposition at

Bulyanhulu

.112 
Figure 7.2 Sulphide depletion with depth during a 5-layer, 150-day simulation of paste deposition at Bulyanhulu....... 


\section{List of Appendices}

A. Effect of shrinking particle diameter on oxidation rate ...................................... 131

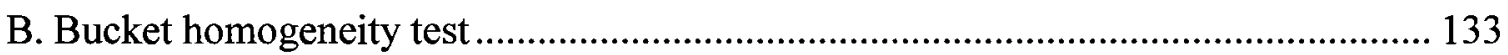

C. Long-term rewetting test: Rewetting and sampling dates .................................... 134

D. Weather conditions defining the top boundary condition in SoilCover.................... 135

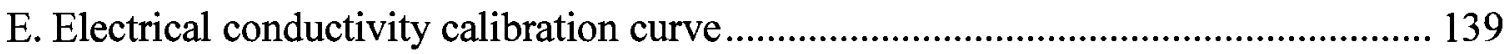

F. Large-scale test sulphide depletion results ....................................................... 140

G. Horizontal profile of sulphide content ........................................................ 142 


\section{List of Acronyms}

\begin{tabular}{|c|c|}
\hline $\mathrm{ABA}$ & Acid-base accounting \\
\hline AMD & Acid mine drainage \\
\hline $\mathrm{AP}$ & Acid-producing potential \\
\hline ASTM & American Society for Testing and Materials \\
\hline ATP & Adenosine triphosphate \\
\hline DO & Dissolved oxygen \\
\hline $\mathrm{EC}$ & Electrical conductivity \\
\hline GWC & Gravimetric water content \\
\hline HD sensors & Heat dissipation matric water potential sensors \\
\hline IC & Inorganic carbon \\
\hline ICP-MS & Inductively coupled plasma with mass spectrometer \\
\hline MAE & Mean absolute error \\
\hline MEND & Mine Environment Neutral Drainage Program \\
\hline $\mathrm{NADH}$ & Nicotinamide adenine dinucleotide \\
\hline NAG & Net acid generation \\
\hline NNP & Net neutralization potential \\
\hline NP & Neutralization potential \\
\hline NPR & Net potential ratio \\
\hline SEM-EDS & Scanning electron microprobe with energy dispersive analyzer \\
\hline SWCC & Soil-water characteristic curve \\
\hline TSF & Tailings storage facility \\
\hline XRD & $\mathrm{X}$-ray diffraction \\
\hline
\end{tabular}




\section{List of Symbols}

In order of appearance:

$K_{s p} \quad$ Solubility product constant

$\Delta G^{\circ} \quad$ Standard Gibbs free energy of formation $(\mathrm{kJ} / \mathrm{mol})$

F Diffusive flux $\left(\mathrm{mol} / \mathrm{m}^{2} / \mathrm{s}\right)$

$D \quad$ Diffusion coefficient $\left(\mathrm{m}^{2} / \mathrm{s}\right)$

$\frac{d C}{d z} \quad$ Concentration gradient $\left(\mathrm{mol} / \mathrm{m}^{3} / \mathrm{m}\right)$

$D_{\text {eff }} \quad$ Effective diffusion coefficient of oxygen $\left(\mathrm{m}^{2} / \mathrm{s}\right)$

n Porosity

$D_{a}^{0} \quad$ Free diffusion coefficient of oxygen in air at room temperature $\left(\mathrm{m}^{2} / \mathrm{s}\right)$

$\theta_{a} \quad$ Volumetric air content of the tailings

$p \quad$ Tortuosity fitting parameter

$H \quad$ Henry's equilibrium constant

$D_{w}^{0} \quad$ Free diffusion coefficient of oxygen in water at room temperature $\left(\mathrm{m}^{2} / \mathrm{s}\right)$

$\theta_{w} \quad$ Volumetric water content of the tailings

$S_{s} \quad$ Specific surface area of pyrite $\left(\mathrm{m}^{2} / \mathrm{kg}\right)$

$\rho \quad$ Particle density $\left(\mathrm{kg} / \mathrm{m}^{3}\right)$

d $\quad$ Mean particle diameter (m)

$r \quad$ Reaction rate (mol/day)

$k \quad$ Reaction rate constant

a Reaction order with respect to oxygen 


\begin{tabular}{|c|c|}
\hline$A$ & Pre-exponential factor \\
\hline$R$ & Gas constant $(\mathrm{kJ} / \mathrm{mol} / \mathrm{K})$ \\
\hline$T$ & Temperature $(\mathrm{K})$ \\
\hline$E_{a}$ & Activation energy $(\mathrm{kJ} / \mathrm{mol})$ \\
\hline$r_{p y}$ & Rate of pyrite destruction $\left(\mathrm{mol} / \mathrm{m}^{2} / \mathrm{s}\right)$ \\
\hline$m$ & Species concentration $(\mathrm{mol} / \mathrm{kg})$ \\
\hline$r_{O_{2}}$ & Rate of oxygen consumption $\left(\mathrm{mol} / \mathrm{m}^{2} / \mathrm{s}\right)$ \\
\hline$P_{\mathrm{O}_{2}}$ & Partial pressure of oxygen (atm) \\
\hline$K_{s}$ & Saturated hydraulic conductivity $(\mathrm{m} / \mathrm{s})$ \\
\hline$S$ & Sink term (mol/L/day) \\
\hline$u_{a}-u_{w}$ & Pressure difference across the air-water interface $(\mathrm{Pa})$ \\
\hline$T_{s}$ & Surface tension $\left(\mathrm{J} / \mathrm{m}^{2}\right)$ \\
\hline$\sigma$ & Contact angle \\
\hline$r_{\text {pore }}$ & Pore radius $(\mathrm{m})$ \\
\hline$h_{r}$ & Relative humidity at the soil surface \\
\hline$\Psi$ & Total suction $(\mathrm{m})$ \\
\hline$g$ & Acceleration due to gravity $\left(\mathrm{m} / \mathrm{s}^{2}\right)$ \\
\hline$W_{v}$ & Molecular weight of water $(\mathrm{kg} / \mathrm{mol})$ \\
\hline$\Psi_{m}$ & Matric suction \\
\hline$\Psi_{s}$ & Osmotic suction \\
\hline$E C$ & Electrical conductivity $(\mathrm{mS} / \mathrm{cm})$ \\
\hline
\end{tabular}




\begin{tabular}{|c|c|}
\hline$h_{w}$ & Total head (m) \\
\hline$t$ & Time (s) \\
\hline$C_{w}^{1}$ & Coefficient of consolidation with respect to the liquid water phase \\
\hline$y$ & Elevation (m) \\
\hline$k_{w}$ & Hydraulic conductivity $(\mathrm{m} / \mathrm{s})$ \\
\hline$C_{w}^{2}$ & Coefficient of consolidation with respect to the water vapour phase \\
\hline$D_{v}$ & Diffusion coefficient of water vapour $(\mathrm{kg} \cdot \mathrm{m} / \mathrm{kN} \cdot \mathrm{s})$ \\
\hline$P_{v}$ & Partial pressure of water vapour $(\mathrm{kPa})$ \\
\hline$C_{h}$ & Volumetric specific heat of the soil $\left(\mathrm{J} / \mathrm{m}^{3} / \mathrm{K}\right)$ \\
\hline$\lambda$ & Thermal conductivity of the soil $(\mathrm{W} / \mathrm{m} / \mathrm{K})$ \\
\hline$L_{v}$ & Latent heat of vapourization of water $(\mathrm{J} / \mathrm{kg})$ \\
\hline$P$ & Total gas pressure in the air phase $(\mathrm{kPa})$ \\
\hline E & Evaporative flux (mm/day) \\
\hline$\Gamma$ & $\begin{array}{l}\text { Slope of the saturation vapour pressure vs. temperature curve at the mean } \\
\text { temperature of the air }\end{array}$ \\
\hline$Q$ & Net radiant energy available at the surface ( $\mathrm{mm} /$ day) \\
\hline$v$ & Psychrometric constant \\
\hline$E_{w}$ & Evaporation from wind (mm/day) \\
\hline$A$ & Inverse of the relative humidity at the soil surface \\
\hline$f(u)$ & Function of wind speed, surface roughness, and eddy diffusion \\
\hline$P_{a}$ & Vapour pressure in the air above the evaporating surface \\
\hline$B$ & Inverse of the relative humidity of the air \\
\hline
\end{tabular}


Mass concentration of oxygen $(\mathrm{mg} / \mathrm{L})$

Elevation (m)

First-order removal constant for oxygen $\left(\right.$ day $\left.^{-1}\right)$

Neutralization potential $\left(\mathrm{kg} \mathrm{CaCO}_{3} / \mathrm{t}\right)$

Concentration of $\mathrm{HCl}(\mathrm{M})$

Concentration of $\mathrm{NaOH}(\mathrm{M})$

Sample weight $(\mathrm{g})$

Volume of $\mathrm{HCl}$ added (mL)

Volume of $\mathrm{NaOH}$ added $(\mathrm{mL})$

Acid-producing potential $\left(\mathrm{kg} \mathrm{CaCO}_{3} / \mathrm{t}\right)$

Net neutralization potential $\left(\mathrm{kg} \mathrm{CaCO}_{3} / \mathrm{t}\right), \mathrm{NNP}=\mathrm{NP}-\mathrm{AP}$

Net potential ratio, NPR $=$ NP/AP

Heat dissipation sensor calibration parameter

Heat dissipation sensor calibration parameter

Heat dissipation sensor calibration parameter

Heat dissipation sensor calibration parameter

Slope of the soil-water characteristic curve in the positive pore pressure range $\left(\mathrm{kPa}^{-1}\right)$

Relative hydraulic conductivity function 


\section{Chapter 1: Introduction}

The focus of this research is on the early stages of pyrite oxidation in paste tailings from the Bulyanhulu Gold Mine owned and operated by Barrick Gold in Tanzania. The thesis is organized into eight chapters with references and appendices following the main body. The first part of this chapter provides an overview of the problems commonly associated with conventional tailings disposal, setting the scene for the recent interest in surface deposition of paste tailings; the second part describes the research objectives; and the third part summarizes the experimental and modelling work that was done for the thesis.

\subsection{Conventional vs. Paste Tailings Disposal}

Mine tailings are the waste product of the milling process. In many gold mines, more than $95 \%$ of the mined materials end up as tailings (Blowes et al., 2003). Tailings are composed of finely ground host rock, gangue minerals, and small amounts of unrecovered ore minerals. At most mine sites, the tailings and process water are pumped as a slurry to surface impoundments, where they are retained behind large dams. In spite of improvements in impoundment design, several environmental concerns remain associated with these facilities.

The most dramatic environmental concern is the high incidence of tailings-dam failures. Davies (2002) reviewed case histories in the worldwide database of mine tailings impoundment failures and reported that the probability of failure for tailings dams is between 1 in 700 and 1 in 1,750 , compared to 1 in 10,000 for conventional waterretention dams. 
The consequences of impoundment dam failures can be devastating. For example, the 1985 Stava tailings dam failure in Northern Italy killed 265 people (Chandler and Tosatti, 1995); the 1998 Aznalcóllar dam failure at the Los Frailes Mine in Spain released 5.5 million $\mathrm{m}^{3}$ of acidic water and 1.3 million $\mathrm{m}^{3}$ of heavy-metal bearing tailings over 4,600 hectares of arable land (Hudson-Edwards et al., 2003); and two dam failures in Romania, both in 2000 released $200,000 \mathrm{~m}^{3}$ of contaminated water and 40,000 tonnes of tailings into tributaries of the Danube River. The high concentrations of cyanide and metals resulted in fish kills as far downstream as Hungary, Serbia and Bulgaria (Macklin et al., 2003).

The more gradual release of contaminated water through small breaches and leaks in the impoundment facility is a pervasive environmental problem. This type of uncontrolled and sometimes undetected drainage can occur during mining and long after mining ceases (Blowes et al., 2003). The effluent may be acidic and/or contain high concentrations of heavy metals. If it is not captured and treated, the leachate can contaminate groundwater and surface-water resources.

Many of the problems with conventional slurried-tailings disposal result from the differential settling of particles. The coarse fraction of the tailings particles will tend to settle more quickly and remain nearer the discharge pipe. Due to its higher porosity, it is difficult to maintain a water cover over the coarse tailings fraction (Martin et al., 2006). Consequently, reactive sulphide minerals found in the tailings may be exposed to oxidizing conditions in the air. The coarse fraction also lacks the stabilizing and cementing effect of the fines so it is prone to erosion and dusting (Blight, 2007). Meanwhile, the fine fraction is carried along with the process water to the centre of the 
impoundment where the particles settle beneath the water cover. While this is reasonably effective in limiting oxygen contact, wind and wave action can re-suspend the fines beneath the water cover, exposing them to dissolved oxygen near the surface. Also, the fine fraction mixed with the process water is prone to liquefaction, which may lead to catastrophic failure (Vick, 1990).

The issues surrounding conventional tailings impoundments have led mining, environmental, process, and geotechnical engineers to search for less risky alternatives. Surface deposition of paste tailings is one viable option. Paste denotes tailings that have been dewatered to a high-density mixture of water and fine solid particles. During transport, paste travels in plug flow in the centre of the pipeline and laminar flow at the edges. A paste does not exhibit particle size segregation during transport or at rest and produces minimal bleed water. The solids content of a paste generally ranges from $70-$ $85 \%$ and the consistency as measured by the American Society for Testing and Materials (ASTM) slump cone test is typically between 175 and $250 \mathrm{~mm}$ (Newman, 2003). The aim of paste technology in surface disposal is to create a self-supporting stack of tailings, thus minimizing the requirement for confining dams. One of the pioneering mines in paste technology is Barrick Gold's Bulyanhulu Mine in Tanzania. Bulyanhulu has been using surface paste deposition since its opening in 2001 and supplied the paste tailings for this research.

\subsection{Study Objectives}

While surface paste deposition is in many ways more attractive than conventional disposal, it may still pose a threat for acid drainage. In conventional disposal, a water cover may naturally arise due to water-solid segregation in relatively humid climates. The 
water cover inhibits oxygen ingress into the tailings, thus minimizing sulphide oxidation. With paste tailings there is no water cover and as the tailings dry and desaturate, oxygen can diffuse into the unsaturated pore space where it reacts with pyrite and other sulphide minerals. Over time, this could lead to acid drainage conditions.

Since it is a relatively new technology, the long-term acid drainage potential of paste tailings has not been well-studied. Current industry belief is that the homogeneous nature of paste makes it less likely to produce acid drainage than conventional tailings (Martin et al., 2006; Meggyes and Debreczeni, 2006). First, due to the fines content and the non-segregating nature of paste, high matric suctions are maintained. This raises the capillary fringe and may keep the tailings saturated to near-surface levels, thereby reducing oxidation (Verburg, 2001; Theriault et al., 2003). Second, infiltration is reduced by the natural slope of the surface, the physical barrier created by precipitated salts, and the low hydraulic conductivity. This reduces the volume of potentially acidic leachate being generated (e.g., Verburg, 2001; Newman, 2003; Golder, 2005).

However, at the Bulyanhulu mine site, Shuttleworth et al. (2005) reported visible oxidation in disturbed areas of the tailings storage facility. They also observed that rainwater pooling on the tailings surface had a $\mathrm{pH}<4$. Field tests conducted at Bulyanhulu by Golder Associates found that, 2 months after deposition, the average sulphide mineral content in a layer of paste fell from (approx.) $3.5 \mathrm{wt} \%$ to $2.5 \mathrm{wt} \%$. They found this depletion to be relatively uniform with depth up to the maximum sampling depth of $20 \mathrm{~cm}$ (Golder, 2005). The tailings facility at Kidd Creek Mine near Timmins, $\mathrm{ON}$, has also undergone significant oxidation at the surface ( $\mathrm{Al}$ and Blowes, 1995). Kidd Creek uses thickened tailings (62 wt\% solids) rather than paste tailings, but the two 
disposal methods are relatively similar in that the tailings are dewatered and stacked in conical piles without a water cover (see Section 2.3 for the definitions of slurry, thickened, and paste tailings).

At Bulyanhulu, the deposition strategy is to use thin layers of paste $(10-30 \mathrm{~cm})$ and to cover them every 5 - 30 days either by a fresh layer or a cap of non-tailings material (Deschamps et al., 2008). This strategy aims to prevent oxidation from gaining momentum as a self-perpetuating process in the tailings facility.

The overall goal of this thesis is to investigate the factors affecting the early stages of sulphide oxidation in desiccating paste tailings from the Bulyanhulu Gold Mine. The specific objectives are:

1. Quantify the acid generation potential of the tailings based on mineralogy and static tests;

2. Determine through laboratory testing the rate of initial (circumneutral) pyrite oxidation in paste tailings and describe factors which can affect that rate;

3. Evaluate the effects of cracking and pore water ionic strength on evaporation and sulphide oxidation in a laboratory setting;

4. Evaluate the ability of a one-dimensional soil-atmosphere evaporative flux model (SoilCover) and a one-dimensional oxygen diffusion model (POLLUTE) to simulate the observed drying profile and oxygen ingress over short-term two-layer drying tests; and

5. Based on conservative use of the aforementioned modelling tools, evaluate whether Bulyanhulu's deposition strategy is working to inhibit oxidation from progressing to the point where acid mine drainage could occur. 


\subsection{Summary of Experiments and Modelling}

To achieve the study objectives outlined in the previous section, this thesis included both an experimental component and a modelling component. This section gives the reader a brief overview of the contents of the experimental and modelling chapters to provide some overall cohesion and flow to the thesis.

The first experimental chapter (Chapter 3) describes the initial experimental work done to characterize the tailings. This includes the particle size distribution, mineralogy, $\mathrm{NAG}$ and $\mathrm{ABA}$ tests, grain alteration analysis and determination of the reaction rate constant for pyrite oxidation.

The second experimental chapter (Chapter 4) describes the first drying test. This was a small-scale test used to assess whether the models (SoilCover and POLLUTE) were going to be useful tools in predicting the extent of sulphide oxidation in paste tailings or whether a new approach would be required. The results of the small-scale test confirmed that SoilCover and POLLUTE were useful tools for modelling sulphide oxidation. Therefore, a second experiment was designed to take a closer look at the effects of cracking and salt precipitation on drying and oxidation at a larger scale.

The third experimental chapter (Chapter 5) describes the second drying test, which was a large-scale test $(1.5 \mathrm{~m} \times 1.5 \mathrm{~m}$ test cell). Some interesting observations were made regarding the effect of salt precipitation on the rate of evaporation but since there was no control (un-cracked) test cell to compare it to, it was difficult to measure the effects of cracking on the rate of drying and oxidation from this experiment alone. This lead to the third and final drying experiment, which was a pair of columns tests designed specifically to investigate the effects of crack formation on the drying and oxidation of paste. 
The fourth experimental chapter (Chapter 6) describes the pair of column tests (one with cracks and one in which the cracks were backfilled) and compares them to the SoilCover and POLLUTE predictions for drying and oxidation. The column tests found that SoilCover and POLLUTE were able to give a reasonable prediction of sulphide oxidation whether or not the cracks had been filled in.

The final chapter (Chapter 7) focuses on the modelling component of the research. In this chapter, SoilCover and POLLUTE were applied to give a conservative estimate of pyrite oxidation in the Bulyanhulu tailings storage facility. 


\section{Chapter 2: Literature Review}

Metal leaching and acid drainage produced by sulphide mineral oxidation are the most costly and time-consuming environmental issue facing the mining industry today (Price, 2003). In this chapter, the background theory on acid mine drainage (AMD), the rate of sulphide oxidation, surface paste deposition, predictive tests and numerical modelling are presented.

\subsection{Acid Mine Drainage}

Acid drainage from sulphidic mine tailings and waste rock dumps is a major environmental concern for the mining industry. Instances of groundwater and surface water contamination resulting from AMD are well documented (e.g., Clark, 1965; Nordstrom, 1982; Price, 2003).

\subsubsection{Geochemistry}

A mine's potential for generating acidic drainage depends to a large degree on the mineralogy of the deposit being mined. Many ore bodies are found in sulphidic deposits, which contain high percentages of pyrite, pyrrhotite, and other sulphide minerals. Underground, these minerals are stable in the anaerobic, reducing environment. When the waste materials are discharged to a surface storage facility, weathering of the sulphide minerals can lead to acidic, heavy-metal-laden runoff, known as AMD.

The most abundant sulphide minerals are the iron sulphides pyrite $\left[\mathrm{FeS}_{2}\right]$ and pyrrhotite $[\mathrm{Fe}(1-\mathrm{x}) \mathrm{S}](\mathrm{x}=0$ to 0.2$)$. Other sulphide minerals commonly found in mine tailings include sphalerite $[\mathrm{ZnS}]$, chalcopyrite $\left[\mathrm{CuFeS}_{2}\right]$, galena $[\mathrm{PbS}]$, and arsenopyrite 
[FeAsS]. Their presence in tailings may be the result of inefficiencies in the recovery process, or they may not be targeted for recovery because of their low abundance or low value (Blowes et al., 2003). Since pyrite is a ubiquitous sulphide and the primary sulphide mineral in the Bulyanhulu tailings, its behaviour will be the focus of further discussion.

Garrels and Thompson (1960) described the following pyrite oxidation reaction:

$$
\mathrm{FeS}_{2}+14 \mathrm{Fe}^{3+}+8 \mathrm{H}_{2} \mathrm{O} \rightarrow 15 \mathrm{Fe}^{2+}+2 \mathrm{SO}_{4}^{2-}+16 \mathrm{H}^{+}
$$

Reaction 1

This reaction is catalyzed by sulphur-oxidizing bacteria from the Thiobacillus and Sulfolobus genera under both acidic and circumneutral $\mathrm{pH}$ conditions. The biotic rate of Reaction 1 can be up to a million times faster than the abiotic rate (Mills, 1999). The oxidation of the sulphide moiety produces sulphuric acid and releases $\mathrm{Fe}^{2+}$. The supply of $\mathrm{Fe}^{3+}$ is regenerated through the oxidation of $\mathrm{Fe}^{2+}$ by oxygen. The transfer of electrons to dissolved oxygen in Reaction 2 is the rate-limiting step in pyrite oxidation:

$$
\mathrm{Fe}^{2+}+\frac{1}{4} \mathrm{O}_{2}+\mathrm{H}^{+} \rightarrow \mathrm{Fe}^{3+}+\frac{1}{2} \mathrm{H}_{2} \mathrm{O}
$$

Reaction 2

At low $\mathrm{pH}, \mathrm{Fe}(\mathrm{III})$-oxyhydroxide minerals are soluble $\left(K_{s p}=2.79 \times 10^{-39}\right.$ for $\mathrm{Fe}(\mathrm{OH})_{3}$ at $\left.25^{\circ} \mathrm{C}\right)$ and dissolved $\mathrm{Fe}^{3+}$ can travel in solution to fresh pyrite surfaces. Under such conditions, the direct contact between dissolved oxygen and pyrite is not required for oxidation to occur. Also, at $\mathrm{pH}<4$, Reaction 2 is sufficiently energetically favourable $\left(\Delta G^{\circ}=-44.4 \mathrm{~kJ} / \mathrm{mol} \mathrm{Fe} e^{2+}\right.$ at $\mathrm{pH} 0$ compared to $\Delta G^{\circ}=-4.0 \mathrm{~kJ} / \mathrm{mol} \mathrm{Fe}{ }^{2+}$ at $\left.\mathrm{pH} 7\right)$ to be used as an energy source by a number of chemolithoautotrophic ferrous-oxidizing bacteria such as Thiobacillus ferrooxidans (Mills, 1999). These bacteria link the free energy released during oxidation to the formation of high energy bonds in adenosine triphosphate (ATP) and nicotinamide adenine dinucleotide (NADH) molecules, which 
can be used in anabolic cellular processes. Bacterial catalysis can increase the rate of Reaction 2 by five to six orders of magnitude, bringing it up to the same speed as Reaction 1 and making pyrite oxidation a rapid, self-perpetuating process (Nordstrom, 1982). Once oxidation reaches this stage, the generation of acidic conditions and AMD is very difficult to stop.

The focus of this study is on the early stages of tailings weathering, when the conditions are $\mathrm{pH}$-neutral. At circumneutral $\mathrm{pH}, \mathrm{Fe}(\mathrm{III})$ is largely insoluble. Although many Thiobacillus species are capable of sulphide oxidation at neutral $\mathrm{pH}$, bacteria do not catalyze the rate-limiting step in oxidation, which is the conversion of ferrous to ferric iron, above $\mathrm{pH} 4$ (Nicholson et al., 1988). At circumneutral pH, T. ferrooxidans has been shown to adsorb to phosphate-enriched pyrite surfaces, where it creates an acidic nanoenvironment in order to survive; however the level of bacterial activity has no appreciable effect on the overall rate of pyrite oxidation (Mielke et al., 2003). If sulphide weathering can be stopped at an early stage (i.e. before the $\mathrm{pH}$ falls to 4 , the critical value where bacteria will catalyze Reaction 2) it may be possible to prevent AMD from taking hold.

At circumneutral $\mathrm{pH}$, pyrite oxidation still proceeds via Reactions 1 and 2; however, the reactions are coupled at the pyrite surface. An adsorption-based mechanism of the reaction of pyrite with oxygen was described by Moses and Herman in 1991. This mechanism postulates that $\mathrm{Fe}^{2+}$ adsorbs to the surface of pyrite where it loses electrons to dissolved oxygen and is converted to $\mathrm{Fe}$ (III) (Reaction 2). The Fe(III) then rapidly accepts electrons from the pyrite surface and reduces back to Fe(II) (Reaction 1). This cyclic oxidation and reduction of $\mathrm{Fe}(\mathrm{II})$ and $\mathrm{Fe}(\mathrm{III})$ serves as a conduit for electron 
transfer from pyrite to oxygen. The overall reaction (Reaction 3 ) is the sum of Reaction 1 and 14 times Reaction 2:

$$
\mathrm{FeS}_{2}+\frac{7}{2} \mathrm{O}_{2}+\mathrm{H}_{2} \mathrm{O} \rightarrow \mathrm{Fe}^{2+}+2 \mathrm{SO}_{4}^{2-}+2 \mathrm{H}^{+}
$$

Reaction 3

Considering that the $\mathrm{Fe}^{2+}$ moiety formed in Reaction 3 can also react with oxygen, the stoichiometry relating $\mathrm{O}_{2}$ and $\mathrm{FeS}_{2}$ is usually given by Reaction 4:

$$
\mathrm{FeS}_{2}+\frac{15}{4} \mathrm{O}_{2}+\frac{1}{2} \mathrm{H}_{2} \mathrm{O} \rightarrow \mathrm{Fe}^{3+}+2 \mathrm{SO}_{4}^{2-}+\mathrm{H}^{+}
$$

Reaction 4

At circumneutral $\mathrm{pH}$, the $\mathrm{Fe}^{3+}$ will be hydrolyzed and precipitate as a ferricoxyhydroxide according to the following reaction:

$$
\mathrm{Fe}^{3+}+\mathrm{H}_{2} \mathrm{O} \rightarrow \mathrm{Fe}(\mathrm{OH})_{3}+3 \mathrm{H}^{+}
$$

Reaction 5

The Fe(III)-oxyhydroxide precipitate in Reaction 5 may take different forms depending on the chemical species present and $\mathrm{pH}$ and redox conditions. Ferrihydrite $\left(\mathrm{Fe}(\mathrm{OH})_{3}\right), \quad$ goethite $\quad(\alpha-\mathrm{FeOOH}), \quad$ lepidocrocite $\quad(\gamma-\mathrm{FeOOH}), \quad$ and jarosite $\left(\mathrm{KFe}_{3}\left(\mathrm{SO}_{4}\right)_{2}(\mathrm{OH})_{6}\right)$ are some of the commonly observed iron-oxyhydroxide minerals in weathered tailings impoundments (Jambor, 1994; Blowes et al., 2003).

Overall, the reaction of oxygen and pyrite at circumneutral $\mathrm{pH}$ is therefore described by Reaction 6:

$$
\mathrm{FeS}_{2}+\frac{15}{4} \mathrm{O}_{2}+\frac{3}{2} \mathrm{H}_{2} \mathrm{O} \rightarrow \mathrm{Fe}(\mathrm{OH})_{3}+2 \mathrm{SO}_{4}^{2-}+4 \mathrm{H}^{+}
$$

Reaction 6

According to the adsorption mechanism from Moses and Herman (1991), the reduced oxygen then attaches itself to the oxidized sulphur moiety on the pyrite surface. The successive addition of more oxygen eventually results in the dissociation of a thiosulphate anion $\left[\mathrm{S}_{2} \mathrm{O}_{3}^{2-}\right]$. Thiosulphate may undergo various reactions with oxygen or 
other sulphoxy anions, eventually forming tri- and pentathionate $\left[\mathrm{S}_{3} \mathrm{O}_{6}^{2-}, \mathrm{S}_{5} \mathrm{O}_{6}^{2-}\right]$, elemental sulphur, or most commonly, sulphate (Schippers et al., 1996).

Moses and Herman's adsorption mechanism is not the only one being proposed. Williamson and Rimstidt (1994) favour an electrochemical reaction mechanism, which would explain why saturation of the mineral surface by the oxidant could not be demonstrated experimentally. The electrochemical mechanism postulates distinct anodic and cathodic sites on the pyrite surface. The rate of reaction would be limited by electron transfer to the oxidant rather than by a physical process such as adsorption. The observation that redox potential has a strong effect on the rate of pyrite destruction lends further support to this mechanism. Also, isotopic investigations by Reedy et al. (1991) using ${ }^{18} \mathrm{O}$-labeled reactants, concluded that virtually all sulphate-oxygen is derived from water rather than dissolved oxygen. This lends further support to the electrochemical rather than adsorption mechanism. In either case, whether the adsorption or electrochemical mechanism is correct, the stoichiometry of the reaction is still described by Reaction 6 .

Overall, the oxidation of pyrite releases sulphuric acid. If sufficient neutralizing minerals are not present, the $\mathrm{pH}$ of the tailings pore water will drop rapidly. The most effective neutralizing minerals are the carbonates, which buffer in the circumneutral $\mathrm{pH}$ range depending on the mineral (e.g., calcite $\left[\mathrm{CaCO}_{3}\right]$ buffers at $\mathrm{pH} 6.5-7$, siderite $\left[\mathrm{FeCO}_{3}\right]$ buffers at $\mathrm{pH} 5.5-6$ ). The buffering reaction by calcite is given in Reaction 7; the basic reaction is the same for all carbonate minerals:

$$
\mathrm{CaCO}_{3}+2 \mathrm{H}^{+} \rightarrow \mathrm{Ca}^{2+}+\mathrm{H}_{2} \mathrm{CO}_{3}
$$


A mineral such as siderite may tend to form in the very early stages of oxidation, when calcite is dissolving and $\mathrm{Fe}^{2+}$ ions are available from pyrite oxidation. Once calcite is consumed and the $\mathrm{pH}$ continues to fall, the siderite would then start to dissolve around $\mathrm{pH}$ 6, providing some secondary buffering capacity. In the lower $\mathrm{pH}$ range, hydroxides such as $\mathrm{Al}(\mathrm{OH})_{3}(\mathrm{pH} 4.0-4.3)$ and $\mathrm{Fe}(\mathrm{OH})_{3}(\mathrm{pH} 2.5$ - 3.5) and various aluminosilicate minerals offer some buffering capacity (White and Brantley, 1995; Jurjovec et al., 2002).

The acidic environment created by sulphide oxidation generally triggers the dissolution of other mineral phases, which are normally insoluble at circumneutral $\mathrm{pH}$. Acid-dissolution of mineral phases can release a broad range of metals, including $\mathrm{Fe}, \mathrm{Co}$, $\mathrm{Zn}, \mathrm{Cu}, \mathrm{Ni}, \mathrm{Mn}, \mathrm{Pb}$ and $\mathrm{As}$ (Jurjovec et al., 2002; Blowes et al., 2003). Precipitation and infiltration causes the downward movement of contaminated pore water through unoxidized layers in the tailings. Here, neutralizing minerals can raise the $\mathrm{pH}$ and lower the redox potential of the pore water, causing minerals to re-precipitate. The reduction of sulphate to sulphide and subsequent re-precipitation of secondary sulphide minerals has been observed in submerged tailings and uncovered tailings at depth (Simms et al., 2000).

\subsubsection{Treatments for Acid Mine Drainage}

Sulphide oxidation can be inhibited by preventing either water or oxygen or both from contacting the sulphide minerals. This has been accomplished to varying degrees of success using soil covers, water covers, and underground tailings disposal (e.g., MEND, 1997; Yilmaz et al., 2004; Yanful et al., 2006). Once oxidation has taken hold, it is a very difficult process to stop and may produce a contaminated leachate for decades or centuries (Blowes and Jambor, 1990). If the leachate does not meet water quality standards, it may require treatment. Treatment for acid mine drainage falls into two 
general categories: active and passive. Both aim to remove heavy metals, sulphate (if needed) and raise the water $\mathrm{pH}$ to an acceptable level.

As the name implies, active treatment requires the ongoing input of artificial reagents or energy. Examples include on-site wastewater treatment plants (e.g., EPCOR, 2008), alkali tailings additives (e.g., Robb and Robinson, 1995), and impoundment freezing (e.g., INAC, 2008). Operating and maintaining these systems is costly and may require use of or produce additional hazardous materials (U.S. EPA, 2008).

Passive treatment options improve water quality using naturally-available energy sources in systems that require less maintenance and cost less. However, passive treatment systems often require additional land area and may be less reliable than active treatment systems. Examples include engineered wetlands, anoxic limestone drains, bioreactors, reactive barriers, settling ponds and cascade aeration steps (Walton-Day, 2003). Many of the passive treatment systems make use of sulphate and iron reducing bacteria to neutralize acidity and sequester heavy metals. The performance of such biological systems can be vulnerable to washout, fluctuations in temperature, substrate availability, the quality of the untreated leachate, and the retention time (Zagury et al., 2005).

\subsection{Sulphide Oxidation Rate}

Sulphide oxidation can be broken down into three stages: (1) the mass transfer of oxygen from the atmosphere through the pore space to the reaction front; (2) oxygen diffusion through the oxidation by-product layer to the unreacted core of a sulphide mineral grain; and (3) the chemical reaction. The relative importance of each stage in controlling the overall rate of sulphide oxidation depends on the material properties of the 
mining waste and the extent of weathering that has already taken place. The time required at each stage can be also be affected by mineralogy, microbial activity, climate, cracking, salt precipitation, and cementation. The three stages will be addressed individually in this section.

\subsubsection{Mass Transfer through the Pore Space}

Both advection and diffusion in the gas and liquid phase can contribute to oxygen movement in mining waste. Advective transport results from pressure gradients caused by fluctuations in atmospheric pressure or changes in density related to oxygen consumption. Advective transport is a concern when dealing with waste rock dumps (e.g., Molson et al., 2005) but it is generally agreed that advection does not contribute significantly to gas transport in tailings piles because of the fine grain size and low permeability (Jaynes et al., 1984; Elberling and Nicholson, 1996). This leaves diffusion as the primary mechanism for oxygen transport from the tailings surface to the depth where oxidation takes place.

One-dimensional steady-state diffusion can be described by Fick's First Law:

$$
F=-D \frac{d C}{d z}
$$

Equation 2.1

Where $F$ is the diffusion flux $\left(\mathrm{mol} / \mathrm{m}^{2} / \mathrm{s}\right), D$ is the diffusion coefficient $\left(\mathrm{m}^{2} / \mathrm{s}\right)$ and $\frac{d C}{d z}$ is the concentration gradient $\left(\mathrm{mol} / \mathrm{m}^{3} / \mathrm{m}\right)$. The concentration gradient is maintained by the uptake of oxygen within the tailings pile.

The diffusion coefficient of oxygen in water is $1.8 \times 10^{-9} \mathrm{~m}^{2} / \mathrm{s}$ (Elberling, 1996), so if a layer of paste is kept saturated, its oxidation rate will be negligible. As the degree 
of saturation decreases, the pore water is replaced by air. The diffusion coefficient of oxygen in air is $2.0 \times 10^{-5} \mathrm{~m}^{2} / \mathrm{s}$ (Elberling, 1996), more than 10,000 times the rate of diffusion in water; therefore, the saturation profile in a layer of paste tailings will control the rate of oxygen diffusion and consequently the extent of sulphide oxidation. Aachib et al. (2004) proposed the following semi-empirical equation for calculating the effective diffusion coefficient of oxygen in an unsaturated soil:

$$
D_{e f f}=\frac{1}{n^{2}}\left(D_{a}^{0} \theta_{a}^{p}+H D_{w}^{0} \theta_{w}^{p}\right)
$$

Where $D_{\text {eff }}$ is the effective diffusion coefficient of oxygen $\left(\mathrm{m}^{2} / \mathrm{s}\right), n$ is the porosity, $D_{a}^{0}$ is the free diffusion coefficient of oxygen in air at room temperature, $\theta_{a}$ is the volumetric air content of the soil, $p$ is a fitting parameter which accounts for tortuosity (for simplified models, Aachib et al. (2004) concluded that a fixed value of $p=3.4$ can be adopted without much loss of accuracy), $H$ is the dimensionless Henry's equilibrium constant ( $H=0.03$ for oxygen at $20^{\circ} \mathrm{C}$ ), $D_{w}^{0}$ is the free diffusion coefficient of oxygen in water at room temperature and $\theta_{w}$ is the volumetric water content of the soil.

Figure 2.1 shows the $D_{\text {eff }}$ of oxygen in a soil with porosity $n=0.47$ as a function of soil saturation plotted using Equation 2.2. 


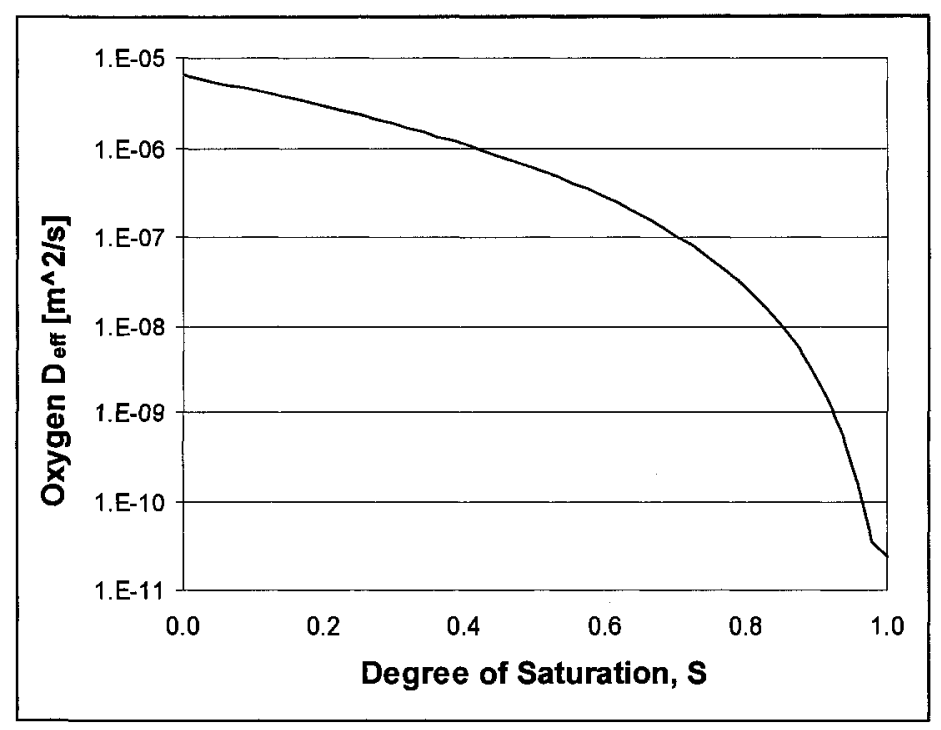

Figure 2.1 Effective diffusion coefficient of oxygen as a function of degree of saturation for a soil of porosity $n=0.47$ (After Aachib et al., 2004).

$D_{\text {eff }}$ can also be affected by non-uniformity in a tailings pile caused by the formation of hardpan layers and cracks. Precipitation of hydrous sulphate salts such as gypsum forms a cemented surface layer on a tailings pile. Cementation seals off some of the voids from the interconnected network of pores, creating a "dead" volume that does not contribute to the continuous air-filled pathways for oxygen diffusion. The result is that general equations describing the diffusion coefficient in non-cemented media are not adequate for cemented materials because of the increased tortuosity and reduced porosity (Elberling, 1996). In the present study, the effects of cementation on $D_{\text {eff }}$ are not considered.

Cracks have the opposite effect on oxygen diffusion. They expose additional surface area and create preferential pathways or conduits for oxygen to enter and moisture to exit the tailings. A severely cracked surface may not be well-represented using one-dimensional modelling. One part of this research is to determine whether one- 
dimensional modelling of evaporation and oxygen diffusion deviates from experimental results due to cracking and salt precipitation.

In the early stages of weathering, the active oxidation front is at or very near to the tailings surface and the control of the overall reaction rate is both kinetic and diffusional (Elberling et al., 1994). If chemical kinetics are not considered, the formulation results in infinitely high oxidation rates at time zero. This would not be suitable for describing short-term oxidation; therefore, when focusing on the early stage of tailings oxidation (such as in this study), one must consider both reaction kinetics and oxygen diffusion as rate-controlling processes.

In the later stages of tailings weathering (for instance, after a few years), a sulphide-depleted zone forms at the surface of a tailings pile. This zone no longer contains reactive sulphide minerals and oxygen must diffuse through it in order to reach the zone of active oxidation. In this stage of weathering, the overall rate of sulphide oxidation is controlled solely by the rate of oxygen diffusion to the active oxidation front.

\subsubsection{Diffusion to the Active Grain Surface}

The second stage in sulphide oxidation is the diffusion of oxygen from the pore space to the unreacted sulphide grain surface. Initially, the surface of an individual sulphide particle is fresh and no additional time is required. As oxidation progresses, the sulphide grain gradually shrinks and a thin film of ferrous sulphate and sulphuric acid forms on the surface of the partially-reacted grains. Solid mineral phases such as ferrous sulphate salts (rozenite, melanterite, szomolnokite) and iron oxyhydroxides also form as the by-product layer becomes more concentrated and the relative humidity in the pore space drops (Jerz and Rimstidt, 2004). In order for oxygen to react with the fresh pyrite 
core, it must first diffuse through this by-product layer. The time required for diffusion through the by-product layer can also be described by Fick's First Law (Equation 2.1) and is a function of the layer thickness and concentration gradient. This second diffusive transport process is known as the shrinking core effect and some computer models include this process in calculating the rate of tailings weathering.

The larger the particles and the longer the oxidation time, the more impact the shrinking core effect will have. For instance, it is an important aspect in modelling the long-term weathering of waste rock piles, where the particle size can be quite large (e.g., Molson et al., 2005). In the current study, it is assumed that the change in particle diameter over a short oxidation period has a negligible effect on the available pyrite surface area (demonstrated in Appendix A). Similarly, the alteration rims on fine-grained pyritic tailings will not be well developed and the time required for oxygen to diffuse through the by-product layer is insignificant (Elberling et al., 1994). For the purpose of this study, it is therefore assumed that the shrinking core effect has no significant impact on the overall rate of sulphide oxidation.

\subsubsection{Kinetic Control}

The majority of the research on pyrite reaction kinetics has been conducted under acidic conditions because the rates are much faster due to $\mathrm{Fe}^{3+}$ mobility and catalysis by acidophilic bacteria. In the current research, the focus is on the kinetics of abiotic pyrite oxidation at circumneutral $\mathrm{pH}$. The principal factors affecting the rate of pyrite oxidation under these conditions are the specific surface area and reactivity of the grains, oxygen concentration and temperature. 
Nicholson et al. (1988) showed that the rate of pyrite oxidation increased linearly with decreasing grain size and consequently with increasing specific surface area. The specific surface area of a spherical particle is inversely proportional to particle size:

$$
S_{s}=\frac{6}{\rho d}
$$

Equation 2.3

Where $S_{s}$ is the specific surface area per unit mass of pyrite $\left(\mathrm{m}^{2} / \mathrm{kg}\right), \rho$ is the density of the particle $\left(\mathrm{kg} / \mathrm{m}^{3}\right)$ and $d$ is the mean particle diameter (m). The surface reactivity of pyrite depends strongly on crystal quality - low-quality pyrite crystals with surface defects and bulk impurities are known to react at much faster rates than highquality pyrite surfaces with no alteration (Kendelewicz, 2004).

In terms of oxygen concentration, the reaction kinetics for pyrite oxidation can be described generally by the following equation:

$$
r=\frac{-d\left[\mathrm{FeS}_{2}\right]}{d t}=-\frac{4}{15} \frac{d\left[\mathrm{O}_{2}\right]}{d t}=k\left[\mathrm{O}_{2}\right]^{a}
$$

Where $r$ is the reaction rate (mol/day), $k$ is the reaction rate constant $\left(\right.$ day $\left.^{-1}\right)$, $\left[\mathrm{O}_{2}\right]$ is the dissolved oxygen concentration $(\mathrm{mol} / \mathrm{L})$ and $a$ is the reaction order with respect to oxygen. The value of $a$ can be approximated by zero-order at high oxygen concentrations, and first-order at low, diffusion-controlled oxygen concentrations. Experimental conditions with intermediate oxygen concentrations take on fractional values for $a$ (Nicholson et al., 1988).

Temperature affects the reaction rate constant, $k$, according to the Arrhenius Equation:

$$
k=A e^{\frac{-E_{a}}{R T}}
$$


Where $A$ is the pre-exponential factor, $R$ is the gas constant $(\mathrm{kJ} / \mathrm{mol} / \mathrm{K}), T$ is the temperature $(\mathrm{K})$, and $E_{a}$ is the activation energy $(\mathrm{kJ} / \mathrm{mol})$. Estimates of the activation energy for pyrite oxidation are between 50 and $88 \mathrm{~kJ} / \mathrm{mol}$ (Nicholson et al., 1988; Williamson and Rimstidt, 1994). Values for $\mathrm{E}_{\mathrm{a}}$ above $\approx 10 \mathrm{~kJ} / \mathrm{mol}$ generally support a kinetic rather than diffusion-controlled process (Williamson and Rimstidt, 1994).

Williamson and Rimstidt (1994) compiled the rate data available in the literature and determined an abiotic reaction rate for pyrite with dissolved oxygen (DO) applicable over four orders of magnitude in $\mathrm{DO}$ concentration and $\mathrm{pH}$ range from $2-10$. The rate law is given as:

$$
r_{p y}=10^{-8.19( \pm 0.10)} \frac{m_{D O}^{0.50( \pm 0.04)}}{m_{H^{+}}^{0.1( \pm 0.01)}}
$$

Where $r_{p y}$ is the rate of pyrite destruction $\left(\mathrm{mol} / \mathrm{m}^{2} / \mathrm{s}\right)$ and $m$ is the species concentration $(\mathrm{mol} / \mathrm{kg})$. Their analysis confirmed a reaction order of $a=0.5$ with respect to oxygen. Although the rate is $\mathrm{pH}-$ dependent, the small reaction order with respect to $\mathrm{H}^{+}$ ( $a=0.11)$ indicates that $\mathrm{pH}$ has a minor effect. The $\mathrm{H}^{+}$concentration must change by nine orders of magnitude to effect a single order of magnitude change in the reaction rate. Jerz and Rimstidt (2004) dervied a similar rate equation describing the oxidation of pyrite by oxygen. The Jerz and Rimstidt equation incorporates a time-dependent factor, which accounts for the slowing of the reaction rate over time due to the builld-up of reaction products on the pyrite surface and allows oxygen concentrations to be reported as gaseous partial pressures. Their empirically-derived rate equation is given in Equation 2.7: 
$r_{O_{2}}=\frac{d n}{d t}=\frac{10^{-6.6} P_{O_{2}}^{0.5}}{t^{0.5}}$

Equation 2.7

Where $r_{O_{2}}$ is the rate of oxygen consumption $\left(\mathrm{mol} / \mathrm{m}^{2} / \mathrm{s}\right), P_{O_{2}}$ is the partial pressure of oxygen (atm) and $t$ is the time (s).

\subsection{Surface Deposition of Paste}

The classification of slurry, thickened tailings and paste tailings is based on solids content. For gold tailings, a slurry generally contains $30-45 \mathrm{wt} \%$ solids, thickened tailings contain 45-70 wt\% solids, and paste tailings contain 70-85 wt\% solids (Martin et al., 2006). The slump test is another means of classifying tailings densities: paste tailings typically have a slump between 175 and $250 \mathrm{~mm}$ (Newman, 2003). A tailings material must also contain at least $15 \mathrm{wt} \%$ of particles passing No. 625 mesh $(20 \mu \mathrm{m})$ to achieve the flow and transport properties characteristic of paste (Brackebusch, 1994).

The concept of paste and thickened tailings has been around for many years. Paste backfill was first used at Germany's Bad Grund Mine in the early 1980s and surface disposal of thickened tailings was first adopted in 1973 at the Kidd Creek Mine in Timmins, Ontario, Canada (Brackebusch, 1994; Robinsky, 1999). Until recently, the technology required for dewatering and pumping a high density paste material was too expensive for surface deposition of paste to be economically viable (Theriault et al., 2003). Advances in dewatering and pumping technologies coupled with the reduced liability and closure costs of paste facilities have now made it a competitive alternative to conventional tailings disposal at many mines.

The technology was first adopted by the aluminum industry for stacking red mud tailings (Newman et al., 2001; Baczek, 2007). The first hardrock metal mine to 
implement surface deposition of paste tailings on an operational scale was the Bulyanhulu Gold Mine. Others, such as the Neves Corvo copper-zinc mine in Portugal are investigating the possibility of switching from conventional sub-aqueous disposal to paste disposal (Verburg et al., 2003).

In this section, the basics of paste technology and the factors affecting the aciddrainage potential from surface paste facilities will be discussed and the paste storage facility at the Bulyanhulu Gold Mine will be presented as an example.

\subsubsection{Paste Technology Basics}

The working consistency of paste is similar to wet cement. Water can be removed in a two-stage process using conventional thickeners and filters, or in a single stage by deep tank dewatering systems (ultra-high-density thickeners or deep-cone thickeners) (Meggyes and Debreczeni, 2006). The paste is then transported through pipes using positive displacement pumps. One of the defining characteristics of a paste is that it will not exhibit particle segregation during transportation or when at rest.

Mixed with Portland cement for additional strength, paste can be used as an underground backfill material (Yilmaz et al., 2004). It can also be discharged from towers into a surface storage facility. From the point of discharge, a thin layer of paste will flow for great distances. Flow stops when the tailings encounter a physical barrier or when they gain sufficient strength through consolidation and desiccation. Over flat terrain, a layer of tailings will come to rest at a gentle slope from 3 to 10 degrees depending on the layer thickness and moisture content (Theriault et al., 2003). Once flow has stopped, a small amount of bleed water may be produced through consolidation. The bleed water 
generally evaporates or is absorbed by underlying layers of tailings (Henriquez and Simms, 2008) and typically does not result in surface runoff.

Once a layer of paste tailings has gained enough strength through self-weight consolidation and desiccation, another layer can be added. Cycling between discharge locations allows sufficient drying time between layer depositions such that selfsupporting fans or conical stacks of tailings are gradually formed around the discharge points. Layers become interlocked for added stack stability by the filling in of desiccation cracks on the old layer with fresh tailings. The stability of paste stacks eliminates the need for high retaining dams; only a low perimeter berm is required for runoff collection.

The commonly cited advantages of paste surface deposition are:

- Water conservation through process water recycling

- Reduced volume and storage facility footprint

- Elimination of superimposed pond of conventional impoundments

$\Rightarrow$ removes the hydrostatic head and reduces seepage

$\Rightarrow$ eliminates risk of tailings liquefaction and dam failure

$\Rightarrow$ reduces total volume of water requiring treatment

- Cementation of the fines and coarse particles forms a hard surface cap, which reduces erosion and dusting

- Rapid drying and strength gain enables machinery to operate on the surface within weeks - this allows for progressive and concurrent reclamation and rehabilitation, which reduces closure costs, environmental impact, and liability 
- Possibility of co-disposal with other wastes (e.g., waste rock, resulting in "paste rock") or use of additives (e.g., Portland cement) to improve paste geochemical and/or geotechnical characteristics

- Better public perception

(Robinsky, 1999; Verburg, 2001; Newman, 2003; Meggyes and Debreczeni, 2006)

\subsubsection{Acid Drainage Potential of Paste Tailings}

In order for $\mathrm{AMD}$ to occur, there must be a source material containing reactive sulphides and a transport medium (i.e. water) for movement of the reaction products.

Water draining through a weathered tailings pile helps dissolve mineral phases and carries the soluble products into the surrounding environment. With paste facilities, the volume of water requiring treatment is reduced by removing most of the process water prior to disposal and by shrinking the footprint exposed to rainfall. Paste also has a low hydraulic conductivity (e.g., Bulyanhulu paste tailings, $K_{s} \approx 10^{-7} \mathrm{~m} / \mathrm{s}$ ) due to its homogeneity and high fines content (Verburg, 2001; Meggyes and Debreczeni, 2006). However, whether precipitation runs off the surface or infiltrates into the tailings depends on the nature of the surface. On steeply sloped surface with a cemented crust layer and few cracks, precipitation will run off quickly. On flatter, cracked surfaces lacking a crust, water will be more likely to pool on the surface and infiltrate into the tailings.

Acid mine drainage also requires the oxidation of sulphide minerals, which is initiated through direct contact with oxygen. Air is a much more permeable medium to oxygen than water and therefore the degree of desaturation (or percentage of air-filled pore space) of paste tailings directly affects the extent of sulphide oxidation. The 
importance of the degree of saturation with regard to sulphide oxidation was demonstrated in a 30-week bench-scale screening of 24 paste and filter cake tailings samples from the Neves Corvo Mine (Verburg et al., 2003). In the field, the desaturation (by evaporation) of paste tailings depends on material properties, salt concentration, cracking, and the site-specific weather conditions (Simms et al., 2007) (more detail on the topic of evaporation can be found in Section 2.5.3).

The material properties that affect soil saturation are: porosity; density; soil-water characteristic curve (SWCC), which relates matric suction to water content; saturated hydraulic conductivity; and relative hydraulic conductivity function, which describes the rate of liquid water transport through the pore space at varying saturations. These material properties can be measured directly or, in the case of the relative hydraulic conductivity function, calculated theoretically using empirical curve-fitting parameters (e.g., Van Genuchten, 1980; Fredlund et al., 1994; Mbonimpa et al., 2006).

At high concentrations, dissolved solids in the pore water will precipitate as salts at the tailings surface. The development of a salt crust suppresses evaporation by increasing albedo and osmotic suction and acting as a physical barrier to liquid and vapour flux (Simms et al., 2007). Shuttleworth et al. (2005) noted that undisturbed paste layers formed a crust rapidly and oxidized very little. Disturbed or loose tailings required re-wetting before forming a salt crust and tended to oxidize rapidly. While desiccation may inhibit oxidation through formation of a stiff crust, it also leads to surface cracking, which may increase the potential for acid drainage. Cracks expose additional surface area for evaporation and oxygen ingress; they also provide flow pathways for preferential infiltration into the tailings. Finally, the climate plays an important role in the rate of 
paste desaturation. The rate of evaporation depends on the solar radiation, wind, relative humidity and temperature as well as the unsaturated properties of the tailings.

Successful operation of a paste storage facility requires a balance between strength gain and oxidation. The longer a layer is allowed to dry, the more stability it will have, but the more oxidation will occur if reactive sulphides are present. Newman (2003) suggested that a possible solution is to ensure that older layers of paste are covered by fresh layers before oxidation is allowed to take hold; for example, at the Kidd Creek Mine, operators have found that as long as a fresh layer of thickened tailings is covered within 12 to18 months, acid drainage conditions do not take hold (Newman et al., 2001).

Layer thickness is also important. Thin layers dry more rapidly and uniformly than thicker layers and stack at higher beach angles, allowing a larger volume of waste to be stored on the footprint; however, for the same reasons, thin layers are more prone to oxidation (Theriault et al., 2003; Golder, 2005).

Leachate quality from paste tailings will also be affected by tailings mineralogy (discussed in Section 2.1.1) and additives. Recent multilayer column experiments (9 layers $\mathrm{x} 4 \mathrm{~cm}$ per layer) showed that the addition of Portland cement to some layers of paste (alternating 2 layers of uncemented tailings with 1 layer of $2 \%$ Portland cement or adding $2 \%$ Portland cement to the two bottom layers and the remaining layers uncemented) reduced seepage volume and also increased the neutralization potential of sulphidic tailings (Deschamps et al., 2008). However, the same study found that when Portland cement was used in a different manner ( $1 \%$ Portland cement added to all layers), cement actually induced cracking, which created preferential pathways for oxidation and seepage and increased the risk of acid drainage. Another series of bench-scale leach 
experiments found that leachate quality was improved through the addition of bactericide, lime and cement; however once the alkalinity of the lime or cement additive had been consumed, the water quality rapidly deteriorated (Verburg et al., 2003).

\subsubsection{Bulyanhulu Gold Mine}

The Bulyanhulu Gold Mine is situated on a late-Archean greenstone belt. The ore deposit is characterized as an atypical mesothermal lode gold deposit; the main lode gold veins (containing quartz-copper-gold-sulphide) overprint an earlier $\mathrm{Cu}$-Au enriched magmatic system. The most abundant sulphide mineral is pyrite, accompanied by chalcopyrite and trace amounts of pyrrhotite and arsenopyrite (Chamberlain et al., 2003). Bulyanhulu is owned and operated by Kahama Mining Corporation Limited, a subsidiary of Barrick Gold Corporation. It has been in operation since 2001 and has adopted a complete paste solution to its tailings management. The tailings are dewatered using high density thickeners and vacuum disc filters. Twenty-five percent of the tailings are used in backfill, the remaining $75 \%$ are pumped approximately $2 \mathrm{~km}$ to the tailings storage facility (TSF) shown in Figure 2.2.

On average, 65,000 tonnes/month of paste are stacked in the TSF at an average gravimetric moisture content of $37 \%$ (Shuttleworth et al., 2005). The TSF is comprised of two cells covering 65 hectares; each cell has five 12-m high discharge towers spaced at $120-\mathrm{m}$ intervals along the centerline. Discharge is cycled between the towers to maximize drying and strength gain while minimizing oxidation. For optimal desiccation, the maximum layer thickness is about $30 \mathrm{~cm}$ and a layer is dried from $5-30$ days before being covered by a fresh layer (Theriault et al., 2003; Deschamps et al., 2008). 


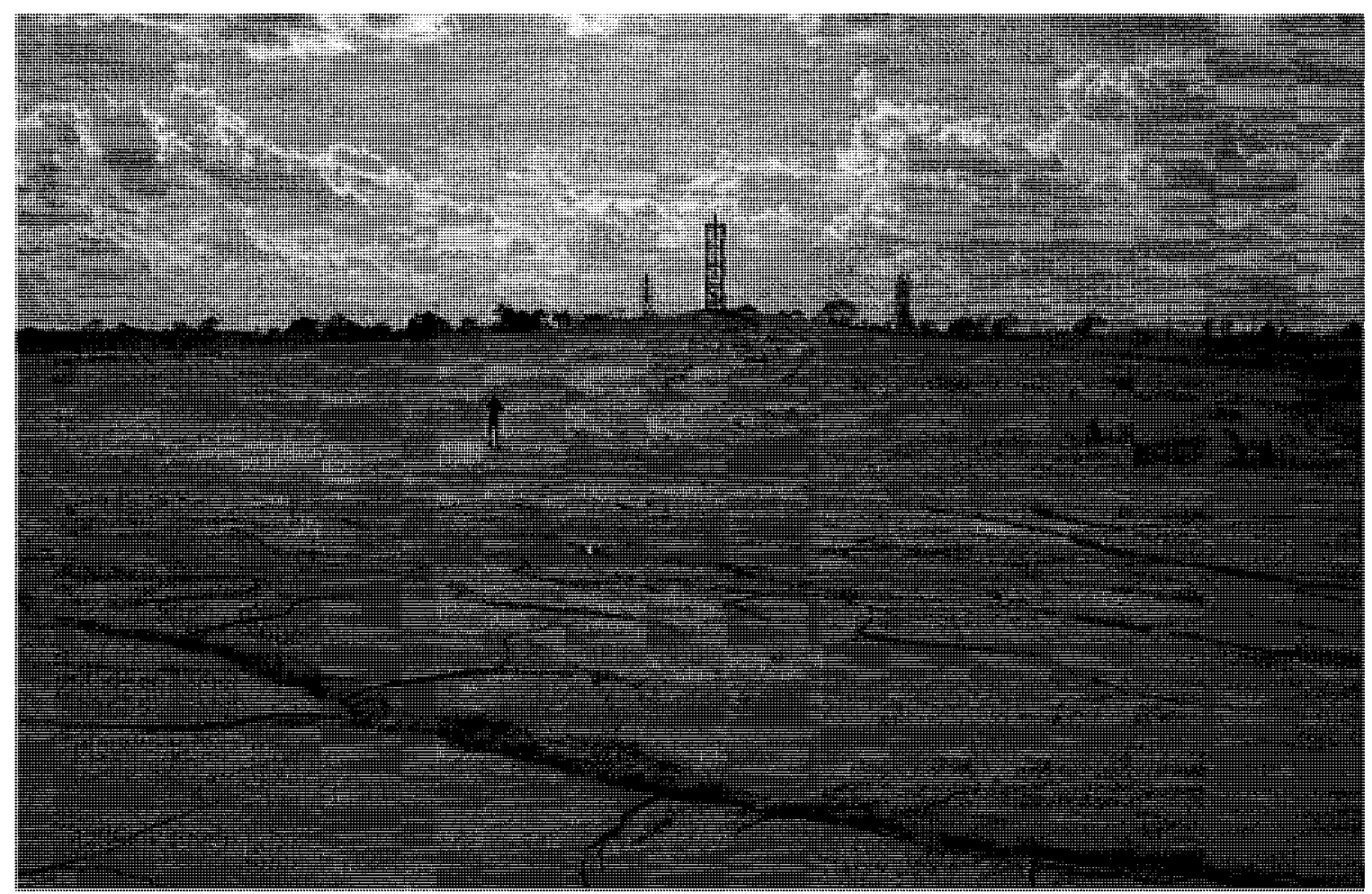

Figure 2.2 Tailings storage facility (TSF) at the Bulyanhulu Gold Mine in Tanzania.

The mine's water must be pumped over $50 \mathrm{~km}$ from Lake Victoria; thus, water conservation was one of the key factors in opting for paste disposal. The semi-arid climate in Tanzania is ideal for rapid drying in the TSF. Annual evaporation averages $1,600 \mathrm{~mm} / \mathrm{yr}$ and precipitation averages $1,200 \mathrm{~mm} / \mathrm{yr}$, most of which falls during two distinct rainy seasons (Theriault et al., 2003). The only containment structure is a 3-m high perimeter berm, which directs runoff water to the sedimentation pond. Overflow from the sedimentation pond drains into the reclamation pond from which it is pumped back to the process plant for reuse (Danielson, 2001).

\subsection{Predictive Tools}

Mine development proposals require, among other things, a detailed environmental and closure plan, which must address issues relating to acid mine 
drainage. Predicting the long-term leachate quality from a yet-to-be-opened mine is one of the challenges in creating an operating and closure plan. To help with this task, the Mine Environment Neutral Drainage (MEND) Program, a division of Natural Resources Canada, has established guidelines for information requirements in metal leaching and acid rock drainage assessment and mitigation work (MEND, 2005). The MEND guidelines recommend using both static and kinetic tests to predict the acid-drainage potential of tailings.

\subsubsection{Static Tests}

A static test is a one-time determination whose results indicate whether a tailings sample will be acid-generating. The MEND guidelines recommend two standard static tests: the net-acid generation (NAG) test and the modified acid-base accounting (ABA) test. Both tests are relatively inexpensive and rapid to perform. The NAG test measures the $\mathrm{pH}$ of a tailings sample after adding $\mathrm{H}_{2} \mathrm{O}_{2}$ and allowing the solution to react over a 12-hour period (Miller et al., 1997). The advantage of the NAG test is that it is a singlestep test whose result reflects both the acid-producing and acid-neutralizing minerals in a sample. The disadvantage is that the NAG pH alone is not a reliable indicator of acid drainage potential. The test requires site-specific calibration by comparison to other static tests like the ABA test and kinetic tests (Jambor, 2003).

A modification of the Sobek test (Sobek et al., 1978), modified ABA is a two-part test that can be used to compare the relative acid-generating potential of different tailings. The ABA test predicts the acid-producing potential (AP) based on sulphide-sulphur content and neutralization potential (NP) based on acid-digestion and titration of the tailings sample. Details of the test are described in MEND (1991). 
Short-term leach tests, where a small sample of tailings is wet and dried to maximize oxidation, are also classified among the static tests. They are designed to be worst-case scenario indicators of leachate quality, but in the case of acid generating mine wastes, they rarely represent terminal (i.e. complete oxidation of sulphides) conditions. Therefore, Verburg (2001) warns against the quantitative interpretation of short-term leach test results, which rarely simulate disposal site conditions and have limited predictive value. They are most useful for identifying elements of environmental concern.

\subsubsection{Kinetic Tests}

Static tests measure a material's potential to be acid-generating but make no claims as far as the rate or likelihood of acid drainage actually occurring. Kinetic tests are weathering tests conducted to aid prediction of drainage quality from mine wastes over time. The most widely used are the humidity cell test, the column test and the field cell test. Protocols for these tests are rarely standardized (the exception being the ASTM protocol for humidity cells); however, general guidelines exist.

Humidity cells are weathering chambers designed to provide control over air flow, temperature, and moisture while allowing for the removal and analysis of weathering products. A typical 7-day humidity cell test involves 3 stages: (1) dry air passed through the sample for 3 days, (2) humid air passed through the sample for 3 days, (3) leaching of the sample for 1 day (MEND, 1991). The leachate can be analyzed for water quality indicators such as $\mathrm{pH}$, sulphate, acidity, alkalinity, conductivity, redox potential and metals.

Column tests are less standardized than humidity cell tests. Columns generally permit water drainage and evaporation and can be flushed to obtain samples for water 
quality analysis. Column tests are also amenable to investigations of stratification with depth and multi-layer deposition. The test protocol can be modified to include bacteria, wet/dry cycles, variable moisture contents, covers, and additives. For example, Deschamps et al. (2008) used column tests to compare different disposal configurations of cemented and uncemented paste tailings.

Perhaps the most informative tests on the long-term behaviour of paste in actual disposal conditions are field tests. Verburg et al. $(2003,2006)$ designed three series of field cell tests and a large-scale pilot paste deposition program to monitor long-term paste weathering under site-specific conditions. The field cells contained monitoring wells for sampling leachate quality from unamended tailings paste, tailings paste amended with Portland cement, and tailings paste amended with bactericide. Because of the similarities between the test site and the actual disposal site, these tests were considered representative of the long-term weathering characteristics of paste. The pilot plant project was started in 2005 at the Neves Corvo Mine in Portugal. It will provide a unique opportunity to investigate deposition techniques including co-disposal with waste rock. The paste tailings have been covered using a number of capping methods and the geotechnical and environmental performance is being monitored (Verburg, pers. comm.).

The extent of sulphide mineral oxidation can also be monitored through the changing mineralogy of the tailings solids. In general, the order of sulphide depletion from the most rapidly depleted to the most resistant follows the sequence (Jambor, 1994):

$$
\text { pyrrhotite }>\text { galena }>\text { sphalerite }>\text { pyrite-arsenopyrite }>\text { chalcopyrite }
$$

A sulphide grain will react from the edge inward, leaving a film of reaction byproducts surrounding the unreacted sulphide core. These alteration layers are visible on 
polished sections under scanning electron microscope. The sulphide alteration index in Table 2.1 is a numerical scale that is used to describe the degree of iron-sulphide oxidation based on the degree of alteration of pyrite and pyrrhotite grains. By assigning a numerical index to qualitative observations of oxidation, the extent of sulphide oxidation can be compared in a semi-quantitative manner at various depths and times in surfacedisposed tailings.

Table 2.1 Description of the iron-sulphide alteration index as used in the Waite Amulet Study (After Blowes and Jambor, 1990).

\begin{tabular}{cl}
\hline $\begin{array}{c}\text { Numerical } \\
\text { Scale }\end{array}$ & Degree of Alteration of Sulphides \\
\hline 10 & $\begin{array}{l}\text { Pyrrhotite and pyrite obliterated; only traces of sulphide, } \\
\text { typically chalcopyrite, are present }\end{array}$ \\
9 & $\begin{array}{l}\text { Similar to 10, but with a few scattered remnant grains of } \\
\text { pyrite }\end{array}$ \\
$8-7$ & $\begin{array}{l}\text { First appearance of trace amounts of pyrrhotite (at scale } \\
8) ; \text { at scale } 7 \text { the vestiges of strongly altered pyrrhotite } \\
\text { increase in abundance or degree of preservation }\end{array}$ \\
$6-2$ & $\begin{array}{l}\text { At scale } 6 \text { the pyrrhotite grains have broad alteration } \\
\text { rims, but the cores of numerous grains are preserved; } \\
\text { gradation to scale } 2 \text { is marked by the appearance of } \\
\text { narrower alternation rims and a predominance of } \\
\text { unaltered grains } \\
\text { Only a few grains of pyrrhotite are weakly altered along } \\
\text { rims and fractures; >95\% of grains have sharp, fresh } \\
\text { margins }\end{array}$ \\
\hline
\end{tabular}

\subsection{Modelling}

\subsubsection{Background}

A number of sulphide oxidation models and reactive-transport models exist for estimating contaminant release and attenuation from mine-waste deposits. Complex reactive-transport models can simulate all stages of tailings weathering from kinetics of 
sulphide-oxidation, to flow and transport processes, to $\mathrm{pH}$ buffering by carbonates and aluminosilicates, to dissolution and precipitation of mineral phases, to the final water quality downstream of a tailings impoundment or waste rock dump. Some examples include:

- Jaynes et al. (1984) considered oxygen diffusion based on an average $D_{\text {eff }}$ and included reaction kinetics, ferric iron oxidation of pyrite and bacterial catalysis.

- PYROX (Wunderly et al., 1996) uses a shrinking-core model and onedimensional oxygen diffusion based on a spatially variable $D_{\text {eff }}$ and does not consider reaction kinetics.

$\Rightarrow$ PYROX has been used in modelling the oxidation of a freshly deposited 50$\mathrm{cm}$ layer of Bulyanhulu paste at the mine site. While field samples showed fairly uniform sulphide depletion to a depth of $20-\mathrm{cm}$ after just 2 months, PYROX modelling predicted that sulphide oxidation would only occur in the top $5 \mathrm{~cm}$ of tailings after 3 months (Golder, 2005).

- MINTOX (Wunderly et al., 1996) combines PYROX with the general-purpose reactive-transport model MINTRAN. MINTOX has been expanded to consider two-dimensional gas transport (Gerke et al., 2001).

- MIN3P (Mayer et al., 2002) solves the fully coupled problem of unsaturated flow and reactive transport using the finite volume method. The model considers transport and interactions between the gas, liquid and vapour phase, includes the shrinking-core model for sulphide oxidation, and considers reaction kinetics in predicting acid mine drainage. 
- Others such as MULTIFLO (Lichtner, 1996), TOUGHREACT and TOUGH2CHEM (Xu et al., 2000), PHREEQC (Parkhurst and Appelo, 1999) and SULPHIDOX (Linklater et al., 2005) incorporate diffusive gas transport, aqueous speciation, equilibrium and kinetically controlled dissolution and precipitation reactions, unsaturated flow and multiphase transport in acid drainage modelling.

While these models are useful for long-term predictions of water quality and aciddrainage from conventional tailings impoundments, they may not be ideal for modelling the initial sulphide depletion in a layer of freshly deposited paste tailings. At Bulyanhulu, a layer is covered after just $5-30$ days of drying. In this case, reactive transport and chemical speciation are less important than an accurate prediction of evaporation and oxygen diffusion.

\subsubsection{Current Study}

As discussed in Section 2.2, the rate of oxidation in the initial stage of paste weathering is controlled by both oxygen diffusion and chemical kinetics. In the current study, therefore, modelling of oxygen diffusion into paste tailings is based on Fick's Second Law with the incorporation of a sink term $S$, which accounts for the removal of oxygen through its reaction with pyrite.

$$
\frac{\partial C}{\partial t}=\frac{\partial}{\partial x}\left(D_{e f f} \frac{\partial C}{\partial x}\right)-S
$$

The models described in the previous section use either an average value for $D_{\text {eff }}$ over the entire depth of the tailings or at best a spatially variable $D_{\text {eff }}$ profile. The conceptual model adopted in this study recognizes that in a layer of drying paste tailings, 
the $D_{\text {eff }}$ profile will be both spatially and temporally variable. Therefore, we will use $D_{\text {eff }}$ values that change with time and depth as the paste dries.

The numerical modelling of sulphide oxidation was set up in two parts as shown in Figure 2.3. First, in order to obtain changing values for $D_{\text {eff }}$ as the tailings dry, a coupled soil-atmosphere evaporation model (SoilCover) was used to estimate the changing saturation profile of the tailings. Second, the values of $D_{\text {eff }}$ were incorporated into a contaminant transport model (POLLUTE) capable of solving the molecular diffusion equation.

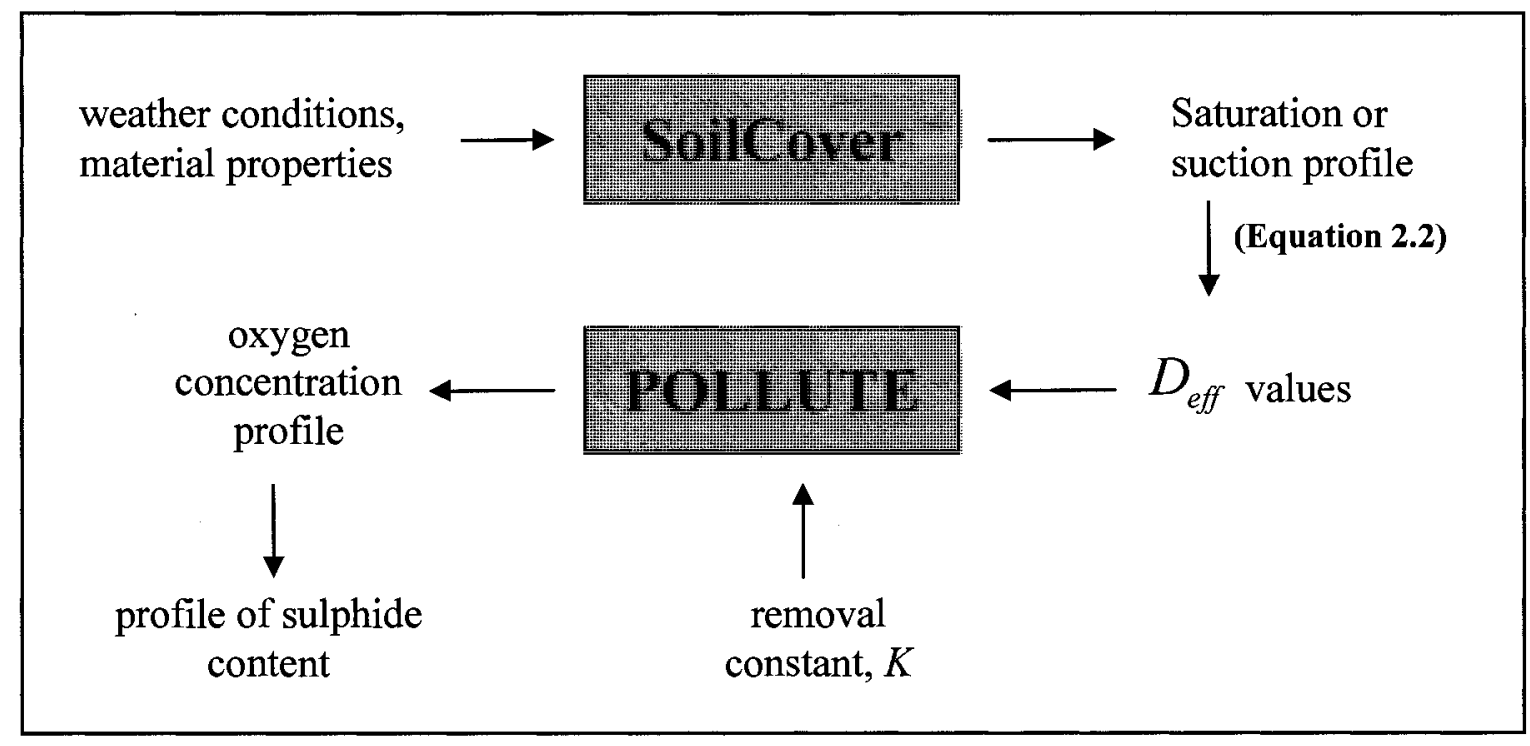

Figure 2.3 Flow chart of sulphide oxidation modelling.

\subsubsection{Soil Evaporation}

The exchange of water at a soil surface is governed by two processes. Liquid water enters the soil by infiltration during a precipitation event and water vapour exfiltrates from the soil by evaporation. To obtain a daily profile of $D_{\text {eff }}$ values within the tailings, it is therefore necessary to predict the change in water content due to evaporation 
and infiltration. The arid climate at Bulyanhulu (see Section 2.3.3) and paste's resistance to water infiltration (see Section 2.3.2) means that, in the field, evaporation is the dominant process for water exchange and hence the primary focus of this study.

The rate of evaporation depends on weather conditions and soil properties. A number of methods exist for predicting the maximum rate of evaporation (also known as the potential evaporation rate) from a soil surface (e.g., Thornwaite, 1948; Penman, 1948; Priestly and Talyor, 1972) but these methods are only accurate for saturated soil surfaces and open water.

Evaporative flux is driven by the vapour pressure gradient that exists between the soil surface and the atmosphere (see Section 2.5.4, Equations 2.14, 2.15). Soil evaporation is typically described as having three stages (Wilson et al., 1997). In Stage I, the relative humidity at the soil surface is $100 \%$ and the actual evaporation rate is equal to the potential rate. Initially, the pores in Stage I are saturated and liquid water forms many continuous pathways to the soil surface. As the soil dries, the pores begin to desaturate, larger pores emptying first according to the Young-Laplace Equation:

$$
u_{a}-u_{w}=\frac{2 T_{s} \cos \sigma}{r_{\text {pore }}}
$$

Where $u_{a}-u_{w}$ is the pressure difference across the air-water interface, $T_{s}$ is the surface tension, $\sigma$ is the contact angle and $r_{\text {pore }}$ is the pore radius.

As more pores empty, the continuous pathways for liquid water transport disappear and water vapour becomes the dominant transport phase for transporting water to the soil surface. In Stage II, the actual evaporation rate drops below the potential rate. The drop is caused by a decrease in the relative humidity at the soil surface and 
corresponding decrease in the vapour pressure gradient between the soil and the atmosphere. During Stage II, the evaporation rate drops rapidly, eventually leveling off at some residual rate; this is Stage III evaporation. Stage III evaporation continues at a residual rate as long as the relative humidity at the soil surface is greater than the atmospheric relative humidity. Relative humidity at the soil surface is a function of total suction as described by Equation 2.10 and shown in Figure 2.4.

$$
h_{r}=e\left(\frac{\Psi g W_{v}}{R T}\right)
$$

Where $h_{r}$ is the relative humidity at the soil surface, $\Psi$ is the total suction (m), $g$ is the acceleration due to gravity $\left(\mathrm{m} / \mathrm{s}^{2}\right), W_{\nu}$ is the molecular weight of water $(\mathrm{kg} / \mathrm{mol})$, $R$ is the universal gas constant $(\mathrm{J} / \mathrm{mol} / \mathrm{K})$ and $T$ is the temperature $(\mathrm{K})$.

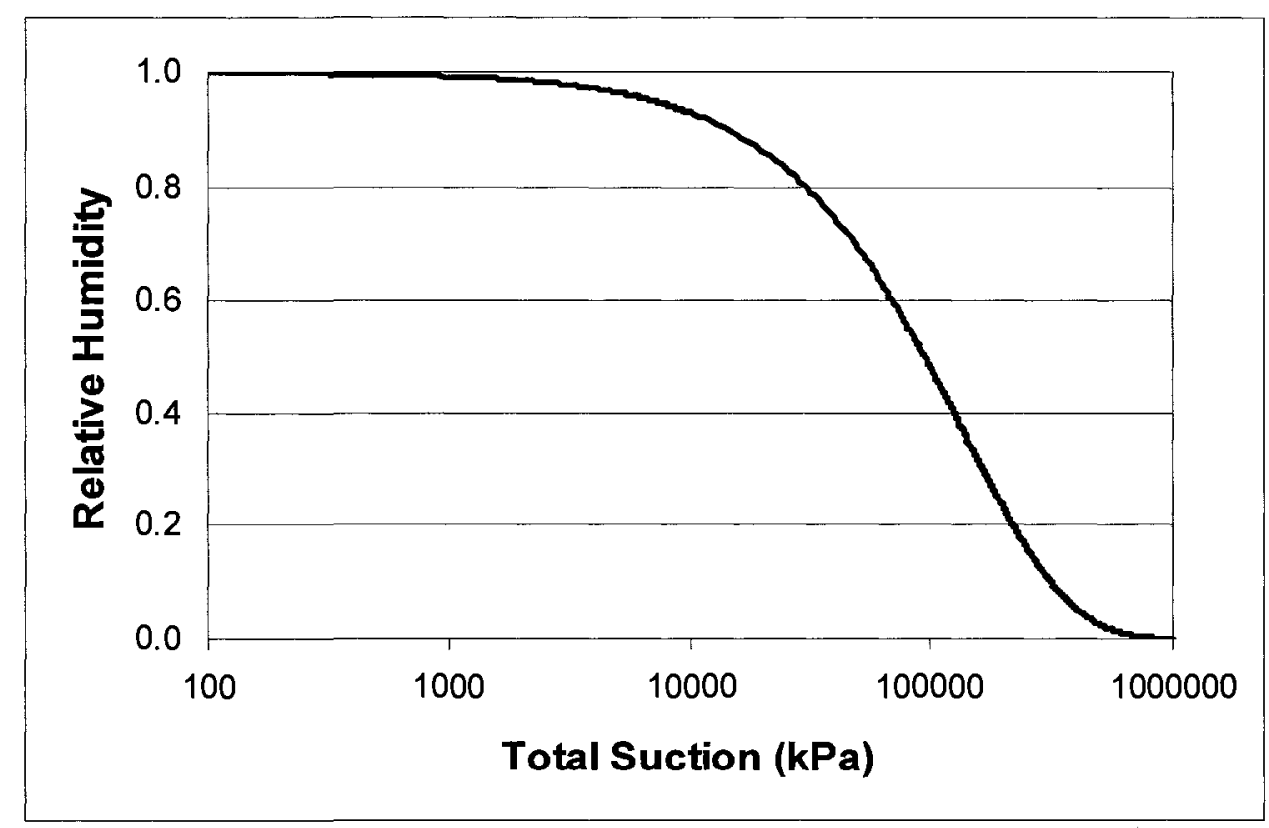

Figure 2.4 Relative humidity at the soil surface as a function of total suction.

Total suction is the sum of the matric suction $\left(\Psi_{m}\right)$ and osmotic suction $\left(\Psi_{s}\right)$ : 


$$
\Psi=\Psi_{m}+\Psi_{s}
$$

Matric suction is the difference in pore water potential caused by capillary forces, and osmotic suction is due to the presence of dissolved species in the pore spaces. The osmotic suction of a soil can be determined from the electrical conductivity (EC) of an undiluted pore water extract using the following equation (Abedi-Koupai and Mehdizadeh, 2008):

$$
\Psi_{s}=-36 E C \rho
$$

Equation 2.12

Where $\Psi_{s}$ is the osmotic suction $(\mathrm{kPa}), E C$ is the electrical conductivity $(\mathrm{mS} / \mathrm{cm})$ and $\rho$ is the density $\left(\mathrm{kg} / \mathrm{m}^{3}\right)$.

These principles of soil evaporation are incorporated into the soil-atmosphere flux model SoilCover; however, SoilCover does not account for the contribution of osmotic suction to total suction.

\subsubsection{SoilCover}

SoilCover is a soil-atmosphere flux model that links the subsurface saturated or unsaturated groundwater system and the atmosphere above. SoilCover is a onedimensional finite element package that models transient water and vapour flow (SoilCover, 2000). SoilCover has been used in a number of applications, from designing covers for landfills and mining wastes to predicting evaporation from agricultural lands (Yanful et al., 2006). In this study, SoilCover was used to estimate the time-dependent saturation profile in layers of paste tailings as they dried. 
SoilCover uses a physically-based method for predicting the exchange of water and energy between the atmosphere and a soil surface. Mass transfer of water is based on liquid and vapour flow described by Darcy's and Fick's Laws (Equation 2.13).

$$
\frac{\delta h_{w}}{\delta t}=C_{w}^{1} \frac{\delta}{\delta y}\left(k_{w} \frac{\delta h_{w}}{\delta y}\right)+C_{w}^{2} \frac{\delta}{\delta y}\left(D_{v} \frac{\delta P_{v}}{\delta y}\right)
$$

Where $h_{w}$ is the total head (m), $t$ is the time (s), $C_{w}^{1}$ is the coefficient of consolidation with respect to the liquid water phase, $y$ is the elevation $(\mathrm{m}), k_{w}$ is the hydraulic conductivity $(\mathrm{m} / \mathrm{s}), C_{w}^{2}$ is the coefficient of consolidation with respect to the water vapour phase, $D_{v}$ is the diffusion coefficient of water vapour through the soil $(\mathrm{kg} \cdot \mathrm{m} / \mathrm{kN} \cdot \mathrm{s})$ and $P_{v}$ is the partial pressure due to water vapour $(\mathrm{kPa})$.

An understanding of temperatures within the soil profile is required for the solution of the moisture flow equation ( $D_{v}$ and $P_{v}$ are temperature-dependent); hence Fourier's Law of conductive and latent heat transfer (Equation 2.14) must be solved simultaneously.

$$
C_{h} \frac{\delta T}{\delta}=\frac{\delta}{\delta y}\left(\lambda \frac{\delta T}{\delta y}\right)-L_{v}\left(\frac{P+P_{v}}{P}\right) \frac{\delta}{\delta y}\left(D_{v} \frac{\delta P_{v}}{\delta y}\right)
$$

Where $C_{h}$ is the volumetric specific heat of the soil as a function of water content $\left(\mathrm{J} / \mathrm{m}^{3} / \mathrm{K}\right), T$ is the temperature $(\mathrm{K}), \lambda$ is the thermal conductivity of the soil $(\mathrm{W} / \mathrm{m} / \mathrm{K})$, $L_{v}$ is the latent heat of vapourization of water $(\mathrm{J} / \mathrm{kg})$ and $P$ is the total gas pressure in the air phase $(\mathrm{kPa})$. 
The rate of evaporation from the soil surface is calculated on the basis of atmospheric conditions (radiation, wind speed, temperature, and relative humidity) and soil properties and conditions. A modified Penman formulation (Equation 2.15) proposed by Wilson (1990) is used to compute the actual rate of evaporation at the soil-atmosphere boundary. SoilCover uses Equation 2.15 to couple soil evaporation to atmospheric conditions because the net evaporative flux is a function of the vapour pressure gradient between the soil surface and the atmosphere.

$$
E=\frac{\Gamma Q+v E_{w}}{\Gamma+A v}
$$

Where $E$ is the evaporative flux $(\mathrm{mm} /$ day), $\Gamma$ is the slope of the saturation vapour pressure vs. temperature curve at the mean temperature of the air, $Q$ is the net radiant energy available at the surface ( $\mathrm{mm} /$ day), $v$ is the psychrometric constant, $E_{w}$ is the evaporation from wind calculated by Equation 2.16 and $A$ is the inverse of the relative humidity at the soil surface.

$$
E_{w}=f(u) P_{a}(B-A)
$$

Equation 2.16

Where $f(u)$ is a function of wind speed, surface roughness, and eddy diffusion, $P_{a}$ is the vapour pressure in the air above the evaporating surface and $B$ is the inverse of the relative humidity of the air.

The output from SoilCover can take the form of a suction profile or a saturation profile, the two being related through the SWCC. In SoilCover, the minimum time interval between outputs is $24 \mathrm{hrs}$ (simulation time, not real time). The volumetric water content profiles can be used in Equation 2.2 to generate a daily profile of $D_{\text {eff }}$ values. 


\subsubsection{POLLUTE}

The $D_{\text {eff }}$ values generated using SoilCover can be fed into a second existing software package, POLLUTE, which is used to predict oxygen ingress (see flow chart in Figure 2.3). POLLUTE is a contaminant transport model that solves the one-dimensional advection-dispersion-diffusion equation for a layered deposit (Rowe and Booker, 1985). Although it was designed for modelling contaminant transport, using POLLUTE to model the molecular diffusion of oxygen through unsaturated porous media is not a novel application. Yanful et al. (1999) used POLLUTE to model the oxidation of slurried tailings with and without soil covers. Renken et al. (2005) and Cabral et al. (2004) used POLLUTE to back-calculate effective diffusion coefficients for oxygen in gold tailings and de-inking residues (a by-product of paper recycling) at different water contents. POLLUTE also has capabilities for inputting user-defined time-varying properties such as changing values of $D_{e f f}$ and a Radioactive/Biological Decay option, which can be used to represent the consumption of oxygen by sulphide minerals.

The primary mechanism of oxygen transport in paste tailings is by molecular diffusion. Therefore, in this study, POLLUTE is used to solve the one-dimensional oxygen diffusion equation with first-order removal given by:

$$
n \frac{d c}{d t}=n D_{e f f} \frac{d^{2} c}{d z^{2}}-n K c
$$

Where $n$ is the soil porosity, $c$ is the mass concentration of oxygen $(\mathrm{mg} / \mathrm{L}), t$ is the time (day), $D_{\text {eff }}$ is the effective diffusion coefficient of oxygen $\left(\mathrm{m}^{2} / \mathrm{s}\right), z$ is the position (m) and $K$ is the first-order oxygen removal constant $\left(\right.$ day $\left.^{-1}\right)$. The sink term $(S)$ 
from Equation 2.7 has been replaced by the first-order removal term $(n K c)$ in Equation 2.16 .

Unlike finite element formulations, which rely on time-marching procedures to obtain transient solutions, POLLUTE uses a finite-layer formulation. This method allows the concentration of oxygen to be determined at any specified time without calculating the concentration at earlier times (GAEA, 2004). The result of POLLUTE simulations is a time-dependent oxygen concentration profile.

If it is assumed that: (1) oxygen is the only oxidant; (2) pyrite oxidation is the only oxygen-consuming process; (3) all solid sulphide-S is present as pyrite; (4) the stoichiometry of reaction is $3.75: 1\left(\mathrm{~mol} \mathrm{O}_{2}: \mathrm{mol} \mathrm{FeS}_{2}\right)$ (given by Reaction 6); and (5) the oxidation is abiotic and no microbial mediation occurs. Then the cumulative oxygen consumed at a given depth (given by $n K c$ in Equation 2.17) can be converted into an equivalent sulphide depletion using the reaction stoichiometry. 


\section{Chapter 3: Initial Tailings Characterization}

The paste tailings were collected from the discharge pipe by Barrick technicians at the Bulyanhulu Gold Mine in 2006. To limit oxygen exposure, an additional water cover was added to the tailings, which were sealed in thick plastic bags, packed in 5gallon buckets, and shipped to Carleton University. The tailings arrived in a consolidated state (solids at approximately $25 \%$ gravimetric water content (GWC)) with a layer of process water on top. When remixed, the average GWC was approximately $45 \%$. When a bucket was ready to be used, some of the excess water was removed to re-adjust the paste to $40 \% \mathrm{GWC}$, which is approximately the moisture content at which the tailings would be discharged to the storage facility.

The initial characterization of the tailings included the particle size distribution, mineralogy, paste $\mathrm{pH}, \mathrm{NAG}$ and $\mathrm{ABA}$ tests, sulphide grain analysis, long-term rewetting test and determination of the reaction rate constant for pyrite oxidation. The characteristics of the tailings generated at Bulyanhulu may change over time depending on the geology of the actively mined ore body, but for the purposes of this study, the tailings in the impoundment are assumed to be the same as the samples received.

\subsection{Particle Size Distribution}

The particle size distribution of the Bulyanhulu tailings is given in Figure 3.1. The distribution for the coarse fraction (grains $>75 \mu \mathrm{m}$, retained on a No. 200 sieve) was determined by sieving analysis. The distribution for the fine fraction (grains $<75 \mu \mathrm{m}$, passing a No. 200 sieve) was determined by sedimentation in a hydrometer test. This type 
of particle-size analysis for soils is a standardized method and the procedure followed was described in ASTM D422-63 (2007).

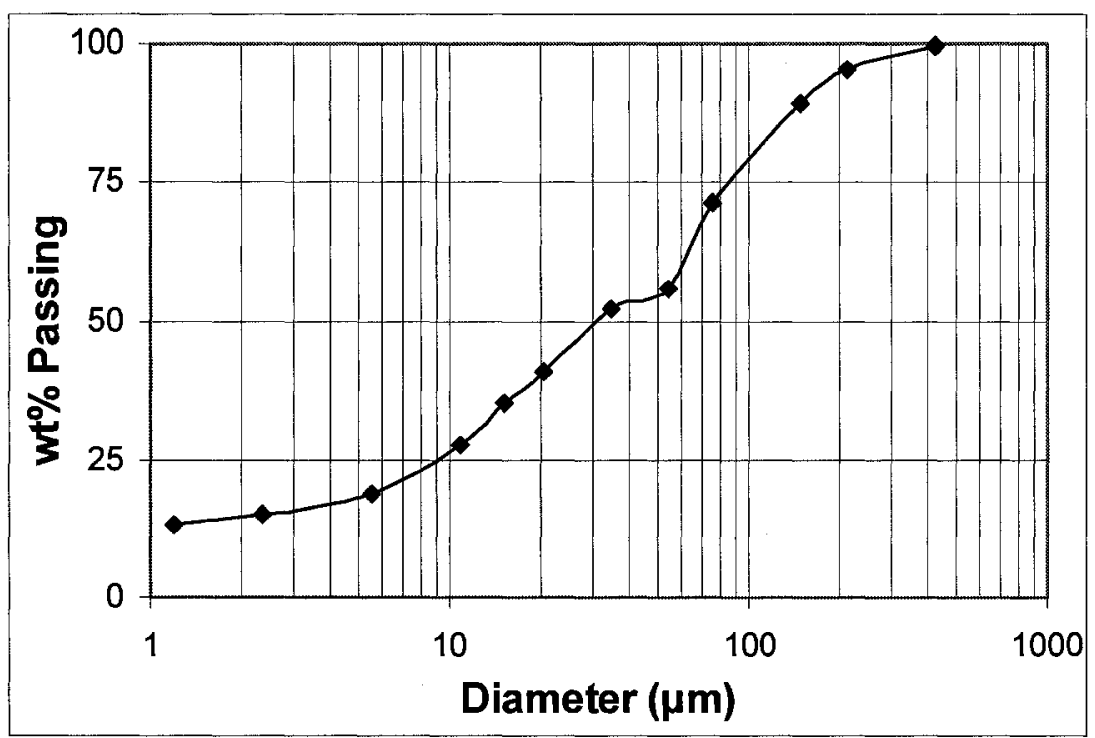

Figure 3.1 Particle size distribution of the Bulyanhulu tailings.

The particle size distribution confirms that these tailings are amenable to paste production since $>15 \mathrm{wt} \%$ of particles have a diameter $<20 \mu \mathrm{m}$, satisfying the fines content requirement for pastes (Brackebusch, 1994). The $d_{50}$ particle diameter for the Bulyanhulu tailings is $30 \mu \mathrm{m}$.

\subsection{Mineralogy}

The solid phase mineral composition of the fresh tailings was determined using a combination of the following analyses: X-Ray Diffraction (XRD), Inorganic Carbon (IC), scanning electron microprobe with energy dispersive analyzer (SEM-EDS), Inductively Coupled Plasma with Mass Spectrometer (ICP-MS), and a Leco C-S analyzer.

For the XRD analysis, a sample of fresh tailings was dried in a desiccator under vacuum, ground with a mortar and pestle, and packed into the sample holder. The X-ray source was a $\mathrm{Cu}$ anode $\mathrm{X}$-ray tube. The $\mathrm{XRD}$ profile identified quartz $\left(\mathrm{SiO}_{2}\right)$ as the 
primary gangue mineral and pyrite as the only sulphide mineral. Other peaks were assigned to birnessite $\left(\mathrm{Na}_{0.3} \mathrm{Ca}_{0.1} \mathrm{~K}_{0.1} \mathrm{Mn}^{4+} \mathrm{Mn}^{3+} \mathrm{O}_{4} \bullet 1.5 \mathrm{H}_{2} \mathrm{O}\right)$, and the silicates muscovite $\left(\mathrm{KAl}_{2}\left(\mathrm{AlSi}_{3} \mathrm{O}_{10}\right)(\mathrm{F}, \mathrm{OH})_{2}\right)$ and taeniolite $\left(\mathrm{KLiMg}_{2} \mathrm{Si}_{4} \mathrm{O}_{10} \mathrm{~F}_{2}\right)$. Of note was the absence of any peaks that could be attributed to carbonate minerals. This was unexpected and contradicted by the IC analysis, ABA test and other reports. For comparison, an XRD profile from the Bulyanhulu tailings done by Golder Associates in 2005 found that the Bulyanhulu tailings contained $9 \%$ carbonate minerals. Their mineralogical data are presented in Table 3.1:

Table 3.1 Mineralogy of the Bulyanhulu tailings (Golder, 2005).

\begin{tabular}{lr}
\hline Mineral & wt\% \\
\hline Silicates (quartz, mica, chlorite) & 80 \\
Pyrite & 11 \\
Calcite & 5 \\
Ankerite & 4 \\
\hline
\end{tabular}

IC analysis was done on a Shamdizu TOC-VCPN Analyzer with a SSM-5000A TC/IC Solid Sample Module. Samples were run in triplicate and the reproducibility of the runs was $\pm 5 \%$ of the mean. The IC analysis determined that the tailings had a mean inorganic carbon content of $6.2 \mathrm{wt} \% \mathrm{C}$ as $\mathrm{CaCO}_{3}$.

One possible reason the XRD analysis may not have detected carbonate minerals could be because of a phenomenon known as peak shifting. XRD identifies minerals based on their unique crystal lattice structure. If that structure is somehow defective, for example due to a fault in the stacking of the lattice layers, the peaks appearing in the XRD profile may be offset from their normal location and therefore not identified properly when matched up against the database of XRD profiles (Makinson et al., 2000).

SEM-EDS analysis served two purposes. The first was to examine individual sulphide grains for alteration rims. The second was to identify the primary and secondary 
minerals in these grains. The methods used for sample preparation can be found in Section 3.6. Chalcopyrite and pyrite were the only two sulphide minerals found in the tailings samples. The electron microprobe analysis was not used for quantitative analysis of mineral abundance, but through visual inspection of polished sections under a light microscope, it was obvious that pyrite grains far outnumbered chalcopyrite grains by at least 20 to 1 . Minerals present in concentrations $<1 \%$ cannot be detected by XRD, which is why chalcopyrite was not detected previously in the XRD analysis but was identified using the electron microprobe.

The determination of metal and sulphate concentrations in the solid phase was conducted by Accutest Laboratories in Ottawa, ON. Unoxidized solids were digested with nitric and hydrochloric acid and analyzed for metals with an ICP-MS. Sulphate was determined by ion chromatography. The following minor constituent concentrations were determined in the solid phase:

Table 3.2 Sulphate and metal/metalloid concentrations in the solid phase of the Bulyanhulu tailings.

\begin{tabular}{lrlr}
\hline Constituent & $\mathbf{m g} / \mathbf{k g}$ & Constituent & $\mathbf{m g} / \mathbf{k g}$ \\
\hline $\mathrm{Ca}$ & 17,700 & $\mathrm{Fe}$ & 78,400 \\
$\mathrm{Mg}$ & 5,070 & $\mathrm{~Pb}$ & 120 \\
$\mathrm{~K}$ & 1,670 & $\mathrm{Mn}$ & 600 \\
$\mathrm{Na}$ & 990 & $\mathrm{Hg}$ & $\mathrm{BDL}$ \\
$\mathrm{Al}$ & 5,730 & $\mathrm{Mo}$ & 2 \\
$\mathrm{Sb}$ & 2 & $\mathrm{Ni}$ & 40 \\
$\mathrm{As}$ & 240 & $\mathrm{Se}$ & 3 \\
$\mathrm{Ba}$ & 20 & $\mathrm{Ag}$ & 3 \\
$\mathrm{Be}$ & $\mathrm{BDL}$ & $\mathrm{Sr}$ & 40 \\
$\mathrm{Cd}$ & $\mathrm{BDL}$ & $\mathrm{TI}$ & $\mathrm{BDL}$ \\
$\mathrm{Cr}$ & 20 & $\mathrm{~V}$ & 10 \\
$\mathrm{Co}$ & 70 & $\mathrm{Zn}$ & 30 \\
$\mathrm{Cu}$ & 320 & $\mathrm{SO}_{4}^{2-}$ & 4,100 \\
\hline
\end{tabular}

$\mathrm{BDL}=$ Below Detection Limit 
Sulphide analysis was performed by SGS Laboratories in Lakefield, Ontario. The samples were first leached with sodium carbonate to remove any sulphate. The residue was then analyzed in a Leco C-S analyzer. The method accuracy was $\pm 0.01 \mathrm{wt} \% \mathrm{~S}$. Sulphide analysis was done on fresh tailings before each drying test. The assumption was made that the sulphide content within a well-mixed bucket of fresh tailings was uniform throughout the bucket (assumption verified in Appendix B). The initial sulphide content of the buckets tested ranged from $5.6-7.2 \mathrm{wt} \% \mathrm{~S}$ or $10.5-13.5 \mathrm{wt} \% \mathrm{~S}$ as pyrite. This agrees with the $11 \%$ pyrite content reported by Golder (Table 3.1).

\subsection{Paste $\mathrm{pH}$}

Paste $\mathrm{pH}$ was measured using an Orion Model 420A pH meter. The paste sample was prepared according to the method described in MEND (1991). The $\mathrm{pH}$ of fresh, unoxidized tailings was 6.9 .

\subsection{NAG Test}

The NAG test is a single-step test whose result reflects both the acid-producing and acid-neutralizing minerals in a sample. In the NAG test, the acid generated by the oxidation of the sulphides is attenuated by its reaction with the non-sulphide neutralizing minerals. The net acidity is then reflected by the $\mathrm{pH}$ of the reacted solution, or NAG $\mathrm{pH}$.

The test protocol followed in this study came from Jambor (2003). Two and a half grams of tailings were pulverized with a mortar and pestle to pass 200 mesh $(75-\mu \mathrm{m})$. At room temperature, $250 \mathrm{~mL}$ of $15 \% \mathrm{H}_{2} \mathrm{O}_{2}$ were added to the tailings and reacted for 12 hours. The mixture was then boiled until visible reaction ceased. The $\mathrm{pH}$ was measured 
using an Orion Model 420A pH meter. The resulting NAG pH was 2.2. Generally, a pH less than 4.5 indicates that a sample is potentially acid-producing.

\subsection{ABA Test}

ABA is a two-part test used to determine the balance between acid-producing and acid-consuming components of a mine waste. The ABA test predicts the acid-producing potential (AP) based on sulphide-sulphur content and neutralization potential (NP) based on acid-digestion and titration of the tailings sample. The difference between the two values, the net neutralization potential (NNP), and the ratio of the two values, the net potential ratio (NPR), allow classification of the sample as potentially acid-consuming or acid-producing.

The protocol used for the ABA test in this study came from MEND (1991). The tailings were pulverized with a mortar and pestle to pass 200 mesh $(75-\mu \mathrm{m})$. A $5-\mathrm{g}$ sample was sent to Accutest Laboratories to be analyzed for sulphide content in the solid phase using a Leco C-S Analyzer (see Section 3.2). The sulphide content was used to calculate the AP of the tailings according to Equation 3.1 . The $\mathrm{AP}$ was $176 \mathrm{~kg} \mathrm{CaCO} / \mathrm{t}$.

$$
\mathrm{AP}=\% \mathrm{~S}_{\text {sulfide }} \times 31.25
$$

Where AP is the acid potential in $\mathrm{kg} \mathrm{CaCO}_{3} / \mathrm{t}$.

The neutralization potential (NP) was determined by reacting $2.00 \mathrm{~g}$ of tailings with $33.0 \mathrm{~mL}$ of $0.0997 \mathrm{M} \mathrm{HCl}$. The mixture was allowed to react for 24-hours in a stirred flask. The contents of the flask were then titrated to $\mathrm{pH} 7.0$ with $0.0996 \mathrm{M} \mathrm{NaOH}$. The determination was done in triplicate and the results were within $\pm 1 \%$. The 
concentrations and volumes of the $\mathrm{HCl}$ and $\mathrm{NaOH}$ solutions were then used to calculate the NP of the tailings according to Equation 3.2. The NP was $53 \mathrm{~kg} \mathrm{CaCO}_{3} / \mathrm{t}$.

$$
\mathrm{NP}=\frac{50 \mathrm{a}[\mathrm{x}-(\mathrm{b} / \mathrm{a}) \mathrm{y}]}{\mathrm{c}}
$$

Equation 3.2

Where NP is the neutralization potential $\left(\mathrm{kg} \mathrm{CaCO}_{3} / \mathrm{t}\right)$, $\mathrm{a}$ is the concentration of $\mathrm{HCl}(\mathrm{M}), \mathrm{b}$ is the concentration of $\mathrm{NaOH}(\mathrm{M}), \mathrm{c}$ is the sample weight $(\mathrm{g}), \mathrm{x}$ is the volume of $\mathrm{HCl}$ added $(\mathrm{mL})$ and $\mathrm{y}$ is the volume of $\mathrm{NaOH}$ added $(\mathrm{mL})$.

For comparison, the IC analysis (Section 3.2) determined that the tailings contained $6.2 \% \mathrm{C}$ as $\mathrm{CaCO}_{3}$, which is equivalent to $62 \mathrm{~kg} \mathrm{CaCO}_{3} / \mathrm{t}$. The two results are in acceptable agreement.

The NNP is the difference between the NP and the AP. For the Bulyanhulu tailings, the NNP $=-123 \mathrm{~kg} \mathrm{CaCO}_{3} / \mathrm{t}$. The NPR is the ratio of the NP over the AP, with the NPR for the sample being 0.3 . Generally, mining wastes are considered potentially acid-generating if the NNP $<0 \mathrm{~kg} \mathrm{CaCO}_{3} / \mathrm{t}$ and if the NPR $<3$. By both indicators, the Bulyanhulu tailings would be classified as potentially acid generating.

\subsection{Grain Analysis and Long-Term Rewetting Test}

Fresh tailings were dried in a desiccator under vacuum. The tailings were screened to minus 100 mesh $(150 \mu \mathrm{m})$ and the fines rejected. The coarse fraction was used to prepare 5 polished sections, which were examined under reflected light and SEMEDS. Pyrite and chalcopyrite were the only sulphide minerals present. In fresh tailings, the sulphide grain edges were sharp with no visible alteration (Figure 3.2). The photos were taken with a Canon Powershot S3 IS camera mounted on a Nikon Optiphot light microscope. 


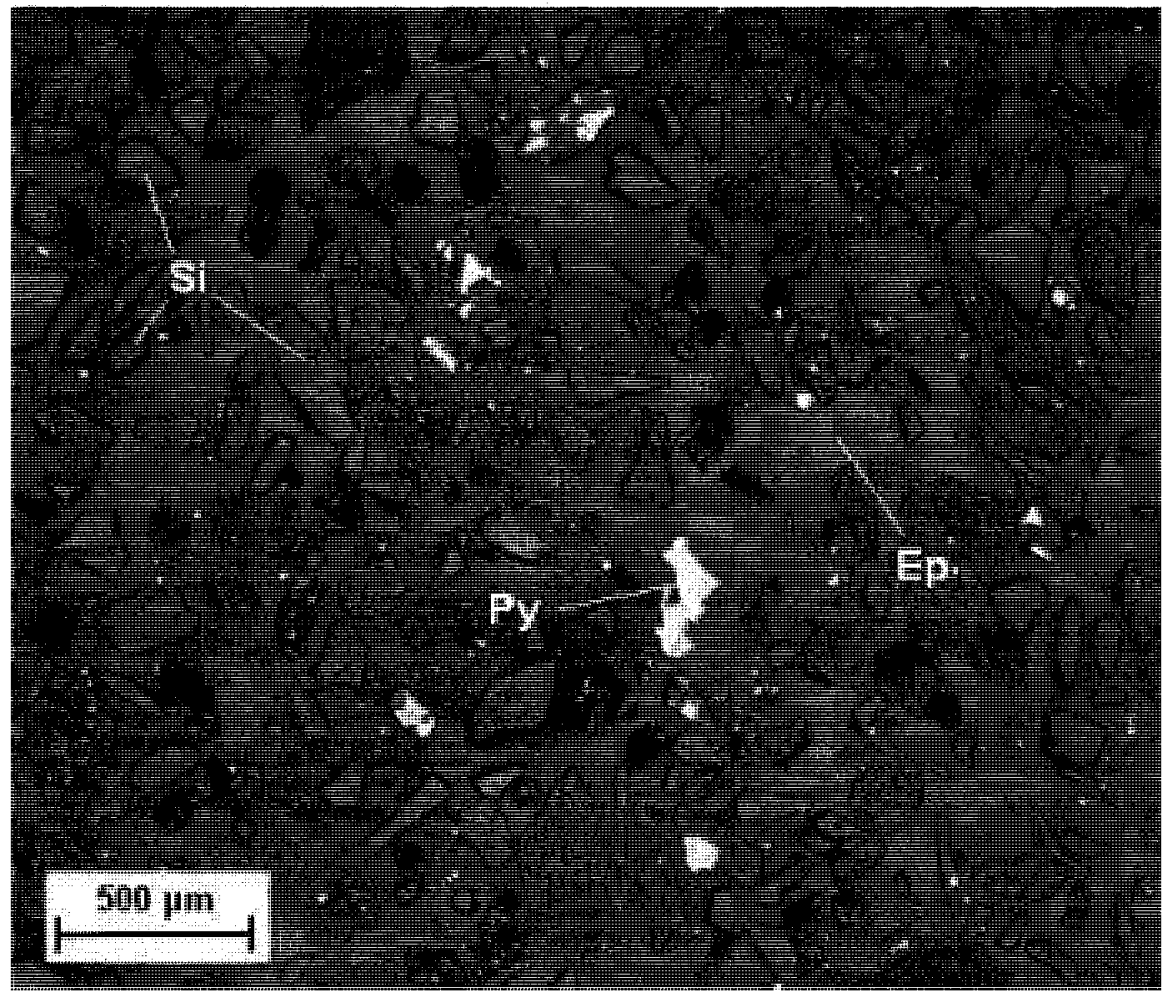

(a)

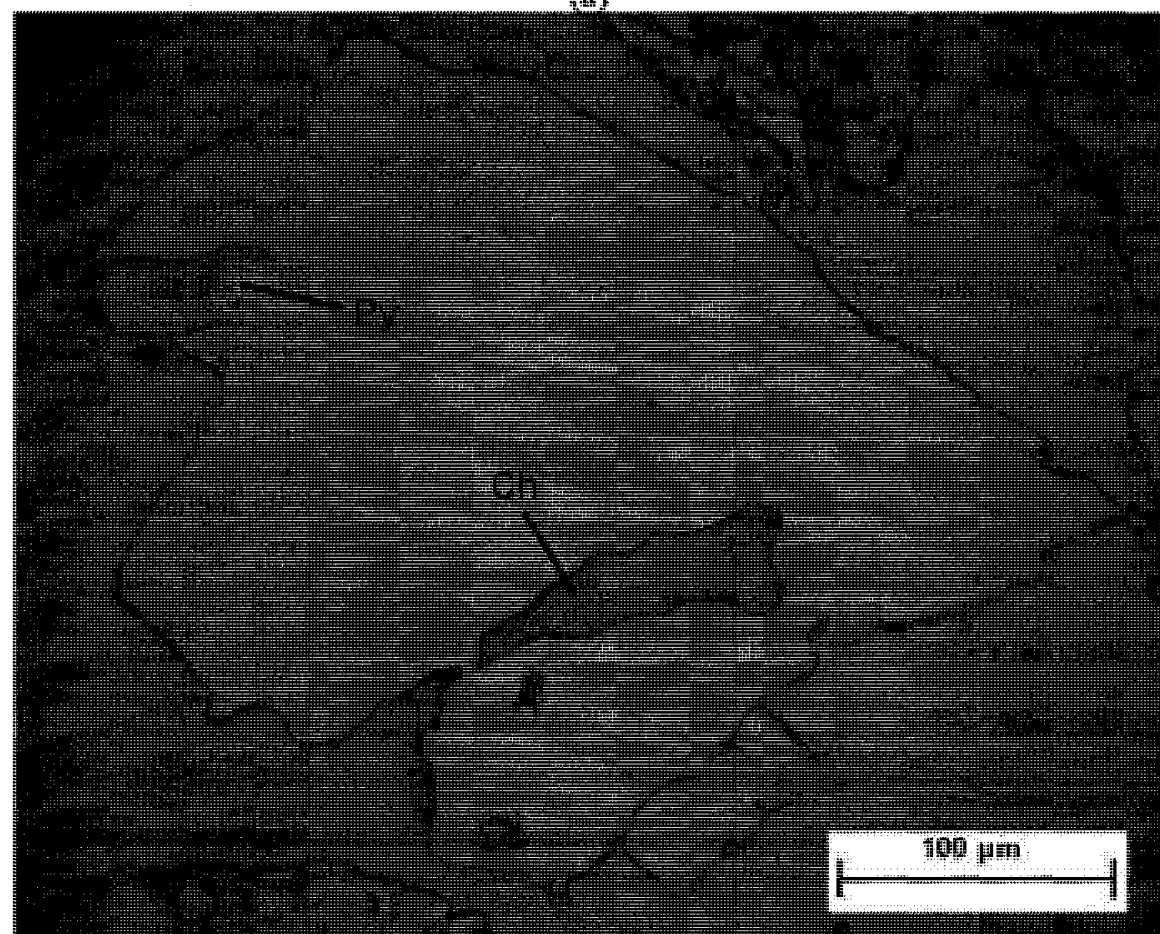

(b)

Figure 3.2 Unoxidized Bulyanhulu tailings showing (a) silicate grains ( $\mathrm{Si}$ ), pyrite grains (Py) and the epoxy matrix (Ep) and (b) pyrite (Py) and chalcopyrite (Ch) in a tailings grain. Photos were taken under reflected light. 
The long-term rewetting test was conducted to determine the extent of sulphide depletion required before alteration rims would become detectable by SEM-EDS. One $\mathrm{kg}$ of unoxidized tailings (150 $\mu \mathrm{m}$ fraction only) was left open to the atmosphere in a stainless steel dish. Over a 150-day period, the tailings were dried and re-saturated 6 times and sampled 5 times (see rewetting and sampling schedule in Appendix C). Twenty-five grams were removed per sample. Five grams of the sample were used for sulphide content analysis (Table 3.3 ) and $20 \mathrm{~g}$ were used to prepare 3 polished sections for SEM-EDS grain analysis.

Table 3.3 Sulphide depletion during the long-term rewetting test.

\begin{tabular}{lr}
\hline Date & wt\% S \\
\hline 26-Jan-08 & 6.60 \\
09-Feb-08 & 5.81 \\
12-Mar-08 & 4.30 \\
14-May-08 & 2.83 \\
19-Jun-08 & 2.68 \\
\hline
\end{tabular}

Although sulphide depletion was evident from the periodic sulphur analyses, there were no alteration rims visible on the pyrite grains in the polished sections. According to Jambor (2003), alteration rims are very difficult to observe on pyrite compared to pyrrhotite grains. Although iron sulphates will form on pyrite surfaces, most coatings are thin, highly water-soluble and difficult to preserve intact for polished-section microscopy (Jambor et al., 2000; Howie, 1992).

\subsection{Reaction Rate Constant}

The sulphide depletion data from the long-term rewetting test were also used to determine the first-order removal constant $(K)$ to be used in POLLUTE modelling (Equation 2.17). 
Since the thickness of the tailings layer was only $3 \mathrm{~cm}$ and the tailings were saturated only 5 times over the course of the 150-day test, the approximation was made that oxygen was present in excess and the supply of oxygen to the pyrite surface was not rate-limiting (i.e. $a=0$, zero-order dependence on $\left[\mathrm{O}_{2}\right]$ in Equation 2.4). Equation 2.4 then simplifies to:

$$
r=\frac{-d\left[\mathrm{FeS}_{2}\right]}{d t}=-\frac{4}{15} \frac{d\left[\mathrm{O}_{2}\right]}{d t}=k
$$

The plot of oxygen consumption versus time in Figure 3.3 yields a line of slope $=0.19$ moles $\mathrm{O}_{2} / 100 \mathrm{~kg}$ tailings $/$ day. Assuming the concentration of oxygen in the pore space is the same as in air $(0.23$ moles $/ 100 \mathrm{~kg}$ tailings $)$, this gives a removal constant $K=0.8$ day $^{-1}$.

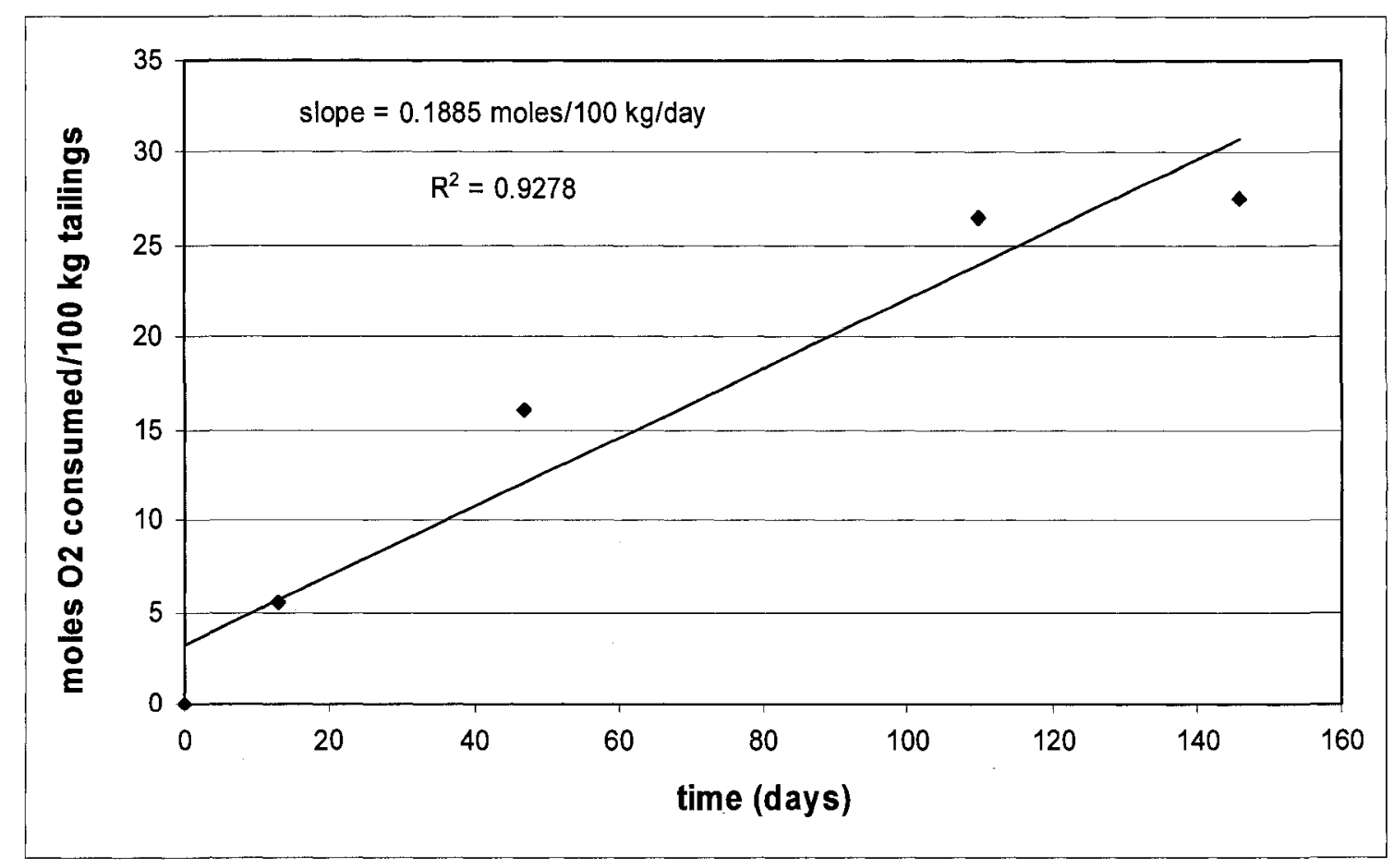

Figure 3.3 Determination of the first-order reaction rate constant for pyrite oxidation by oxygen based on sulphide depletion over a 150-day rewetting test. 
When used in POLLUTE, $K=0.8$ day $^{-1}$ did not give good agreement between experimental and modelled results. When determined empirically, $K=100$ day $^{-1}$ gave the best fit to the experimental data. Yanful et al. (1999) found a similar result when they tried to calculate a value for $K$ using pyrite oxidation rates described in the literature. From the literature, they obtained a value for $K$ of $0.001 \mathrm{day}^{-1}$; however, they obtained the best fits to their experimental data using a reaction rate constant $K$ of 50 per day. Therefore, following the example set by Yanful et al. (1999), a reaction rate constant $K$ of 100 per day was used in the current study. 


\section{Chapter 4: Small-Scale Test}

The small-scale test was a preliminary test used to gauge the extent of sulphide oxidation over a short time period and determine whether modelling with SoilCover and POLLUTE would be useful. The methods, results, and discussion are presented in this chapter.

\subsection{Experimental Methods}

The test consisted of a 2-layer (10-cm each) drying test carried out in a 5-gallon HDPE plastic bucket set on top of an Ohaus Champ SQ bench scale with CD-11 indicator (Figure 4.1).

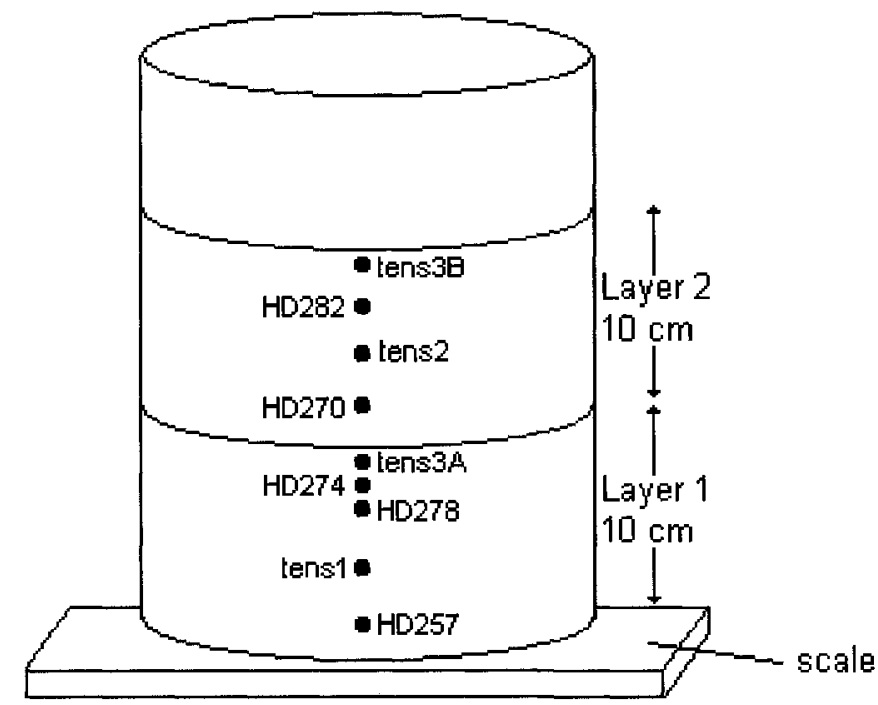

Figure 4.1 Schematic diagram showing the setup for the small-scale test.

The scale was used to measure daily evaporation. A fan, simulating wind, was used to circulate air over the tailings surface. The duration of the drying test was 26 days (August 25 - September 21, 2007). The ambient temperature and relative humidity were 
recorded every 30 minutes using a USB-502 RH/Temperature Data Logger from Measurement Computing.

Eight suction sensors were saturated and buried in the two layers: 3 UMS T5 pressure transducer tensiometers and 5 Campbell Scientific 229 Heat Dissipation Matric Water Potential Sensors (HD sensors). The vertical position of each sensor was determined by excavation at the end of the test (Table 4.1). Tensiometers tens $3 \mathrm{~A}$ and tens3B were physically the same sensor; the sensor cavitated before the second layer had been added so it was removed from the top of Layer 1, re-saturated, and re-buried in Layer 2.

Table 4.1 Matric suction sensor locations in the small-scale test.

\begin{tabular}{lcc}
\hline Sensor ID & Layer & Elevation $(\mathbf{c m})$ \\
\hline HD257 & 1 & 1.7 \\
tens1 & 1 & 4.7 \\
HD278 & 1 & 8.2 \\
HD274 & 1 & 8.7 \\
tens3A & 1 & 9.5 \\
HD270 & 2 & 13.7 \\
tens2 & 2 & 14.5 \\
HD282 & 2 & 16.2 \\
tens3B & 2 & 19.4 \\
\hline
\end{tabular}

The tensiometers provide a direct measurement of matric suction. Water in the acrylic glass shaft contacts the soil water through a porous ceramic tip. The soil water tension is directly conducted to the pressure transducer, which offers a continuous signal. The atmospheric reference pressure is provided through a membrane on the cable. The pressure transducer provides the soil water tension as a linear output signal, with $1 \mathrm{mV}$ corresponding to $1 \mathrm{kPa}$ (UMS, 2008).

The HD sensor uses a heat dissipation method to indirectly measure matric suction. The body of the HD sensor is made of a porous ceramic containing a heating 
wire and a thermocouple. As the soil dries, the matric suction increases and the hydraulic gradient causes water to move from the ceramic into the surrounding soil. This change in water content in the ceramic causes a corresponding change in thermal conductivity of the ceramic-water matrix. The rate of dissipation of a heat pulse $(50 \mathrm{~mA}$ for $30 \mathrm{~s})$ from the heating wire will depend on the water content of the ceramic and hence the soil (Flint et al., 2002). The copper-constantan thermocouple measures the temperature increase, which is converted to soil suction using Equation 4.1 :

$$
\log \left(\Psi_{m}\right)=\frac{1}{\alpha+\beta \Delta T+\gamma \Delta T^{2}+\sigma \Delta T^{3}}
$$

Where $\Psi_{m}$ is the matric suction (cm), $\Delta T$ is the change in temperature $(\mathrm{K})$ and $\alpha, \beta, \gamma$, and $\sigma$ are calibration parameters specific to each sensor (provided by manufacturer - Campbell Scientific, 2006).

The suction sensors were wired to a computer capable of taking over 200,000 measurements per second. To minimize noise, the readings displayed on-screen were an average of every 1,000 measurements taken by the computer. Every 10 seconds, the onscreen suction displayed for each tensiometer was stored in a data file. For the HD sensors, temperature values were stored every 0.25 seconds during the 30 -second heating cycle. Because the heating cycle had to be initiated manually, HD sensor readings were irregular but generally were taken every 1 or 2 hours during the daytime.

Fresh tailings were adjusted to $40 \%$ GWC by removing excess liquid and a $13-\mathrm{cm}$ layer was poured on Day 1. By Day 15, the evaporation rate had dropped off significantly and a second layer was added. Layer 2, initially $40 \%$ GWC, was poured on top of Layer 1 to a total combined height of $22 \mathrm{~cm}$. The two layers were dried until Day 26 . 
To measure solid sulphide content, samples were taken from the tailings surface every 5 days. On Day 26, the tailings were profiled with depth (sampled every $5 \mathrm{~cm}$ ). All samples were wrapped in plastic, sealed in Ziploc bags and refrigerated until analyzed (procedure same as Section 3.2). On Day 26, a sample was also taken for mineralogical analysis by XRD and SEM-EDS. To minimize contact with oxygen, this sample was dried under vacuum in a desiccator. Fifty grams of the dried tailings were used for XRD (procedure same as Section 3.2). The remaining tailings were screened to minus 100 mesh $(150 \mu \mathrm{m})$ and the coarse fraction was used in the preparation of 3 polished sections (procedure same as Section 3.6).

\subsection{Modelling Methods}

There were two stages to the modelling component of this research: SoilCover and POLLUTE (see flow chart in Figure 2.3) . Each will be addressed at length in this section. For modelling of the large-scale test (Section 5.2) and column tests (Section 6.2), the modelling methods are the same as those presented in this chapter unless otherwise stated in those sections.

\subsubsection{SoilCover}

This section describes the boundary conditions, mesh generation, time steps, convergence criteria and material parameters used in SoilCover modelling. It also describes how the model was adaptated to account for volume change due to self-weight consolidation and shrinkage. 


\section{Boundary conditions}

In the bench-scale experiments, there is no water loss through the base of the container; therefore, a no flow bottom boundary condition was required. Since SoilCover does not have a no flow bottom boundary option, one was artificially created in the simulation using a $2-\mathrm{cm}$ impermeable layer. The hydraulic conductivity of this layer was $5 \times 10^{-15} \mathrm{~cm} / \mathrm{s}$ and it was given a low air entry value $(<0.1 \mathrm{kPa})$ to avoid inflated suctions in the bottom elements of the tailings. The total flux through the bottom of the mesh was zero for all simulations.

The top boundary condition was defined by the temperature, relative humidity, solar radiation, and wind speed (wind was artificially generated using a fan) in the laboratory. The ambient temperature and relative humidity were measured directly, radiation was assumed to be zero since the test was conducted indoors, and wind speed was determined by equating the average potential evaporation rate of the model to that measured in the lab. The daily weather conditions are tabulated in Appendix D.

\section{Mesh generation}

SoilCover allows the one-dimensional mesh to be divided into a maximum of 99 elements (100 nodes). The simulations carried out in this study used elements ranging in size from $0.2 \mathrm{~cm}$ at the boundaries and layer-layer interfaces, to $2 \mathrm{~cm}$ in the centre of each layer. The rate of increase of the element size was 1.2 . The sensitivity of the solution to mesh size was tested (using elements ranging from $0.1 \mathrm{~cm}$ to $1 \mathrm{~cm}$ ) and found to have no appreciable effect on the final suction profile. Further discusssion regarding the effects of soil-shrinkage on mesh generation can be found in this section under the heading Volume Change Considerations. 


\section{Time Steps and Convergence Criteria}

The initial time step was set to $0.1 \mathrm{~s}$. Subsequent time steps ranged from $0.1 \mathrm{~s}$ to $500 \mathrm{~s}$. For each time step, the convergence criteria had to be satisfied at every node. To achieve convergence, both temperature and suction values had to change by $<0.01 \%$ from one iteration to the next. The maximum number of iterations for convergence was set to 100 , as recommended (SoilCover, 2000). The maximum change in temperature and suction between time steps was set to $0.01 \%$ and dampening for both temperature and suction was set to $10 \%$. With these settings, run times ranged from 30 seconds for simulations with suctions in the $<100 \mathrm{kPa}$ range, up to 40 minutes for simulations where surface suctions exceeded $10,000 \mathrm{kPa}$. The sensitivity of the model to the time step was tested by changing the convergence criteria to $<0.001 \%$ change in temperature and suction from one iteration to the next. This simulation took longer to run, but demonstrated that there was no appreciable difference between the final suction profiles generated using the different convergence criteria.

\section{Material Parameters}

The solids density, porosity and saturated hydraulic conductivity were determined previously: $\rho=2.98 \mathrm{~g} / \mathrm{cm}^{3}, n=0.47$, and $K_{s}=5 \times 10^{-7} \mathrm{~m} / \mathrm{s}$ (Fisseha, 2008). The SWCC (Figure 4.2) for the Bulyanhulu tailings was measured using the axis translation technique by Simms et al. (2007) and verified by Fisseha (2008).

The assumption was made that the porosity, density, hydraluic conductivity and SWCC of the tailings would not change over time. In reality, this is not the case. Precipitation and dissolution reactions in the tailings will affect material parameters as the tailings weather. However, given the relatively short oxidation times in this study, it 
was felt that this approximation (constant material properties) was reasonable. One way to verify this assumption would be to compare the paste tailings to a non-reactive graded silt with the same initial particle size distribution. If the geochemical processes occuring in the tailings were impacting their geotechnical properties then the difference would be apparent when compared to the non-reactive material. In this study, we did not verify the assumption by comparing the tailings to a non-reactive material, so it may be something to consider in the future.

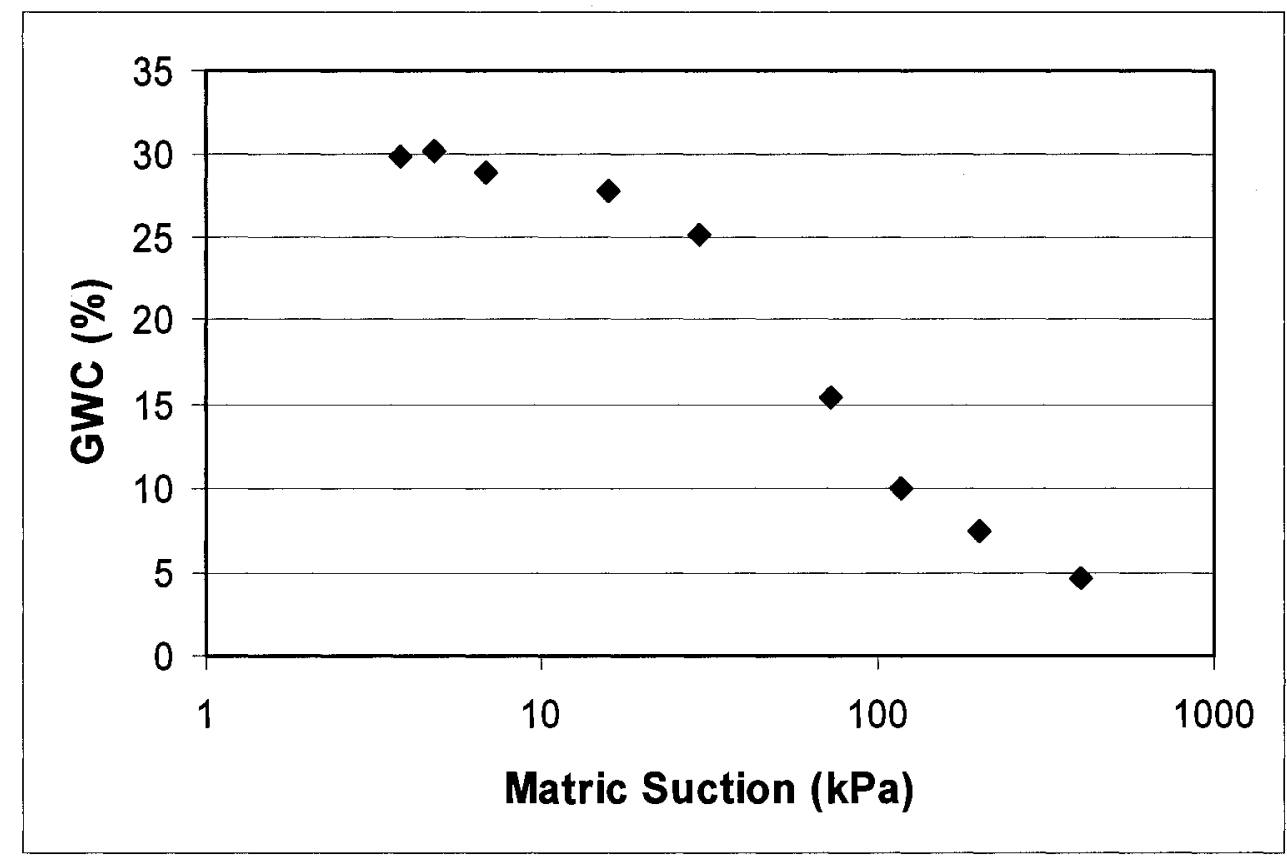

Figure 4.2 Soil-water characteristic curve for the Bulyanhulu tailings (After Simms et al., 2007).

The specific heat and thermal conductivity functions were derived automatically in SoilCover through theoretical relationships. SoilCover generates the volumetric specific heat using the mass density of the soil and the mass specific heat. SoilCover also generates a thermal conductivity function using the method proposed by Johansen (1975). The method requires knowledge of the weight percent quartz in the soil. The value of 
$80 \%$ was used for the Bulyanhulu tailings based on the XRD mineralogy (Table 3.1). SoilCover numerical solutions have been found to be insensitive to thermal conductivity and specific heat properties so using theoretical derivations for these two soil properties should not significantly affect the results (SoilCover, 2000; Swanson et al., 2003).

\section{Self-weight Consolidation}

Paste tailings are thickened to a consistency at which they can be pumped without undergoing particle segregation. At the Bulyanhulu Mine, the pumping water content is typically around $38 \%$ GWC (Simms et al., 2007). Once the paste flow has ceased, the tailings continue to settle, undergoing self-weight consolidation. The liquid extruded from the pores during self-weight consolidation, also called bleed water, accumulates on the surface of the tailings. In the field, the bleed water may run off due to the natural slope of the tailings pile, it may be absorbed by underlying layers, or it may evaporate. In the small-scale and column experiments, runoff was not possible and the bleed water either evaporated during the first few days of drying or it was absorbed by the underlying layer. Settling tests show that self-weight consolidation of the Bulyanhulu tailings reduces the GWC to $27 \%$ and the void ratio to 0.97 (Figure 4.3).

The settling test was carried out in 1-L glass beaker. The beaker was filled approximately two-thirds full (initial height $8.20 \mathrm{~cm}$ ) with freshly mixed tailings at $40 \%$ GWC. The beaker was covered with plastic wrap to prevent evaporation and the tailings were allowed to settle. As the bleed water accumulated at the surface, it was drawn off using a syringe. Each time bleed water was drawn off, the void ratio of the paste was calculated based on the change in height of the settled tailings (void ratio $=$ volume voids/volume solids). The GWC was also calculated based on the amount of water 
removed. The process of drawing off bleed water continued until no further bleed water accumulated at the surface (final height $6.73 \mathrm{~cm}$ ).

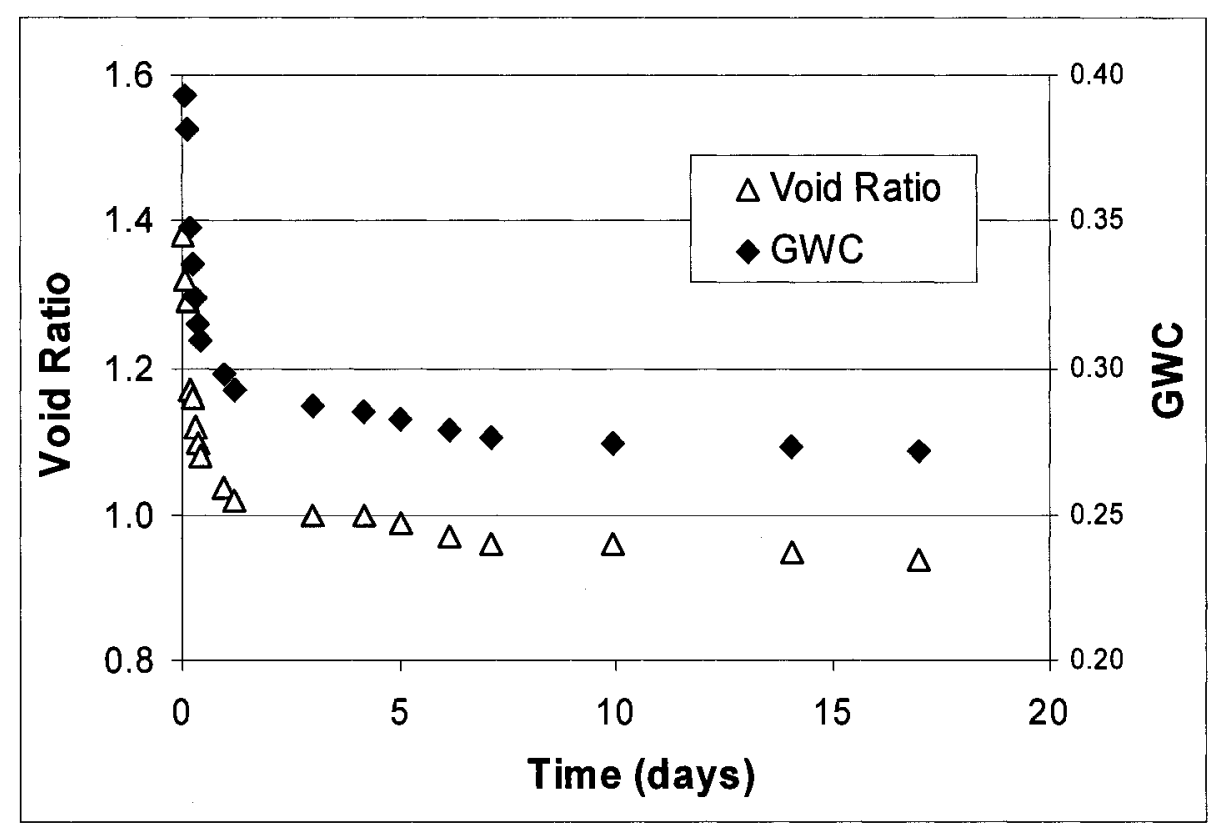

Figure 4.3 Settling test results showing the decrease in void ratio and gravimetric water content (GWC) with time due to self-weight consolidation of the Bulyanhulu tailings.

SoilCover uses the parameter Mv to account for the bleed water produced through self-weight consolidation. Mv is the slope of the SWCC in the positive pore pressure range. The Mv value was determined for each test based on the initial pore pressure distribution and the change in water content due to self-weight consolidation. For example, in the small-scale test, the initial volumetric water content was 0.53 and after self-weight consolidation it would be 0.47 . Since each layer was $10 \mathrm{~cm}$, the average initial hydrostatic pressure in a layer was $0.49 \mathrm{kPa}$. Therefore, the Mv value was calculated as follows: $\mathrm{Mv}=(0.53-0.47) / 0.49=0.13 / \mathrm{kPa}$.

\section{Volume Change Considerations}

Once all the bleed water has evaporated, pore water begins to evaporate. This creates suction within the soil pores, causing the soil to shrink. The volume will continue 
to change until the shrinkage limit is reached. The void ratio of the Bulyanhulu tailings at the shrinkage limit is approximately 0.8 . The shrinkage curve of the Bulyanhulu tailings due to matric suction is shown in Figure 4.4.

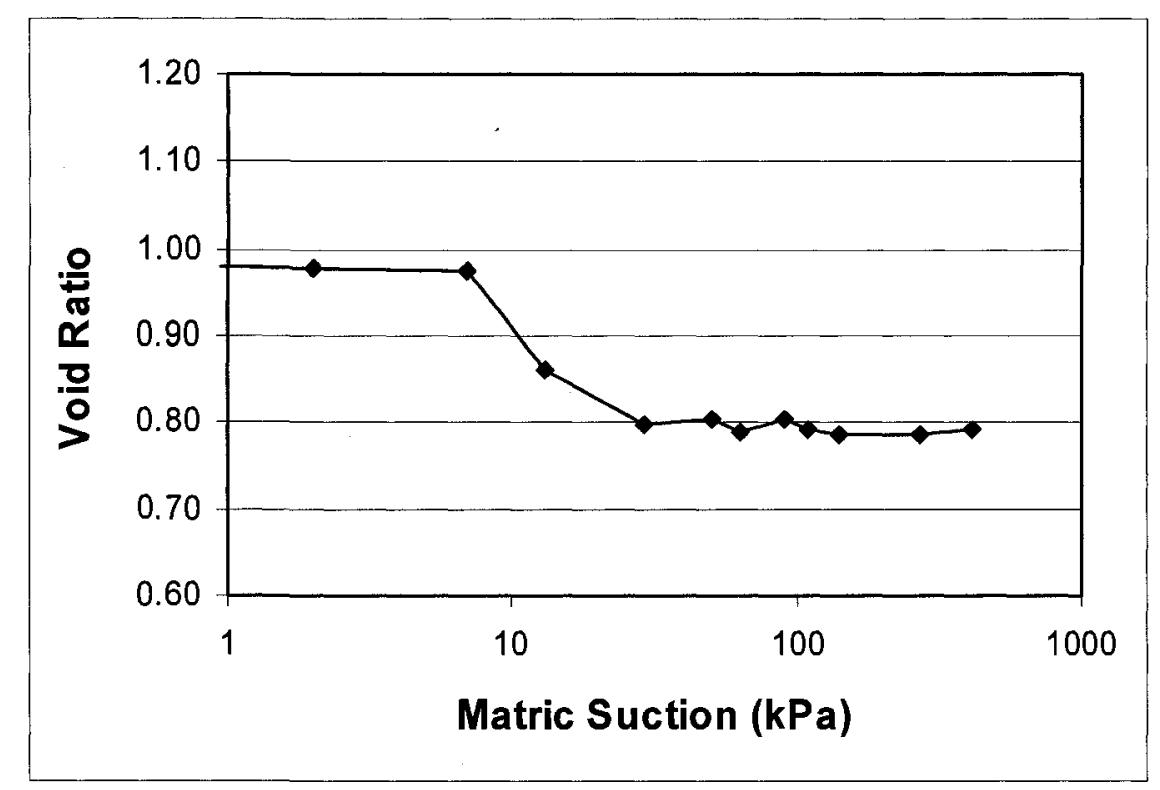

Figure 4.4 Shrinkage curve due to matric suction (After Simms et al., 2007)

SoilCover does not incorporate soil shrinkage into its numerical model. There are two issues that need to be resolved manually when using SoilCover to model a shrinking soil: those are the changing mesh size and the method used to derive the relative hydraulic conductivity function.

The effect of soil shrinkage on mesh size is obvious. As a soil shrinks, the length of the one-dimensional mesh representing the height of that soil will also shrink. To model this shrinkage, the length of each element in the mesh was shortened based on the daily decrease in that element's void ratio. The change in an element's void ratio was calculated based on the change in soil suction in that element over 24 hours. Suction values were converted into void ratios based on the shrinkage curves in Figure 4.3 and Figure 4.4. In this manner, the mesh was shrunk element by element each day until each 
element had reached the void ratio of 0.80 , corresponding to the observed minimum void ratio. Drying after this point did not result in any further mesh shrinkage.

The second parameter that is affected by soil shrinkage is the relative hydraulic conductivity $\left(K_{r}\right)$ function. The $K_{r}$ function is difficult to measure experimentally but can be derived by statistical methods using the SWCC (e.g., Van Genuchten, 1980; Fredlund et al., 1994). SoilCover will automatically calculate the $K_{r}$ function based on the userdefined GWC vs. suction curve. However, the method used by SoilCover for determining $K_{r}$ assumes that the soil does not undergo any volume change as the suction increases. Since the Bulyanhulu tailings do exhibit significant volume change (see the shrinkage curve in Figure 4.4), this results in an underestimation of the degree of saturation of the tailings and consequently of $K_{r}$. The low hydraulic conductivity limits the rate at which moisture can be supplied to the tailings surface, causing the mesh elements near the surface to desaturate. Ultimately, this method overestimates the soil suction gradient at the surface, which results in a premature decline in the evaporation rate.

To avoid this problem, the $K_{r}$ function can instead be calculated manually to reflect the changing volume of the tailings. To account for volume change, the curve fit parameters can be derived from the measured soil saturation vs. suction curve rather than the GWC vs. suction curve. For the Bulyanhulu tailings, the curve fit parameters used were $a=38, m=0.47, n=1.89$ (using Van Genuchten's method (1980)). For comparison, the $K_{r}$ functions derived automatically and manually are shown in Figure 4.5. 


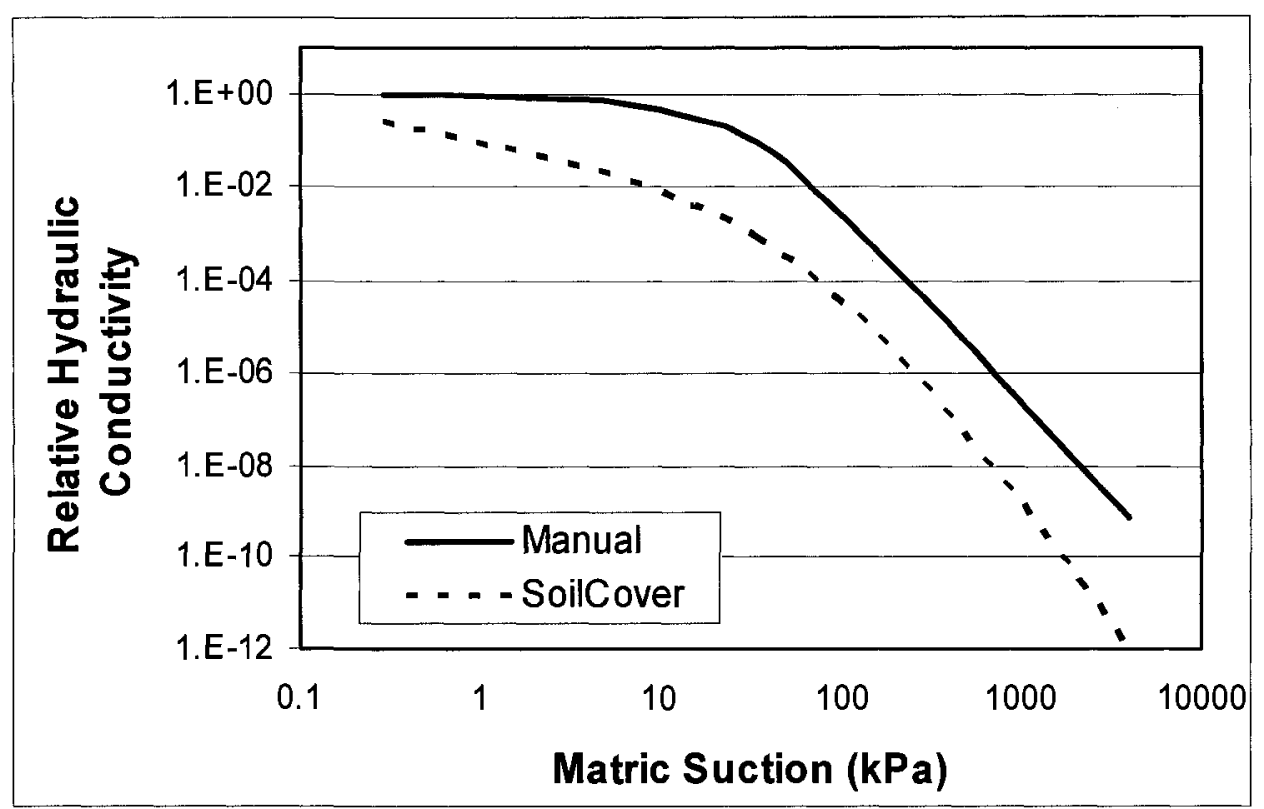

Figure 4.5 Effect of volume change on prediction of the relative hydraulic conductivity function for Bulyanhulu tailings. The "SoilCover" curve was calculated automatically and does not account for volume change. The "Manual" curve was calculated manually to reflect the changing volume of the tailings.

Four simulations were conducted to test the effects of volume change on the predicted soil suction profile and evaporation rate (Figure 4.6). The four scenarios were:

1) Unadjusted - $K_{r}$ calculated automatically by SoilCover, mesh unaltered

2) $\mathrm{Kr}$ Adjusted - $K_{r}$ calculated manually, mesh unaltered

3) Mesh Adjusted - $K_{r}$ calculated automatically by SoilCover, mesh shrunk

4) Both Adjusted - $K_{r}$ calculated manually, mesh shrunk

Aside from conditions $1-4$, the simulations were otherwise identical. The initial layer was $15 \mathrm{~cm}$ and the moisture content was $38 \% \mathrm{GWC}$ (void ratio $=1.25$ ), the drying period was 9 days and the potential evaporation rate was $9.3 \mathrm{~mm} /$ day. If the mesh was shrunk, the final height was $12 \mathrm{~cm}$ (void ratio $=0.80$ ). 


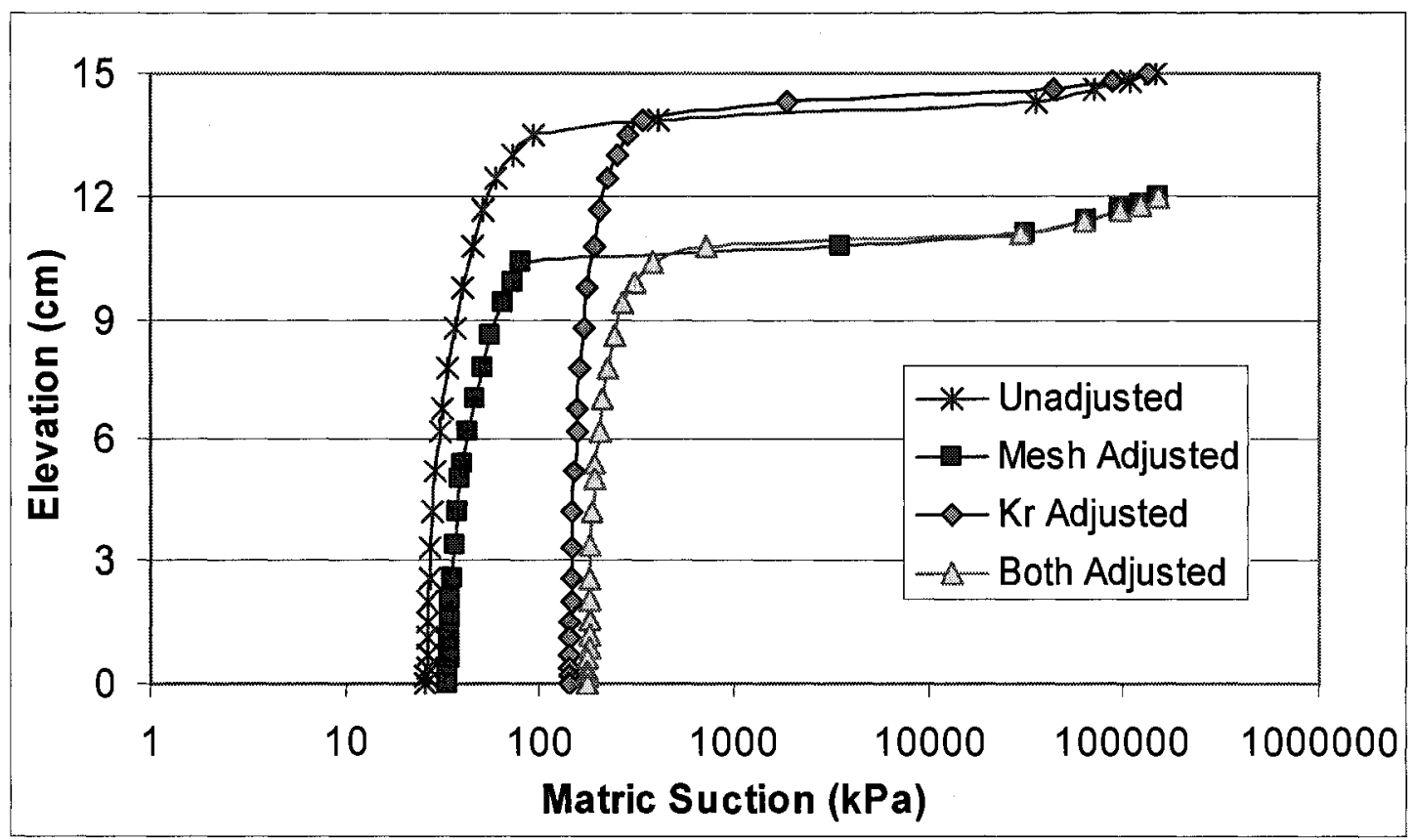

(a)

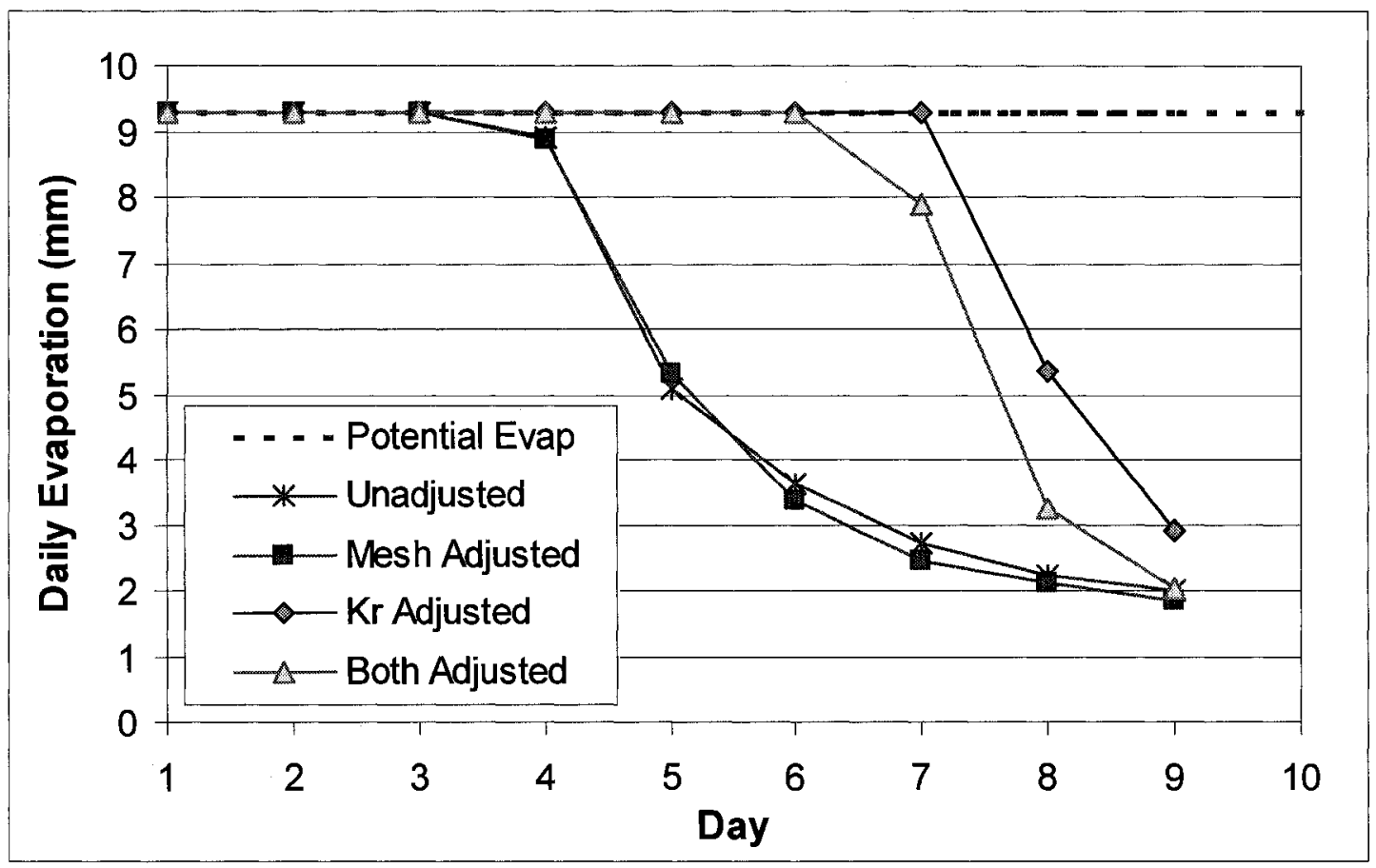

(b)

Figure 4.6 (a) Suction profiles and (b) daily evaporation rates predicted by SoilCover for a single $15-\mathrm{cm}$ layer subjected to $9.3 \mathrm{~mm} /$ day potential evaporation for 9 days. The four datasets show the variability in the suction profile and evaporation rate when mesh size and relative hydraulic conductivity $\left(K_{r}\right)$ function are adjusted to reflect the changing volume or left unadjusted. 
These simulations show that shrinking the mesh has little effect on the suction profile and evaporation rate; however, in terms of physical reality, by shrinking the mesh elements, the model does represent the change in the total depth of the tailings. The method used to predict $K_{r}$ has a significant impact on the suction profile and evaporation rate. By accounting for volume change, a more uniform drying profile is observed and the rate of evaporation remains closer to the potential rate of evaporation for a longer period. The most realistic conceptual model, accounting for volume change in both mesh adjustment and $K_{r}$ prediction, was used for all modelling in this study.

\subsubsection{POLLUTE}

The size and number of layers used in POLLUTE simulations were the same as the mesh elements used in SoilCover. The boundary condition at the soil surface was a constant concentration boundary equal to the atmospheric concentration of oxygen ( 280 $\mathrm{mg} / \mathrm{L}$ ). The bottom boundary condition was zero flux. Oxygen concentration profiles were output daily over the course of the drying test. The half-life value for the Radioactive/Biological Decay was $\mathrm{t}_{0.5}=0.17 \mathrm{hr}^{-1}$ (i.e. removal rate constant, $K=100$ per day). Approximating oxygen removal using a first-order removal constant is not ideal; however, the sensitivity of the final oxygen profile to the value of $K$ was tested (comparing $K=40,50$ and $60 \mathrm{day}^{-1}$ ) and the effect on the final sulphide depletion profile was negligible. Using the time-varying properties option in POLLUTE, $D_{\text {eff }}$ values (calculated using the SoilCover results for volumetric water content and Equation 2.2) were assigned daily to each layer. 


\subsubsection{Sulphide Depletion}

POLLUTE gives a time-dependent oxygen concentration profile in the paste tailings as they dry. The daily profiles were then used to estimate the sulphide consumption in the tailings. Two methods were used and they will be referred to as the nKc method and the Jerz and Rimstidt method.

In the nKc method, the amount of oxygen consumed (given by $n K c$ in Equation 2.17) was converted stoichiometrically to pyrite depletion over each 1-day interval. The corresponding mass of sulphide consumed each day was then subtracted from the initial sulphide content of the tailings to obtain a final profile of sulphide content with time and with depth in the tailings.

In the Jerz and Rimstidt method, an oxygen consumption rate was calculated for each 24-hour period based on the POLLUTE-derived oxygen concentration at the depth of interest (using Jerz and Rimstidt's (2004) rate equation for the abiotic oxidation of pyrite by gaseous oxygen given in Equation 2.7). The specific surface area of pyrite was calculated by Equation 2.3 using a particle size of $20 \mu \mathrm{m}$.

The Jerz and Rimstidt rate equation (Equation 2.7) depends inversely on the reaction time $(t)$, which accounts for the reduction of the reaction rate with time due to the build-up of oxidation products. However, the reaction time at any given depth depends on when the reaction was initiated (i.e. when oxygen first diffused to the depth of interest). Therefore, to account for the time-dependent nature of the reaction rate, the reaction start time $(t=0 \mathrm{~s})$ at a given depth corresponded to the time when oxygen was first detected at depth. From that point forward, the value of $t$ at the depth of interest increased each day by $86400 \mathrm{~s}$ ( $86400 \mathrm{~s}=24 \mathrm{hrs})$. Oxygen depletion was converted 
stoichiometrically to pyrite depletion for each 1-day interval. The corresponding mass of sulphide consumed every 24 hours was then subtracted from the initial sulphide content of the tailings.

\subsection{Results}

The bleed water evaporated from Layer 1 by Day 3. Separation from the bucket edges was first observed on Day 7, and after Day 12 no further volume change was observed. The bleed water observed on the surface of Layer 2 was very minimal and short-lived because most of the excess water was absorbed by the underlying layer. Separation from the edges was noted on Day 17 and volume change ceased by Day 21 at a final combined height of $20 \mathrm{~cm}$. The two layers were allowed to dry until Day 26. A summary of the vertical shrinkage and change in void ratio is given in Table 4.2.

Table 4.2 Summary of the vertical shrinkage and change in void ratio during the smallscale test.

\begin{tabular}{ccc}
\hline Day & Void Ratio & Elevation $(\mathrm{cm})$ \\
\hline 1 & 1.34 & 13.0 \\
3 & 0.97 & 10.9 \\
12 & 0.80 & 10.0 \\
15 & 0.80 & 10.0 \\
16 & 1.22 & 22.3 \\
17 & 0.97 & 20.9 \\
21 & 0.80 & 20.0 \\
26 & 0.80 & 20.0 \\
\hline
\end{tabular}


A comparison of the modelled and measured evaporation is given in Figure 4.7. For comparison, two scenarios were run in SoilCover; the first used $\mathrm{Mv}=0$, representing a case where no extra water was generated by self-weight consolidation of the tailings; the second used $\mathrm{Mv}=0.13 / \mathrm{kPa}$ to account for the bleed water produced from self-weight consolidation (calculated previously, see Section 4.2.1 Self-weight Consolidation).

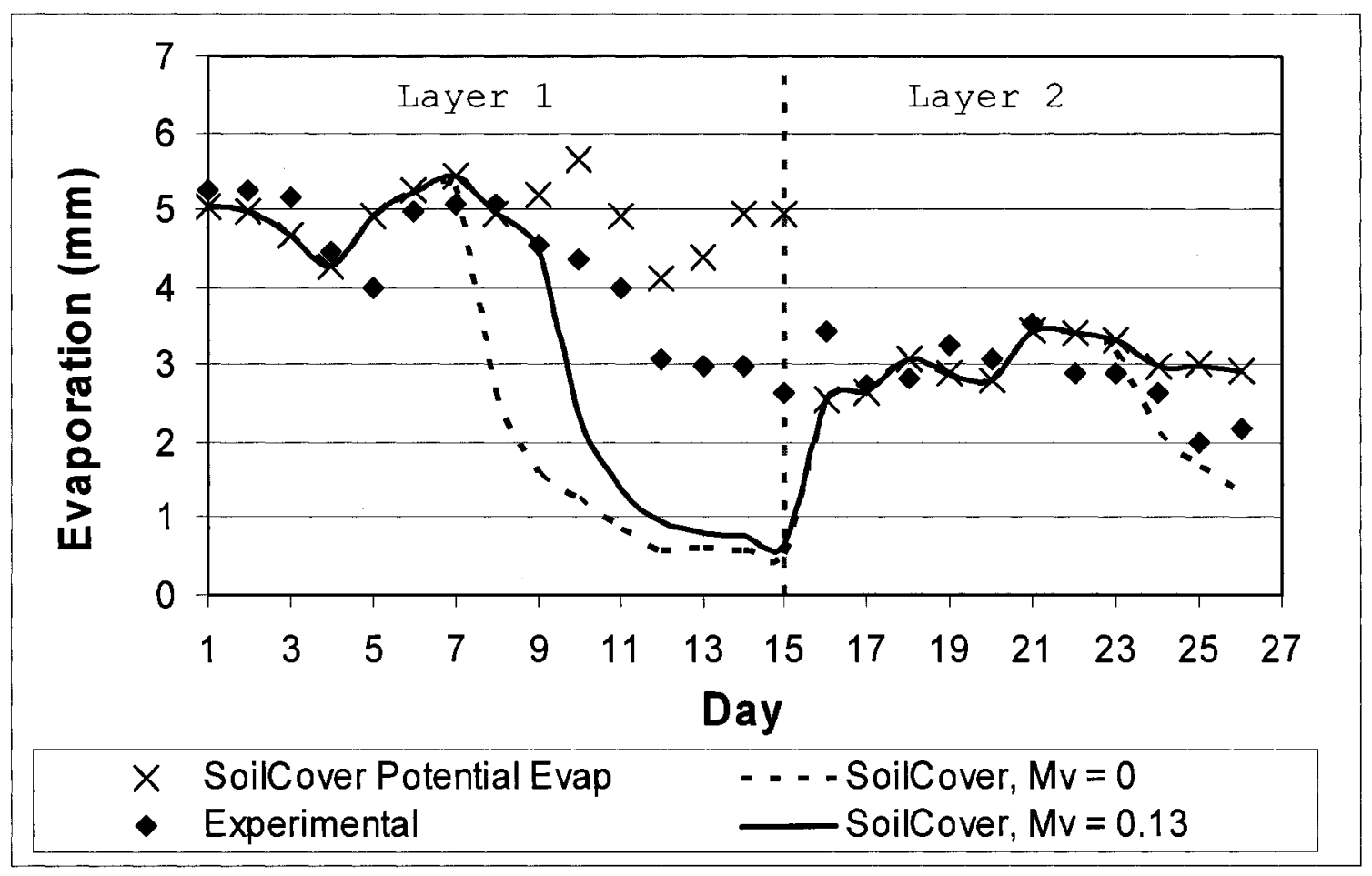

Figure 4.7 Measured (Experimental) and modelled (SoilCover $\mathrm{Mv}=\mathbf{0}$ and $\mathrm{Mv}=0.13$ ) evaporation during the small-scale test. The modelled potential rate of evaporation is also shown (SoilCover Potential Evap). 
The modelled ("SC") and measured matric suctions are shown in Figure 4.8. At suctions greater than approximately $100 \mathrm{kPa}$, the tensiometers tend to cavitate, which is why readings do not extend far beyond that value (UMS, 2008). HD sensors have a minimum detection limit of $10 \mathrm{kPa}$ (because $10 \mathrm{kPa}$ is the air entry value of the ceramic) and will not measure suctions below this. They rely on detecting differences in heat dissipation ability of the ceramic-water matrix; at high degrees of saturation a small difference in water content will not affect the ability of the matrix to dissipate heat (Flint et al., 2002).

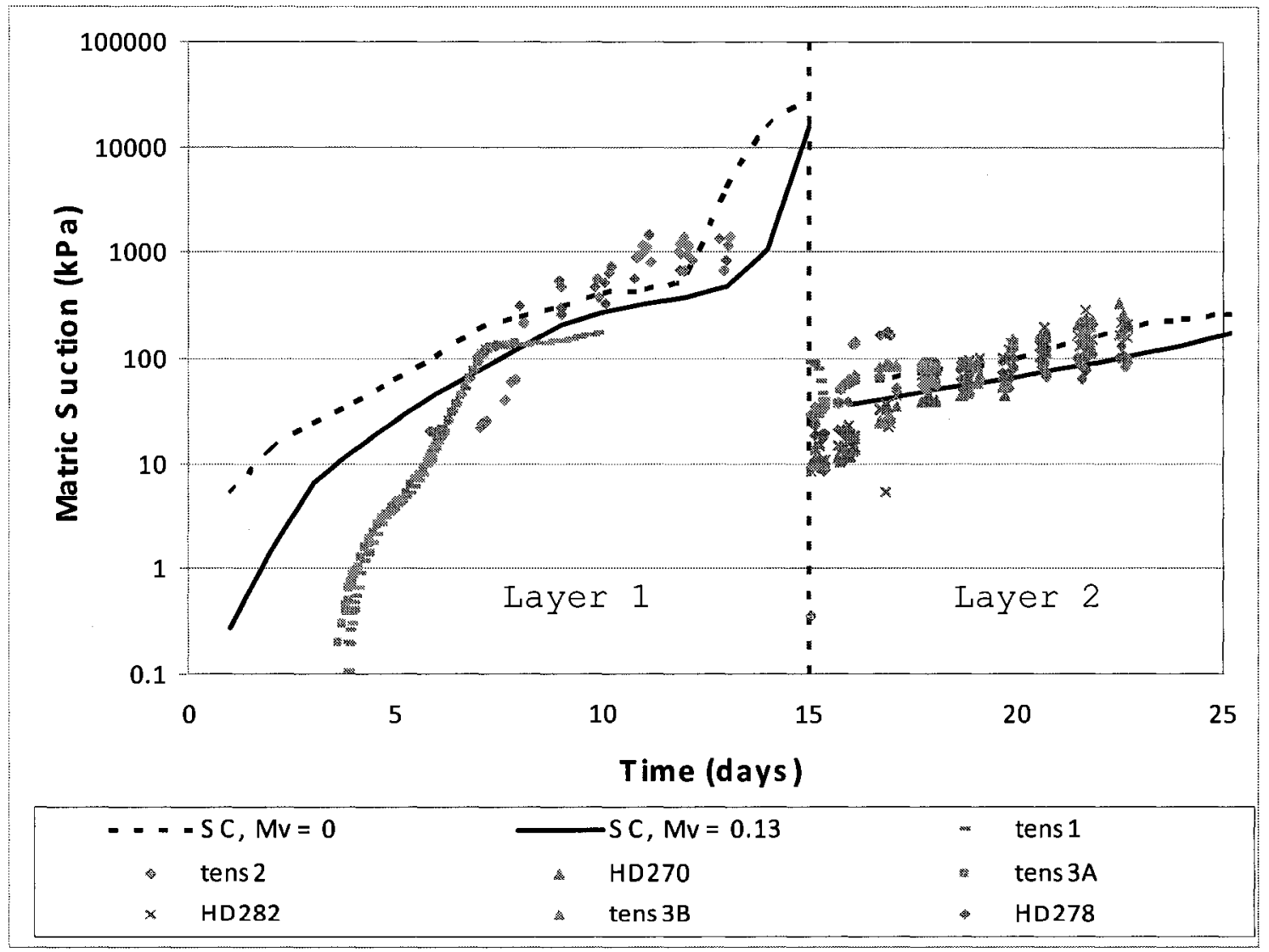

Figure 4.8 Measured and modelled (solid and dashed lines) matric suctions during the small-scale test. Matric suctions were measured by tensiometers and HD sensors located at the depths given in Table 4.1. SoilCover (SC) suctions were taken at a depth of $2 \mathrm{~cm}$ below the tailings surface. 
The oxygen concentration profile predicted using POLLUTE is shown in Figure 4.9 and the final comparison between modelled and measured sulphide contents is shown in Figure 4.10.

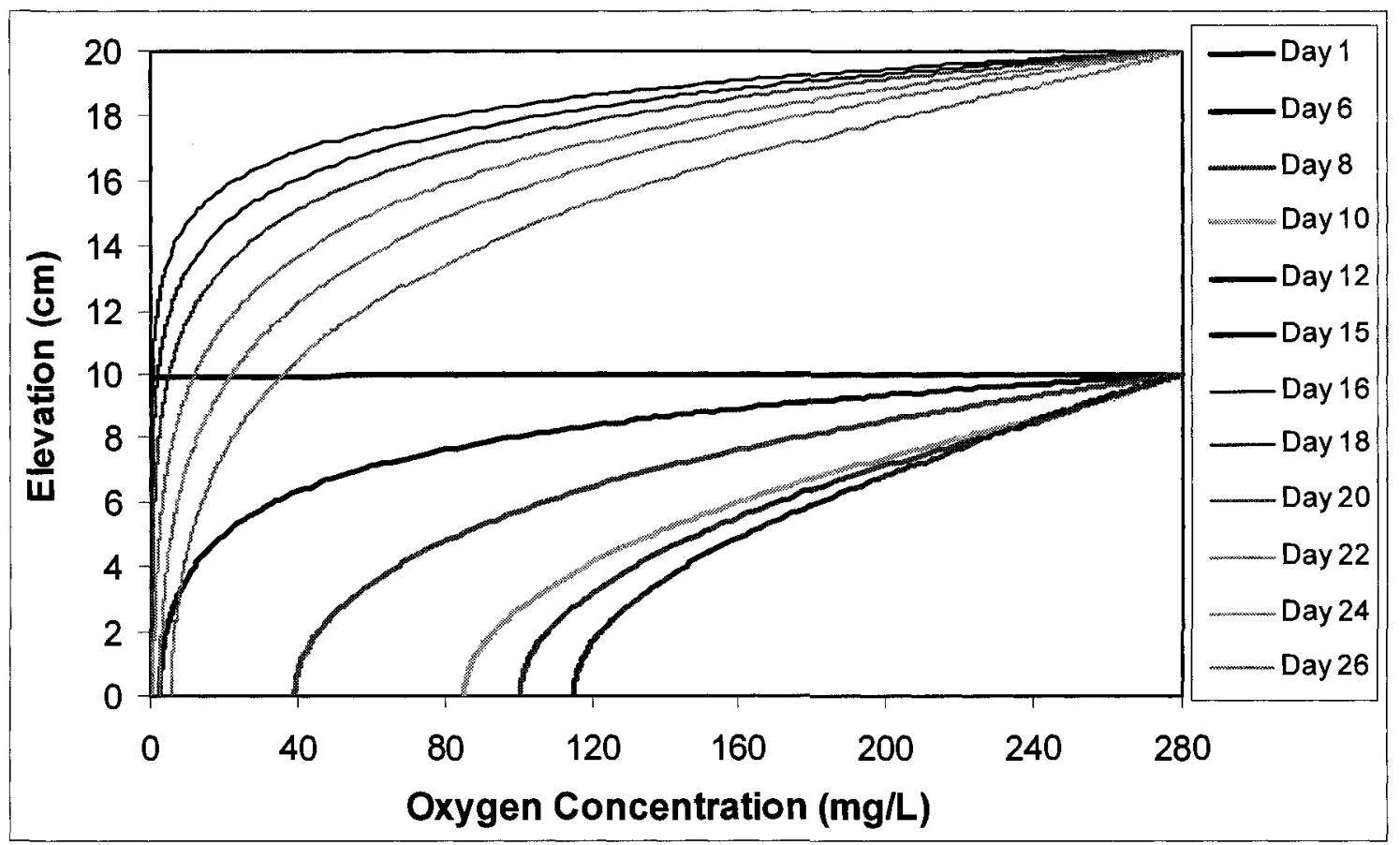

Figure 4.9 POLLUTE-modelled oxygen concentration profile during the small-scale test. 


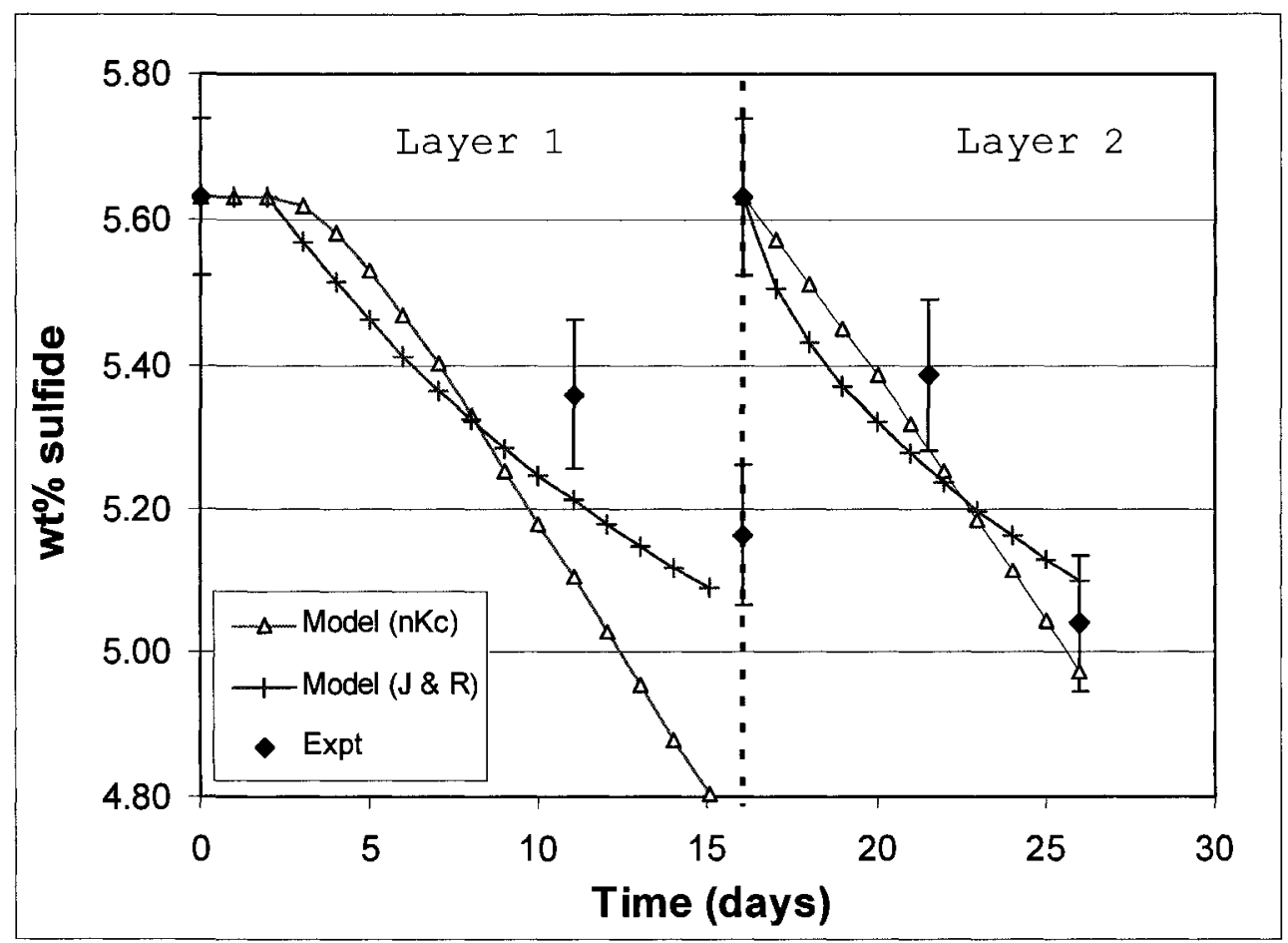

(a)

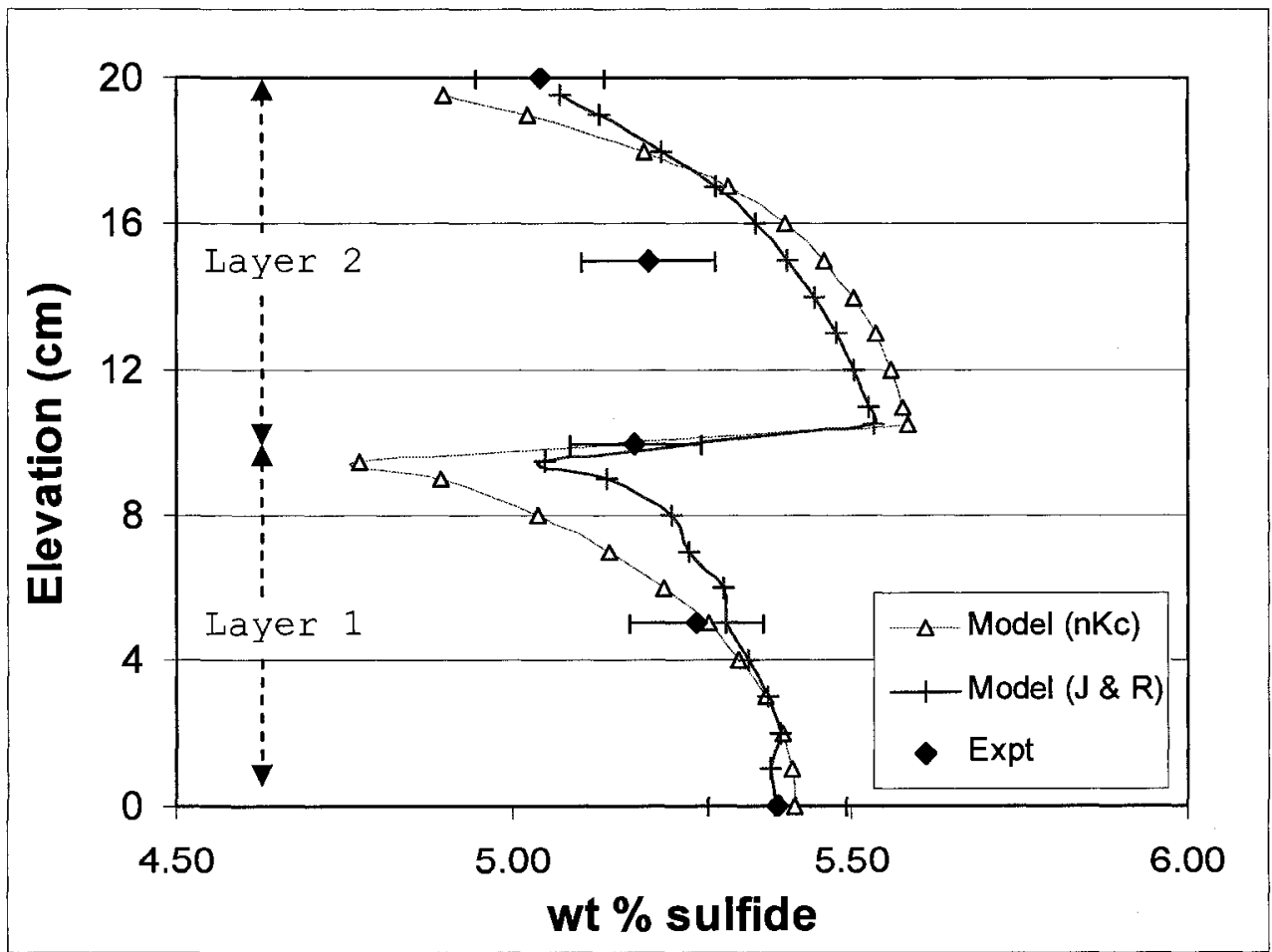

(b)

Figure 4.10 Measured (Expt) and modelled (by nKc method and by Jerz and Rimstidt ( $\mathrm{\&} \mathrm{R}$ ) method) sulphide depletion during the small-scale test (a) at the surface of the tailings over time and (b) with depth on Day 26. Error bars represent the standard deviation in the sulphide content measurements (see Appendix B). 
In the last days of the small-scale test, a white precipitate appeared on the tailings surface. This precipitate was identified by XRD as gypsum $\left(\mathrm{CaSO}_{4} \cdot 2 \mathrm{H}_{2} \mathrm{O}\right)$. The presence of calcium sulphate rather than iron or magnesium sulphates points toward the presence of calcite as one of the carbonate minerals measured in the IC analysis (Section 3.2). No oxidation rims were observed on pyrite or chalcopyrite grains using SEM-EDS.

\subsection{Discussion}

Layer 1 in Figure 4.7 clearly demonstrates the importance of the Mv parameter in generating bleed water from self-weight consolidation. In the $\mathrm{Mv}=0$ simulation, the modelled evaporation rate falls below the potential rate by Day 8 because there is not enough moisture in the modelled system. With $\mathrm{Mv}=0.13 / \mathrm{kPa}$, the evaporation rate remains closer to the experimental rate until Day 10 before also falling off. The effect of Mv was less pronounced in Layer 2 but by Day 24, the Mv $=0$ run fell off from the potential evaporation rate while the $\mathrm{Mv}=0.13 / \mathrm{kPa}$ run did not.

The decrease in the rate of potential evaporation from Layer 1 to Layer 2 in Figure 4.7 was caused by a decrease in the effective wind speed at the tailings surface (see Appendix D). The wind speed was controlled by the fan positioned above the experiment. The fan had to be moved when Layer 2 was added; when it was replaced, its orientation with respect to the surface of the tailings would have been slightly different, which caused the drop in the potential evaporation rate.

Based on the evaporation data in Figure 4.7, it is not clear whether cracking played a role in increasing the rate of evaporation. For Layer 1, cracks first appeared on Day 7 and from Day 8 onward, there was no increase in the observed evaporation rate 
despite the increased surface area. Similarly, for Layer 2, the experimental evaporation rate did not increase when cracks first appeared on Day 17. However, this was expected since cracking is known not to increase the rate of evaporation in Stage I drying (Fujiyasu, 1997).

From Day 11 to Day 15 in Layer 1, the evaporation rate predicted by SoilCover dropped below the observed evaporation rate. This may have been partially due to cracking. In Stage II drying, when the surface of the tailings dries out and the rate of evaporation falls below the potential rate, cracks have been observed to contribute up to $80 \%$ of the total evaporation from a soil (Fujiyasu et al., 2000). This could explain why the observed rate of evaporation was maintained above the rate predicted by SoilCover.

A small amount of salt precipitation was observed on the tailings surface by the end of the test. This may have contributed to the drop in evaporation rate on Day $24-26$ below the $\mathrm{Mv}=0.13 / \mathrm{kPa}$ prediction. In the large-scale test, the $\mathrm{EC}$ of the pore water was measured to judge whether osmotic suction is reaching levels that may affect evaporation. Pore water salinity does not significantly affect matric suction measurements by HD sensors and tensiometers (Bulut and Leong, 2008).

The suction profile in Figure 4.8 shows fairly good agreement between experimental and modelled matric suctions. Again, the $\mathrm{Mv}=0.13 / \mathrm{kPa}$ simulation is in better agreement with the experimental suctions than the $\mathrm{Mv}=0$ run. Small differences between the modelled and measured suctions should not have a major impact on the final sulphide depletion profile because of the steep slope of the SWCC in the $10-1000 \mathrm{kPa}$ range (see Figure 4.2). Within this range, small changes in water content result in large changes in suction. Since oxygen diffusion depends on the saturation profile rather than 
suction profile, small discrepancies between measured and modelled suction values should not significantly affect the extent of sulphide depletion.

To confirm this, the saturation profiles from both the $\mathrm{Mv}=0$ and $\mathrm{Mv}=0.13 / \mathrm{kPa}$ simulations were used to calculate $D_{\text {eff }}$ values and sulphide depletion profiles. The difference in the final sulphide depletion prediction was very minimal. Therefore, the final result is relatively insensitive to small differences in matric suction predictions.

The Jerz and Rimstidt method of modelling sulphide depletion gave a much better fit to the experimental data than the nKc method (Figure 4.10). The two modelling methods were compared using the mean absolute error (MAE) between the measured and modelled results. The MAE values are tabulated in Table 4.3:

Table 4.3 Mean absolute error (MAE) values between measured and modelled sulphide concentrations for the small-scale test. The two modelling methods were the nKc method and the Jerz and Rimstidt ( $\mathrm{J} \& \mathrm{R}$ ) method. The modelled and experimental values are shown in Figure 4.10.

\begin{tabular}{lcr}
\hline & \multicolumn{2}{c}{ MAE (wt\% S) } \\
& nKc & J \& R \\
\hline At surface & 0.20 & 0.11 \\
With depth on Day 26 & 0.11 & 0.08 \\
\hline
\end{tabular}

The Jerz and Rimstidt method is quite sensitive to the specific surface area of pyrite, which depends on the mean particle diameter (Equation 2.3). Figure 4.11 shows the difference in modelled sulphide depletion using an average particle diameter of 10 , 20, 30 and $40 \mu \mathrm{m}$. The $\mathrm{d}_{50}$ particle diameter from the particle size distribution in Figure 3.1 is approximately $30 \mu \mathrm{m}$. However, the size distribution is reported on a percent mass basis. Since mass is proportional to the diameter cubed and surface area is proportional to the diameter squared, the distribution in Figure 3.1 does not represent the average particle diameter based on surface area. Based on surface area, a smaller particle would better 
represent the average particle size. For the small-scale test, the best fit was achieved (best fit was determined by minimizing the sum of the MAE for the surface profile and the depth profile in Figure 4.10) using a $21-\mu \mathrm{m}$ diameter particle.

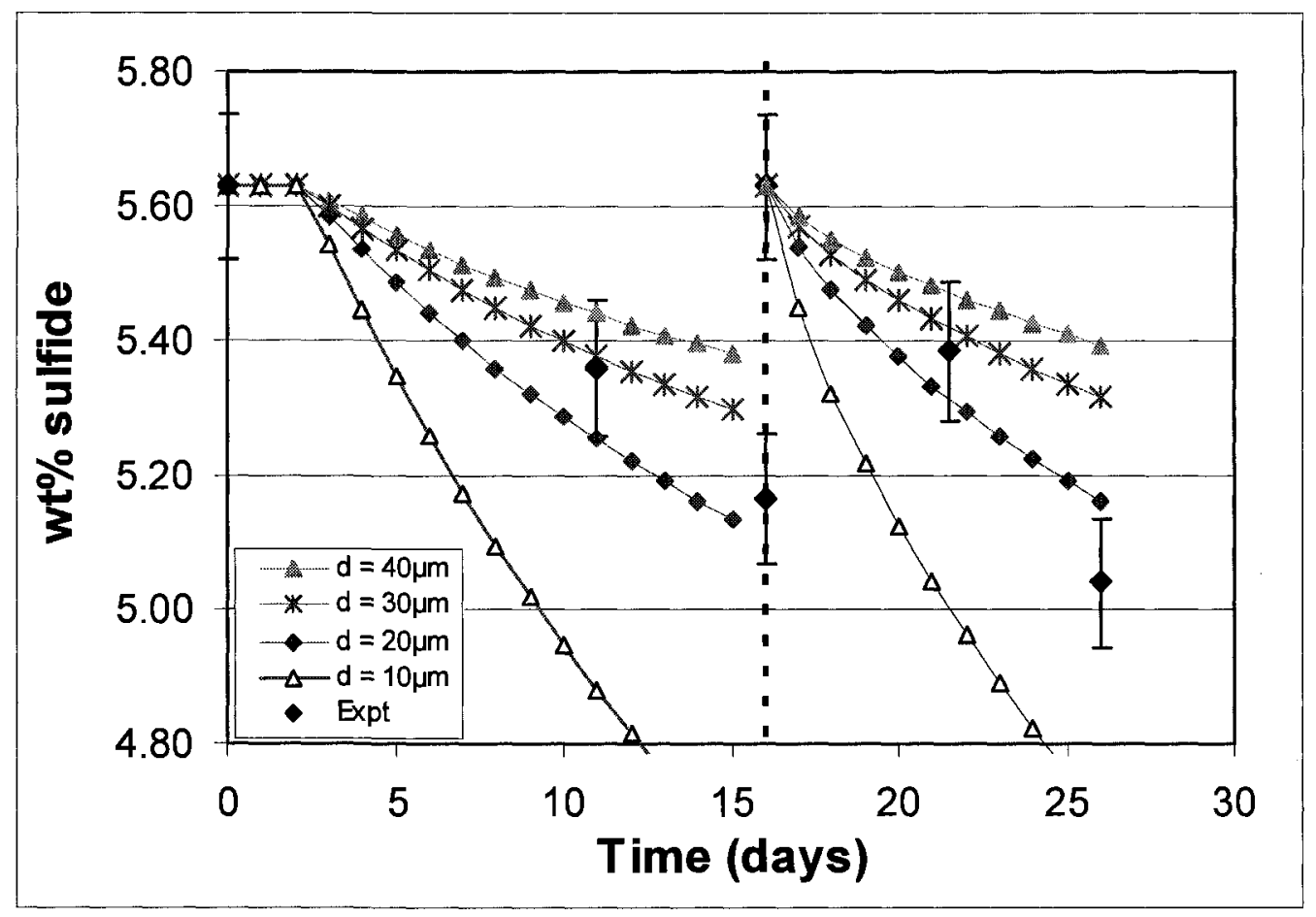

Figure 4.11 Sensitivity of the Jerz and Rimstidt-modelled sulphide depletion to particle diameter. Error bars represent the standard deviation in the experimental sulphide content measurements (see Appendix B).

Overall, the measured and modelled sulphide depletion profiles were in good agreement. Therefore, in spite of some cracking and salt precipitation, the onedimensional models, SoilCover and POLLUTE, could be effective tools to predict the extent of sulphide oxidation in paste tailings. 


\section{Chapter 5: Large-Scale Test}

The large-scale test was used to study the effects of cracking and salt precipitation on the rate of tailings desaturation and oxidation. The large size of the test cell mimicked actual disposal site conditions and was therefore considered a better analogue of site conditions than the small-scale and column tests.

\subsection{Experimental Methods}

This 2-layer test was carried out over a 19-day period from January 26 to February 13, 2008. The setup for the large-scale test is shown in Figure 5.1. Two wooden walls were built into an existing metal tank to create a $1.5 \times 1.5 \mathrm{~m}$ test cell for the tailings. The wooden walls fit tightly enough into the metal tank to prevent tailings from escaping, but the juncture was not water-tight so liquid was able to leak out of the cell space, similar to the way bleed water might run off a layer of tailings in the field. Two fans were installed on the edges of the tank to simulate wind. The tank's feet were set on four loading cells to measure water loss due to evaporation. Relative humidity and temperature were recorded in the room using the same device as in the small-scale test.

Two changes were made to the computerized data collection:

1) the 30 -second $\mathrm{HD}$ sensor heating pulse was automated so that a reading was taken once every 60 minutes; and

2) the load cells were wired to the computer so that the tank weight was recorded every 10 seconds. 


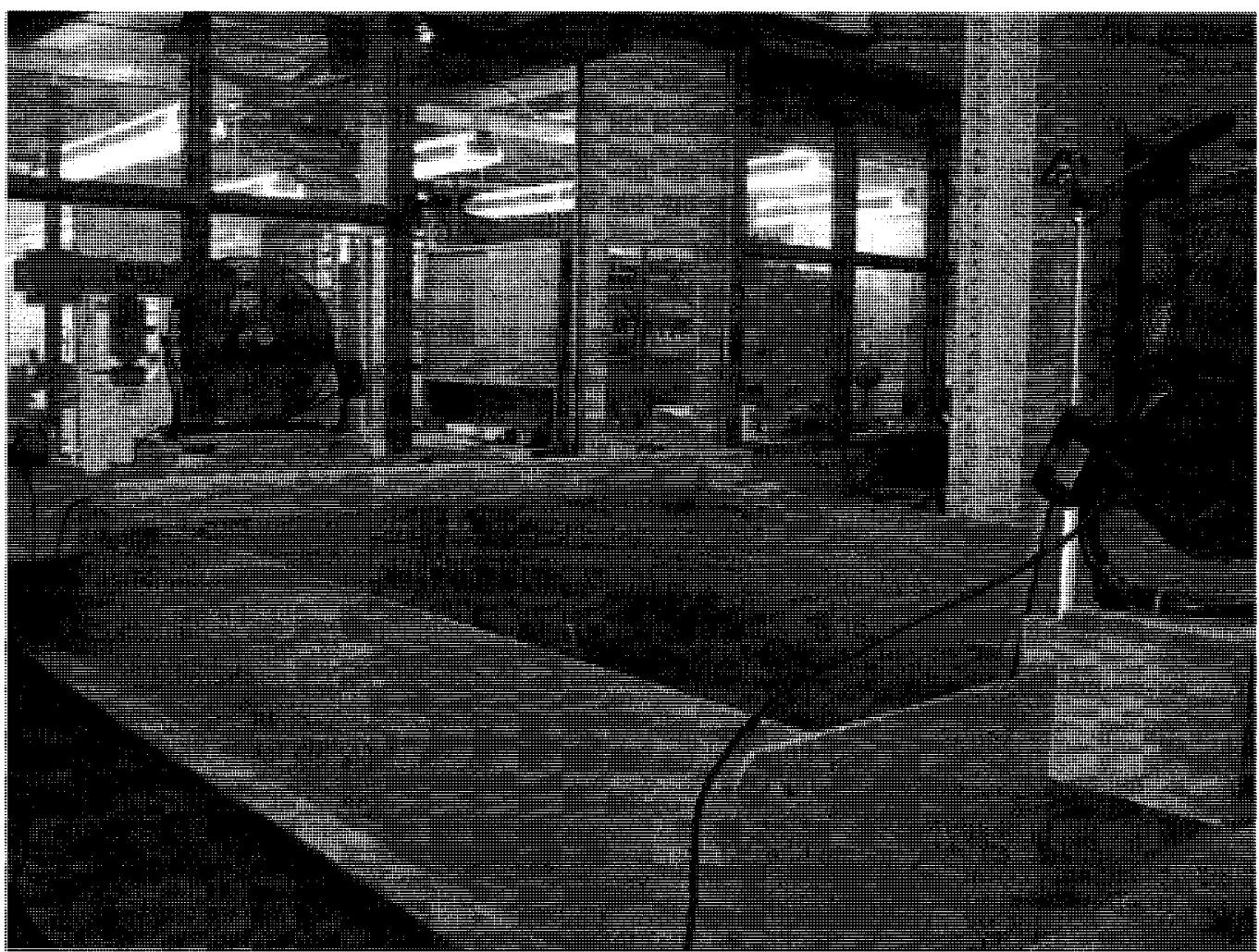

(a)

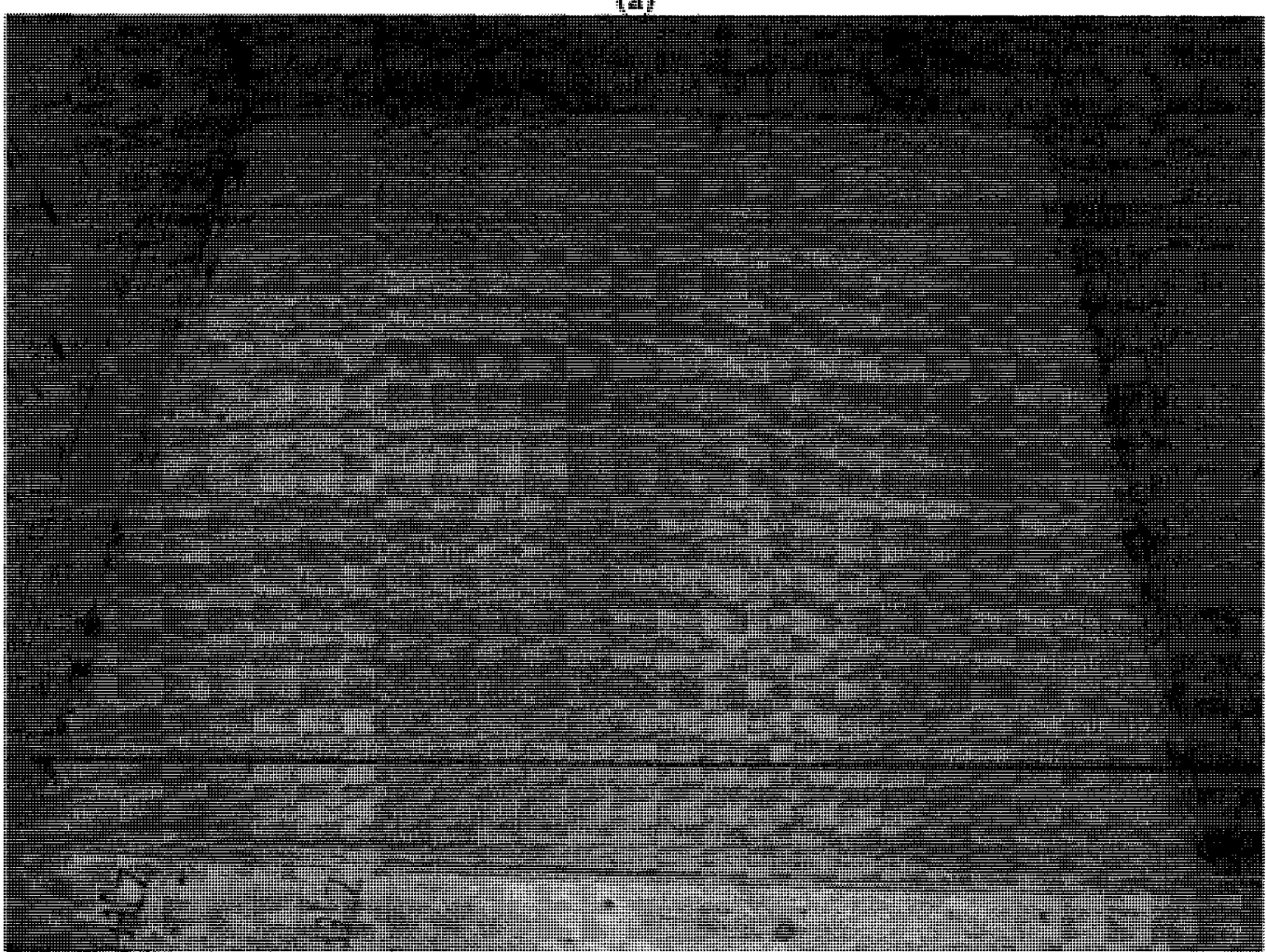

(b)

Figure 5.1 (a) Side view and (b) planar view of the empty tank used for the large-scale test. Tank dimensions were $1.50 \mathrm{~m} \times 1.50 \mathrm{~m}$ (length $\mathrm{x}$ width). 
The first layer was poured at $40 \%$ GWC and allowed to dry until Day 10 . The second layer was added (also 40\% GWC) on Day 11 and dried until Day 15. The layers were rewet on Day 16 by slowly and uniformly adding $159 \mathrm{~L}$ of water to the tailings surface so that both layers were re-saturated. The layers were then dried until Day 19. A total of 15 matric suction sensors were buried in the two layers. The sensor types and elevations are given in Table 5.1 and their locations are also shown on the schematic in Figure 5.2. Elevations were determined by excavation after the test was completed.

Table 5.1 Matric suction sensor locations in the large-scale test.

\begin{tabular}{ccc}
\hline Sensor ID & Layer & Elevation $(\mathbf{c m})$ \\
\hline tens1 & 1 & 2.0 \\
HD278 & 1 & 2.0 \\
HD273 & 1 & 4.5 \\
HD274 & 1 & 5.5 \\
tens3 & 1 & 6.0 \\
HD270 & 1 & 6.0 \\
tens2 & 1 & 6.3 \\
tens4 & 2 & 8.0 \\
HD282 & 2 & 9.0 \\
HD257 & 2 & 9.0 \\
tens5 & 2 & 10.3 \\
HD279 & 2 & 14.5 \\
HD276 & 2 & 14.5 \\
tens6 & 2 & 14.9 \\
tens7 & 2 & 14.9 \\
\hline Total height $\approx 15 \mathrm{~cm}$ (Layer 1 = $8 \mathrm{~cm}$; Layer $2=7 \mathrm{~cm}$ )
\end{tabular}




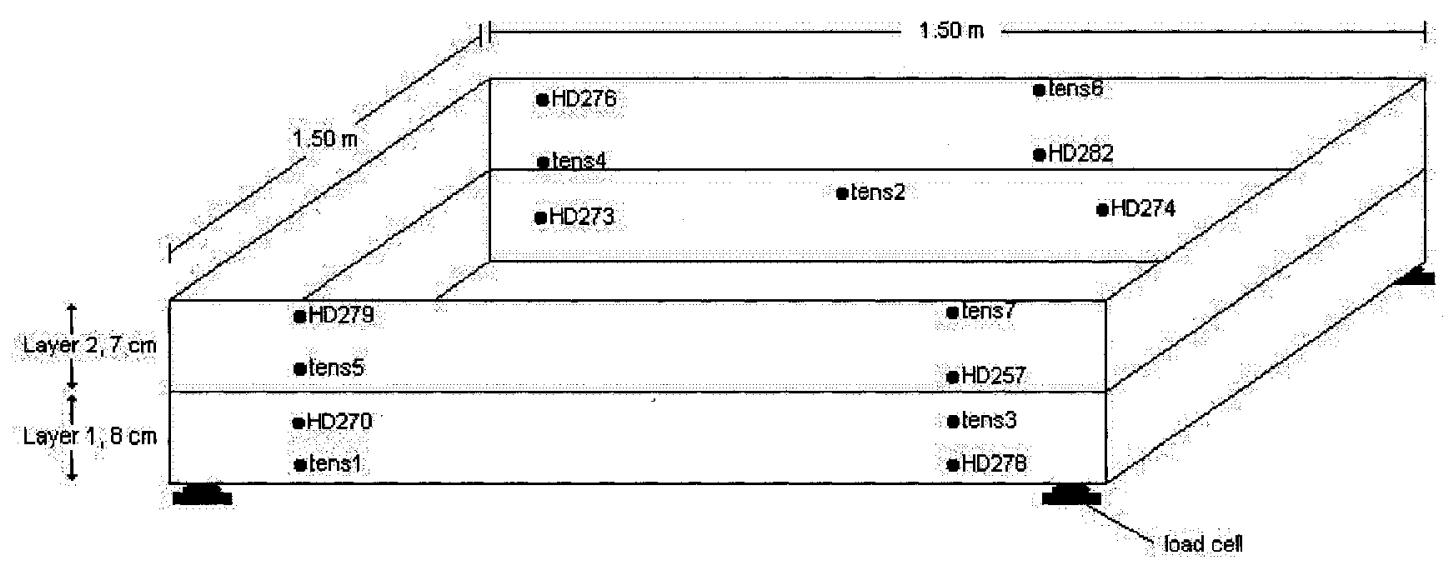

Figure 5.2 Schematic diagram showing the setup for the large-scale test.

The change in volume of the tailings was estimated by taking 100 individual point height measurements uniformly over the tailings surface. The height-measuring device was created using a slotted $2 \times 4$ across the width of the tank and a ruled broom handle (Figure $5.1 \mathrm{a}$ ). Each point height measurement was assigned Cartesian coordinates (x, y, z) and using the inverse distance weighted tool in ArcMap, a $0.5 \times 0.5 \mathrm{~cm}$ raster grid of the tailings surface elevation was created. The same was done before the tailings were poured to create a surface elevation raster of the tank bottom. The bottom surface was subtracted from the tailings surface in ArcMap to get a total tailings volume. From this value, the volume of cracks had to be subtracted. To estimate the total crack volume, the length and width of each significant crack ( $\geq 2 \mathrm{~mm}$ width) were measured with a tape measure and the depth was estimated by inserting a ruler to the base of the crack. The increase in exposed surface area due to cracking was accounted for by adding twice the crack length times the crack depth to the planar surface area.

The results from the small-scale test suggested that the concentration of dissolved species in the tailings pore water might have been impeding evaporation by increasing the osmotic suction. Therefore, pore water sampling was added to the sampling protocol 
in the large-scale test. Surface samples were collected every 4 days for solid phase sulphide analysis and every $1-2$ days to test the EC of the pore water (provided enough moisture was present to extract at least $100 \mu \mathrm{L}$ of liquid). Samples for sulphide analysis were treated the same as in the small-scale test (see Section 4.1). For EC measurements, the pore water was extracted by squeezing the moist tailings in a compressible cylinder between two plates; pressure was applied using a hydraulic jack. If $>3 \mathrm{~mL}$ of liquid could be extracted, the EC was measured directly using a VWR Traceable ${ }^{\mathrm{TM}}$ conductivity probe. On Day 5 and Day 13, there was not enough sample for a direct measurement, so a $100 \mu \mathrm{L}$ aliquot was used to spike $10 \mathrm{~mL}$ of $996 \mu \mathrm{S} / \mathrm{cm}$ standard solution and the $\mathrm{EC}$ of the unknown was determined using a calibration curve (Appendix E).

On Day 9, Day 15 and Day 19, samples were taken for sulphide content analysis every $4 \mathrm{~cm}$ with depth. The depth profiles were completed in two locations on each of those days: one far from a crack edge ("Middle"), the other at the edge of a large crack ("Crack"). Unfortunately, the cracking patterns in Layer 1 and Layer 2 were not the same (Figure 5.3). Since cracks were not continuous between Layers 1 and 2, this meant the absence or presence of a crack in Layer 1 may not have translated in the same pattern in Layer 2. Because of this oversight, the vertical depth profiles were muddled with different oxygen exposures and the resulting sulphide depletion profiles did not follow the expected trends. The results are shown in Appendix F but they will not be discussed further.

\subsection{Modelling Methods}

Only modifications to the modelling methods presented in Section 4.2 are discussed in this section. 


\subsubsection{SoilCover}

The top boundary condition was defined by the weather conditions given in Appendix D. The mesh was shrunk from 10.0 to $8.0 \mathrm{~cm}$ for Layer 1 and 8.8 to $7.0 \mathrm{~cm}$ for Layer 2. Two simulations were used to compare the effect of Mv: no bleed water produced, $\mathrm{Mv}=0$ and bleed water produced, $\mathrm{Mv}=0.18 / \mathrm{kPa}$ (value calculated as per Section 4.2.1 Self-weight Consolidation using an average pore pressure of $0.34 \mathrm{kPa}$ ). Rewetting on Day 15 was simulated by a $70.7 \mathrm{~mm}$ rainfall event in SoilCover $(159 \mathrm{~L}$ over the $2.25 \mathrm{~m}^{2}$ surface).

\subsection{Results}

The tailings layers in the large-scale test exhibited significant cracking and salt precipitation over the course of the experiment. For Layer 1, the bleed water drained out between the wood and metal walls to the bottom of the metal tank. The layer began to separate from the walls on Day 3 and surface cracks became visible on Day 4. The layer continued to shrink and crack until Day 7 (Figure 5.3 a). Visible salt precipitation first appeared on Day 5 near the crack edges and by Day 10, covered about $30 \%$ of the surface. Layer 2 was poured on Day 10 and began cracking within hours of deposition (Figure 5.3 b). No bleed water was observed from Layer 2. The layer finished shrinking by Day 12 and salt precipitation was first noted on Day 13.

The layers were re-wet on Day 15 to simulate a fully-saturating rainfall event. By Day 19 significant salt precipitation covered most of the tailings surface (Figure $5.3 \mathrm{c}$ ). A summary of the tailings volume (accounting for cracks) and surface area (accounting for cracks and not accounting for cracks) over the course of the experiment is given in Table 5.2. 
Table 5.2 Change in tailings volume and surface area during the large-scale test. Two surface areas are tabulated: one accounting for crack formation ("with cracks") and one ignoring the increased surface area from crack formation ("no cracks").

\begin{tabular}{cccc}
\hline Day & \multicolumn{2}{c}{$\begin{array}{c}\text { Surface Area } \\
\left(\mathbf{c m}^{2}\right) \\
\text { with cracks }\end{array}$} & $\begin{array}{c}\text { Volume } \\
\left(\mathbf{c m}^{\mathbf{3}}\right)\end{array}$ \\
\hline 1 & 22040 & 22040 & 215400 \\
3 & 21980 & 23150 & 185300 \\
4 & 21890 & 29940 & 173800 \\
5 & 21830 & 36760 & 171200 \\
6 & 21830 & 43630 & 167100 \\
7 & 21830 & 45910 & 168550 \\
11 & 22040 & 32170 & 338000 \\
12 & 21800 & 48050 & 322130 \\
13 & 21800 & 49320 & 322100 \\
14 & 21800 & 49320 & 322100 \\
19 & 21800 & 49320 & 322100 \\
\hline
\end{tabular}

Once fully formed, cracks increased the tailings surface area by approximately $100 \%$ and $125 \%$ for Layer 1 and Layer 2, respectively. 


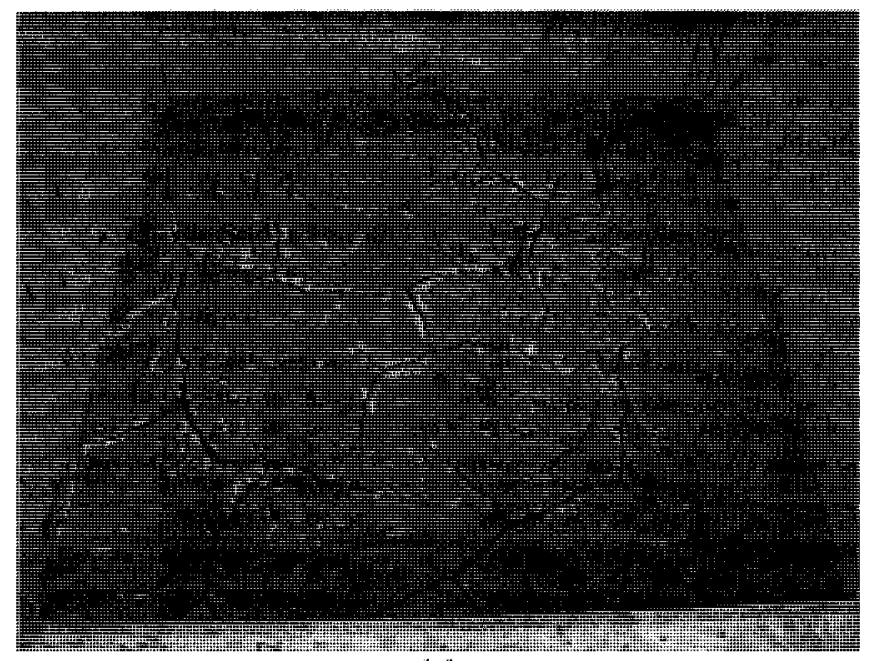

(a)

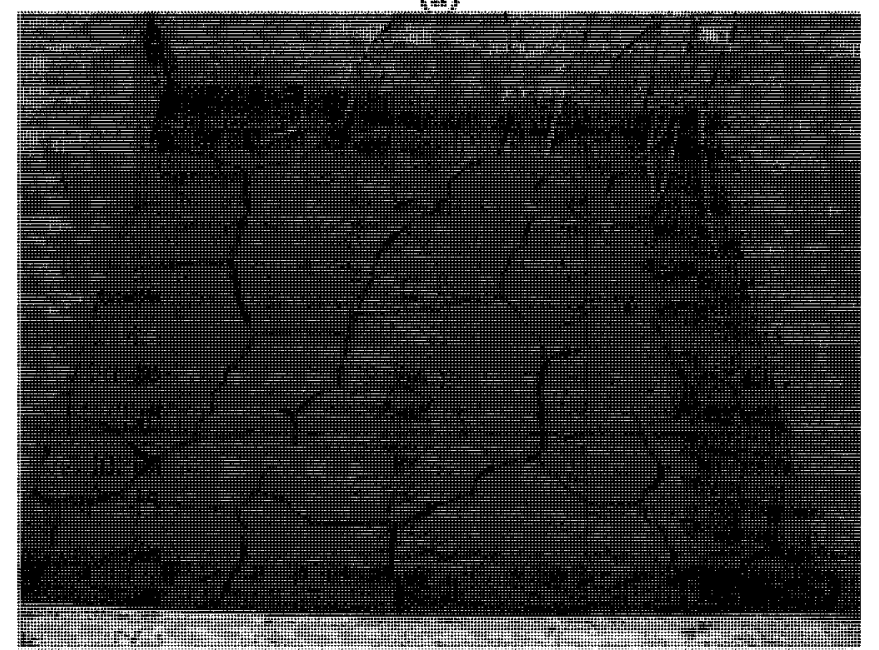

(b)

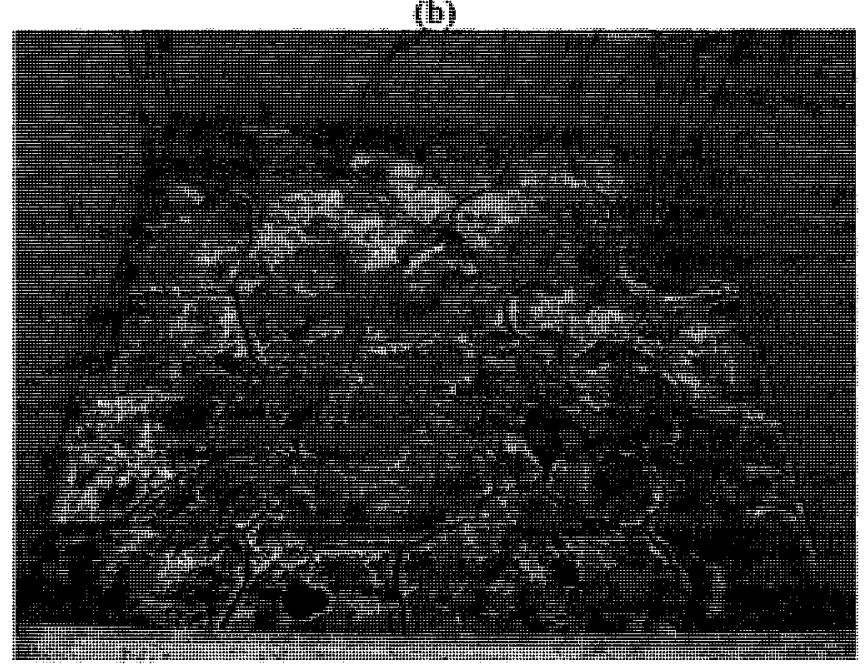

(c)

Figure 5.3 (a) Salt precipitation on Day 7 (Layer 1); (b) cracking on Day 11 (Layer 2); and (c) salt precipitation after rewetting and drying on Day 19 (Layer 2). 
The measured and modelled daily evaporation data are given in Figure 5.4.

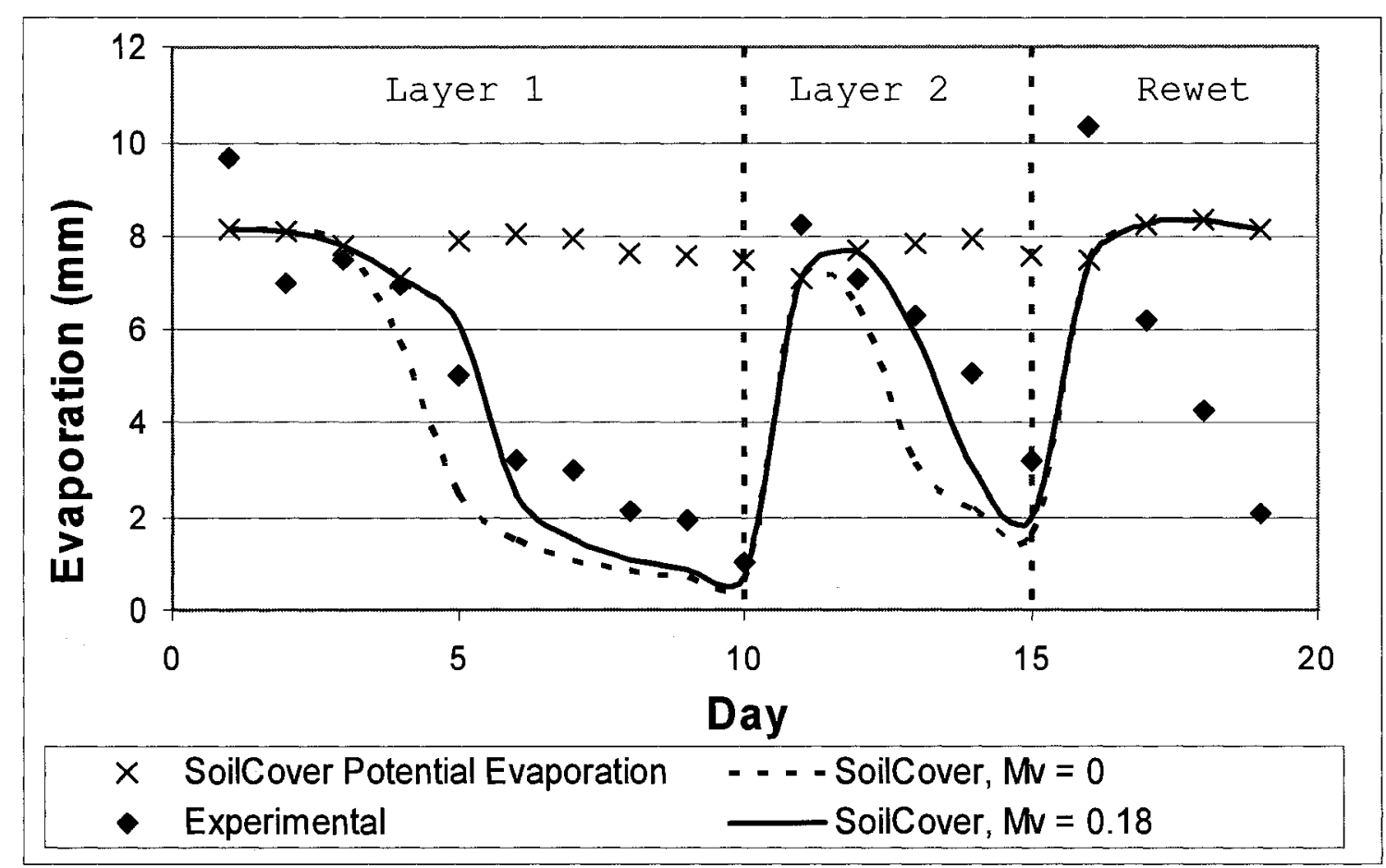

Figure 5.4 Measured (Experimental) and modelled (SoilCover $\mathrm{Mv}=0$ and $\mathrm{Mv}=0.18$ ) evaporation during the large-scale test (measurements from Fisseha, 2008). The modelled potential rate of evaporation is also shown (SoilCover Potential Evaporation).

Similar to the results from the small-scale test, the $\mathrm{Mv}=0$ modelled evaporation rate falls off prematurely from the experimental rate on Day 4 (Layer 1) and Day 12 (Layer 2). The agreement between the $\mathrm{Mv}=0.18 / \mathrm{kPa}$ simulation and the observed evaporation rate for Layers 1 and 2 is good. Both SoilCover simulations over-predicted the experimental evaporation rate during the re-wetting portion of the experiment (Day $15-19)$.

The measured and modelled ("SC) soil suction results are presented in Figure 5.5. 


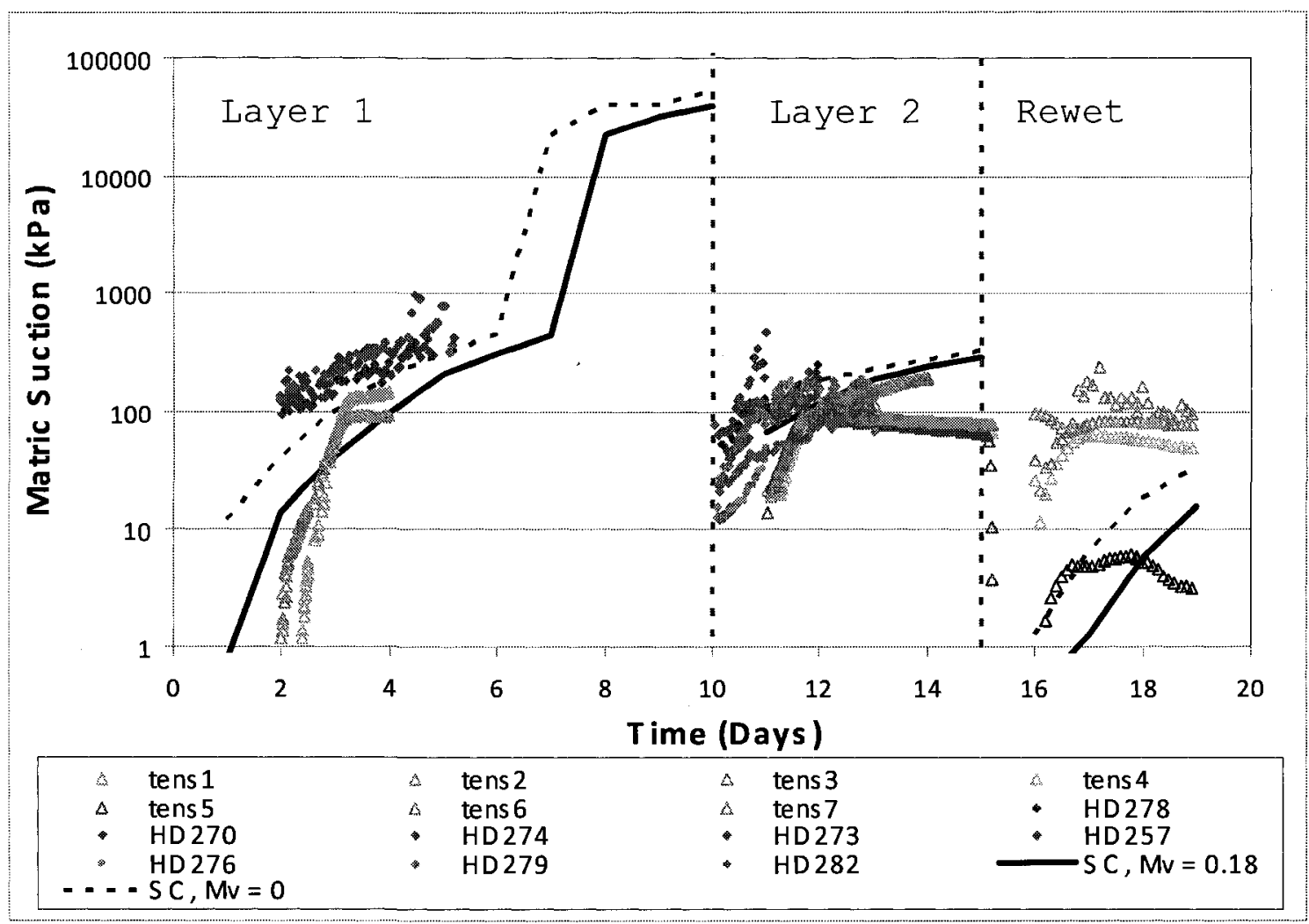

Figure 5.5 Measured and modelled matric suctions during the large-scale test. Matric suctions were measured by tensiometers and HD sensors located at the depths given in Table 5.1. SoilCover (SC) suctions were taken at a depth of $2 \mathrm{~cm}$ below the tailings surface. (measurements from Fisseha, 2008)

Similar to the small-scale test, the experimental and SoilCover $\mathrm{Mv}=0.18 / \mathrm{kPa}$ suctions are in close agreement for Layers 1 and 2 , while the $\mathrm{Mv}=0$ simulation predicts higher suctions in the first layer. For the rewetting phase (Day 15 - 19), SoilCover appears to slightly under-predict the suctions.

Pore water samples were drawn on 8 of the 19 test days to measure the EC. The trend in Figure 5.6 shows that the EC and corresponding osmotic suctions of the pore water increased rapidly. The highest EC was $16.88 \mathrm{mS} / \mathrm{cm}$ (or $\Psi_{s}=1811 \mathrm{kPa}$ ), measured on Day 13. 


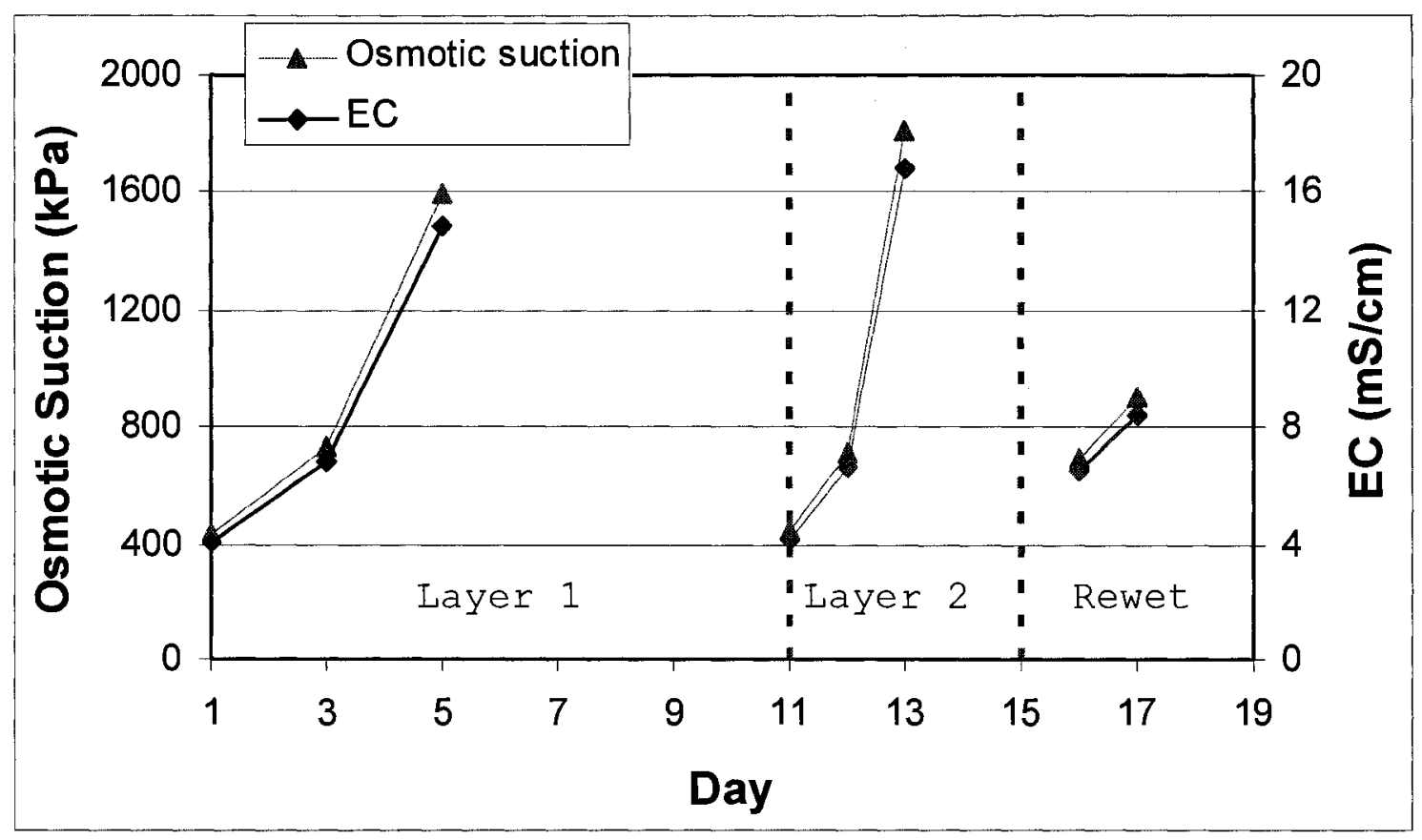

Figure 5.6 Electrical conductivity (EC) and osmotic suction of tailings pore water during the large-scale test.

\subsection{Discussion}

The same general trends from the small-scale test were also observed in the largescale test. The modelled and measured evaporation rate and soil suction were in reasonable agreement when $\mathrm{Mv}=0.18 / \mathrm{kPa}$ was used. The $\mathrm{Mv}=0$ simulation did not generate enough bleed water to maintain the observed evaporation rate on Day $4-7$ and over-estimated the soil suction in Layer 1.

Cracking did not appear to contribute to an increase in the evaporation rate, nor did it seem to affect the agreement between SoilCover suctions and measured suction values. By Day 7, the cracks on Layer 1 increased the total surface area by $100 \%$. By Day 13 , the cracks on Layer 2 increased the surface area by $125 \%$. There was not a corresponding increase in the rate of evaporation. 
It is possible that the evaporation from cracks is not as high as from the tailings surface because the micro-environment in a crack is different. The relative humidity in the crack space is higher and the rate of air circulation in the cracks is not as great as at the tailings surface. Therefore although the cracks increased the total surface area by $100 \%$, there was not a corresponding doubling of the evaporation rate.

The EC measurements lend support to the theory that osmotic suction might be contributing to a decline in the evaporation rate, especially from Day 17 to 19 in Figure 5.4 , when the decline in the rate of evaporation corresponded to significant salt precipitation (Figure $5.3 \mathrm{c}$ ). If the trend of increasing osmotic suction in Figure 5.6 were to continue, then by Day 18 and 19 the osmotic suction would be close to $4,000 \mathrm{kPa}$. The relationship between total suction and relative humidity (Figure 2.4) shows that at 4,000 $\mathrm{kPa}$ the relative humidity at the soil surface starts to decline. If the soil relative humidity falls to the same level as the atmospheric relative humidity, there would no longer be a vapour pressure gradient driving evaporation from the soil surface and evaporation would cease.

SoilCover does not account for the contribution of osmotic suction to total suction in the tailings. Therefore, in tailings with high pore water salinity, SoilCover underestimates the total suction, overestimates the relative humidity in the soil, and as a result, overestimates the rate of evaporation (i.e. Day $17-19$ in Figure 5.4). 


\section{Chapter 6: Column Tests}

This pair of column experiments was conducted to determine the effects of cracking on oxygen ingress and sulphide oxidation. Two drying tests were carried out in this round of experiments. In the first test, the cracks were allowed to form and propagate as usual ("Cracked Column"). In the second, the cracks were filled with paraffin wax and capped with Lexel (a rubber-based sealant) to seal them off from circulating air ("Sealed Column"). An oxygen gas sensor was buried in each layer of paste to measure the in situ oxygen concentration. The methodology, results, and discussion for the pair of experiments are presented in this chapter.

\subsection{Experimental Methods}

The setup, drying time, and sampling protocol were the same for the Cracked and Sealed Columns. The setup is shown in Figure 6.1. The 60-cm column had 6 holes drilled in the side for inserting suction sensors and a single hole in the base. The base hole was sealed during the drying phase of the tests and opened on the last day to collect a leachate sample after re-saturating the column. The cables of HD sensors and ceramic tips of the tensiometers were passed through rubber stoppers, which sealed the holes on the side of the column. If a side hole was not being used for a sensor, it was sealed with a rubber stopper to prevent leakage. The inner diameter of the column was $16.2 \mathrm{~cm}$ and 3 tape measures were taped on the inside wall to measure the height of the tailings. An SO-121 model gaseous oxygen sensor from Apogee Instruments Inc. was buried near the bottom of each layer. These are galvanic cell sensors that have a lead anode, a gold cathode, an acid electrolyte and a Teflon membrane. The current flow between the electrodes is 
proportional to the gaseous oxygen concentration being measured. Initially, the oxygen sensors were covered in fresh tailings and purged with nitrogen gas until the concentration was $<0.1 \%$.

The column was set on top of a scale to measure evaporation, a fan was used to simulate wind, and ambient temperature and relative humidity were measured with the USB data logger. Two modifications were made to the computerized data collection:

1. the scale weight was recorded; and

2. the millivolt output from the oxygen sensors was recorded.

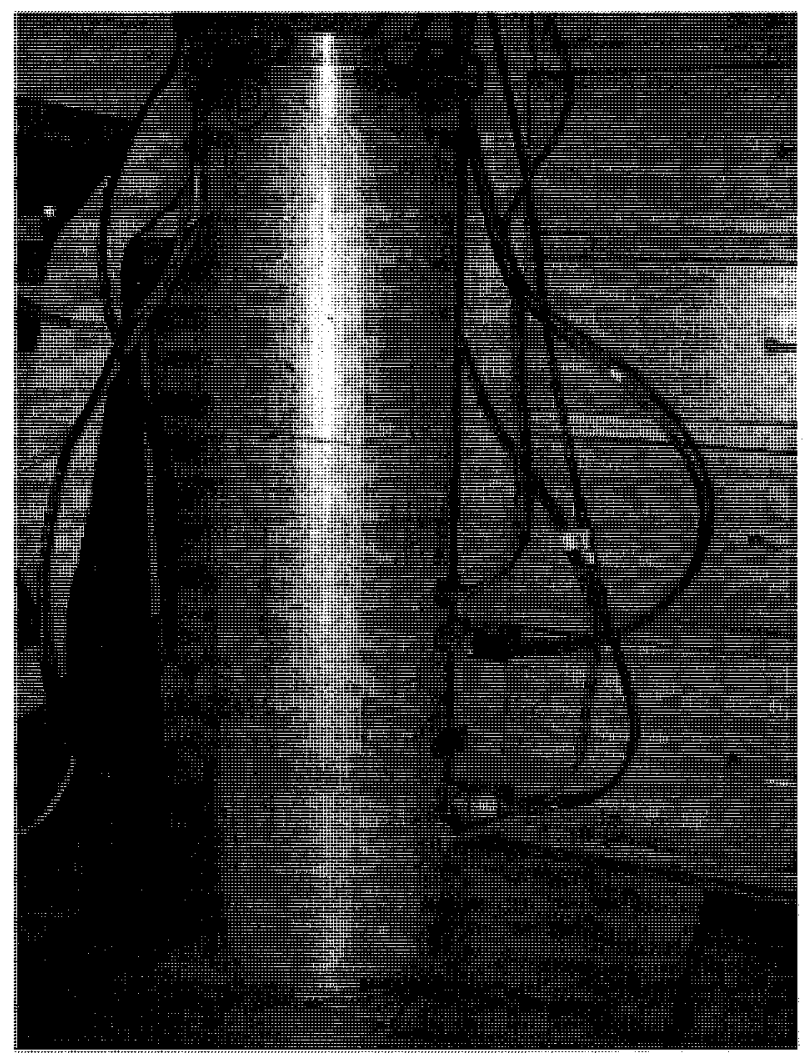

Figure 6.1 Photo of the column test setup.

Both tests ran for 28 days: Cracked Column from June 16 to July 14, 2008 and Sealed Column from July 15 to August 12 , 2008. Layer 1 was poured at $40 \%$ GWC and 
dried for 14 days, then Layer 2 was added and dried for 14 more days. Matric suction sensors were inserted through the side holes at the following heights:

Table 6.1 Matric suction sensor locations in (a) the Cracked Column and (b) the Sealed Column

(a)

\begin{tabular}{lcc}
\hline Sensor ID & Layer & Elevation $(\mathrm{cm})$ \\
\hline tens1a & 1 & 2 \\
HD279 & 1 & 10 \\
tens2 & 1 & 13 \\
tens1b & 2 & 25 \\
HD282 & 2 & 28 \\
\hline
\end{tabular}

(b)

\begin{tabular}{lcc}
\hline Sensor ID & Layer & Elevation $(\mathrm{cm})$ \\
\hline tens1 & 1 & 2 \\
HD282 & 1 & 10 \\
tens2 & 1 & 13 \\
tens3 & 2 & 17 \\
HD279 & 2 & 25 \\
tens4 & 2 & 28 \\
\hline
\end{tabular}

For the Cracked Column, tensla and tens $1 \mathrm{~b}$ were physically the same sensor; it was removed from Layer 1 on Day 14, re-saturated and used in Layer 2. The setup is also shown in the schematic diagram in Figure 6.2.

The height of the tailings was measured with tape measures taped to the inside wall of the cylinder. The uncracked planar surface area of the tailings was $206 \mathrm{~cm}^{2}$. The uncracked volume was $206 \mathrm{~cm}^{2}$ times the measured height. When cracks appeared, their length, depth, and width were measured daily using a ruler. For the Cracked Column, the volume of the cracks was subtracted from the total volume to get the net tailings volume and the surface area created by the cracks was added to the planar surface area to get the total surface area. For the Sealed Column, no additional surface area was created by the cracks because the cracks were sealed upon formation. The volume of the cracks was estimated based on the volume of cracks from the Cracked Column and the amount of backfilling that was done. 


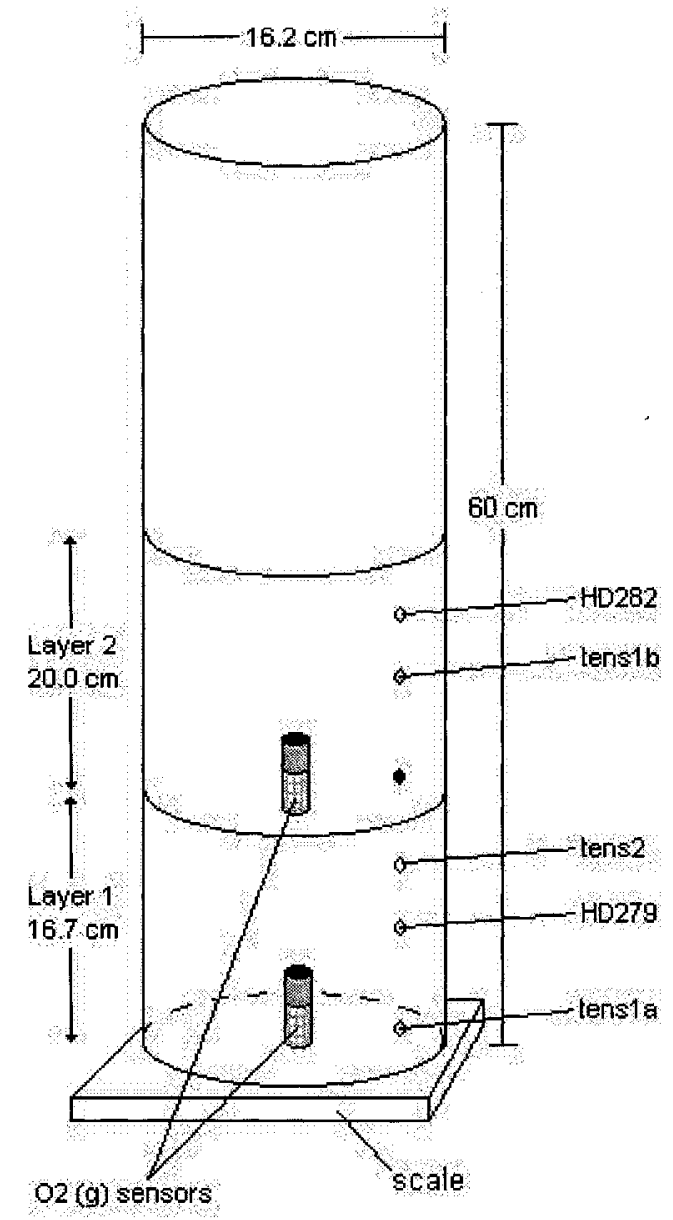

(a) Cracked Column

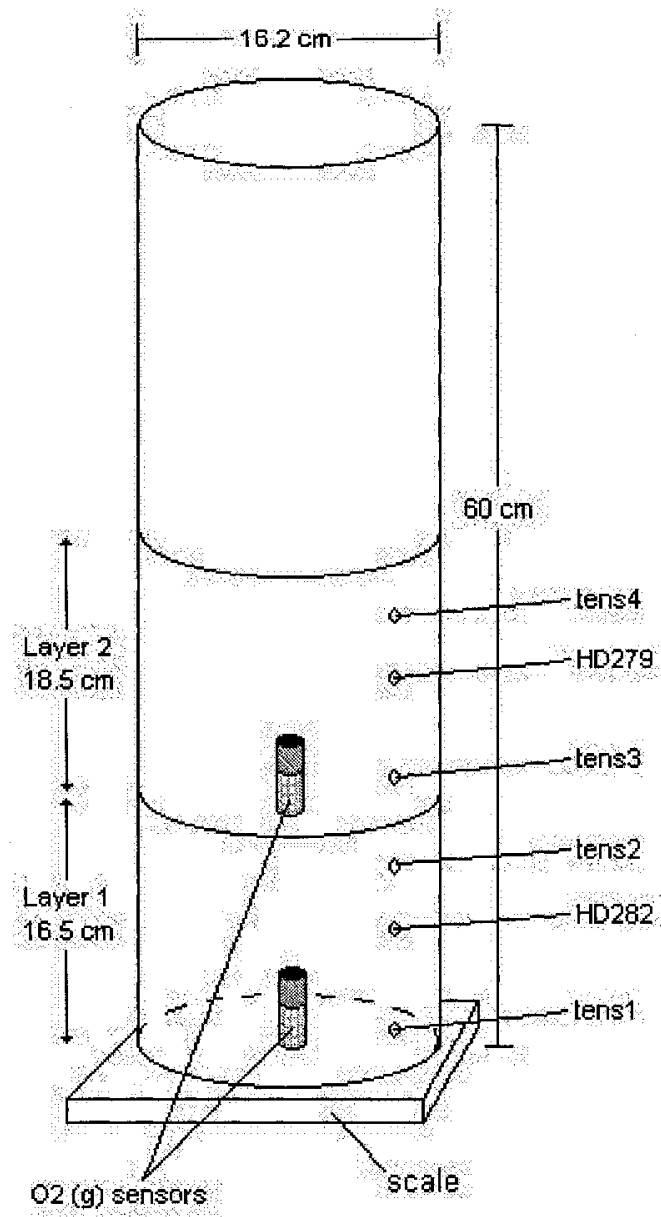

(b) Sealed Column

Figure 6.2 Schematic diagram showing the setup for (a) the Cracked Column and (b) the Sealed Column.

Geochemical analyses included sulphide content (solids) and leachate $\mathrm{pH}$, conductivity, ICP metals, and sulphate. Solid samples were taken from the tailings surface every few days for sulphide analysis. Sample handling is described in Section 4.1. The sulphide content in the solid phase was also profiled with depth at the end of the test by driving a 1" diameter thin-walled aluminum pipe to the base of the column and removing a core sample. Liquid samples were obtained from the fresh tailings using the pore water squeezer. The $\mathrm{pH}$ and $\mathrm{EC}$ of the liquid were tested as described in Section 5.1. A 50-mL sample was also sent to Accutest Laboratories, where 24 cations were analyzed by ICP-MS and sulphate by ion chromatography. 
On Day 28 , the entire column was slowly re-saturated by adding $1 \mathrm{~L}$ of distilled water over 3 hours using an eye dropper. The plug in the base of the column was removed and a $50-\mathrm{mL}$ sample was collected to repeat the $\mathrm{pH}$, conductivity, metals and sulphate analyses described above.

The only differences between the Cracked and Sealed Columns were:

- The cracks formed on the tailings surface and between the tailings and the column wall were filled with paraffin wax and sealed with Lexel sealant in the Sealed Column test

- Initial height of Layer 1 was $16.7 \mathrm{~cm}$ for the Cracked Column and $16.5 \mathrm{~cm}$ for the Sealed Column

- Initial height of Layer 2 was $20.0 \mathrm{~cm}$ for the Cracked Column and $18.5 \mathrm{~cm}$ for the Sealed Column

- The climate conditions (and hence evaporation rates) were not the same because the wind, relative humidity and temperature changed. Weather data were collected during each test and can be found in Appendix D.

\subsection{Modelling Methods}

Only modifications to the modelling methods in Section 4.2 are presented in this section.

\subsubsection{SoilCover}

The top boundary condition was defined by the weather conditions given in Appendix D. For the Cracked Column, the mesh was shrunk from 16.7 to $14.0 \mathrm{~cm}$ for Layer 1 and from 20.0 to $17.0 \mathrm{~cm}$ for Layer 2. For the Sealed Column, the mesh was 
shrunk from 16.5 to $13.7 \mathrm{~cm}$ for Layer 1 and from 18.5 to $15.3 \mathrm{~cm}$ for Layer $2 . \mathrm{Mv}=0$ and $\mathrm{Mv}=0.08 / \mathrm{kPa}$ runs were compared in SoilCover $(\mathrm{Mv}=0.08 / \mathrm{kPa}$ value calculated as per Section 4.2.1 Self-weight Consolidation using an average pore pressure of 0.78 $\mathrm{kPa})$.

\subsubsection{Sulphide Depletion}

The mean particle diameter used in the Jerz and Rimstidt modelling was the $d_{25}$ value from the particle size distribution in Figure 3.1 $(10 \mu \mathrm{m})$.

\subsection{Results}

In both columns, the bleed water layer evaporated after 3 days and vertical shrinkage ceased by Day 7. Tiny surface cracks first appeared on Day 7 followed by separation of the tailings from the column wall on Day $8-9$. Figure 6.3 compares the changes in void ratio, degree of saturation, and normalized surface area during the two column tests. For Layer 2, the bleed water disappeared after 1 day and cracks first appeared on Day 19. Salt precipitation was only observed for the Cracked Column on Day 13 and Day 26 near the crack edges. No salt precipitation was observed in the Sealed Column, possibly because the sealants covered the crack edges. Although the surface area available for evaporation was much larger in the Cracked Column (increased by $150 \%$ and $110 \%$ at the termination of testing for Layer 1 and Layer 2, respectively), this did not result in a lower degree of saturation of the tailings in the Cracked Column relative to the Sealed Column. 


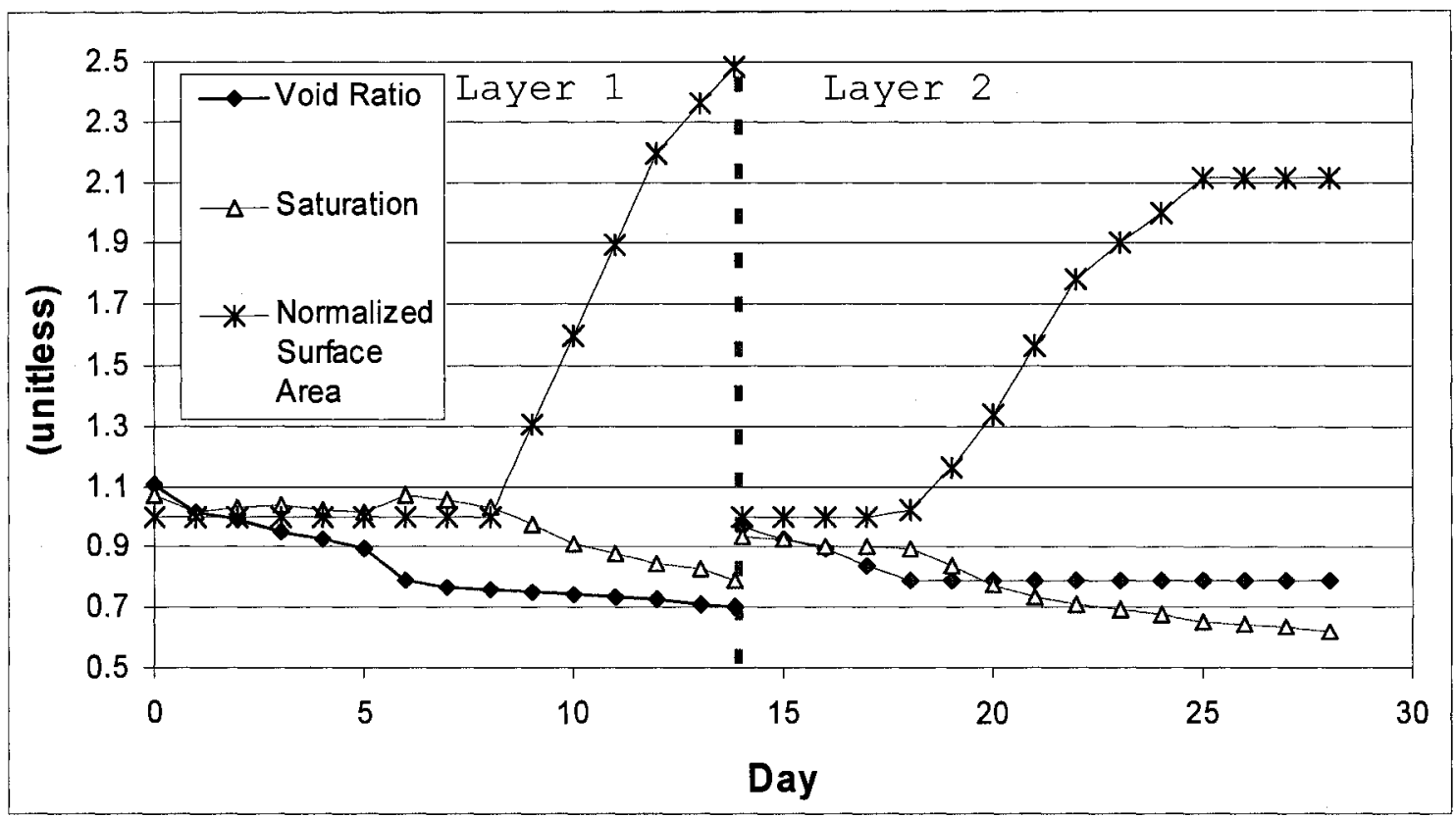

(a) Cracked Column

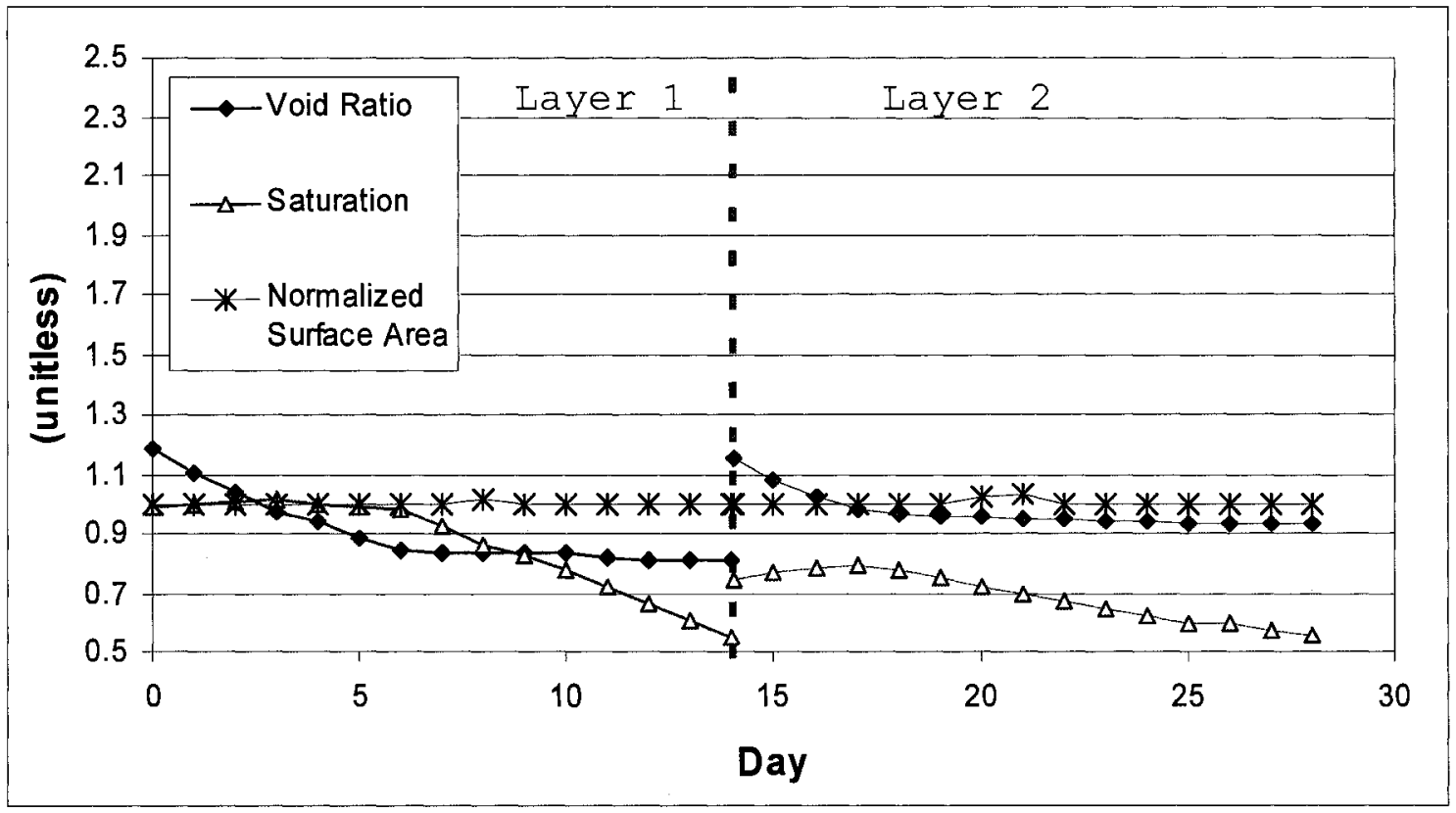

(b) Sealed Column

Figure 6.3 Change in void ratio, degree of saturation and normalized surface area during (a) the Cracked Column test and (b) the Sealed Column test. Surface area was normalized by dividing the total surface area by the planar surface area of the tailings $\left(206 \mathrm{~cm}^{2}\right)$. 
The measured and modelled daily evaporation data for both columns are compared in Figure 6.4.

In the Cracked Column test, both the $\mathrm{Mv}=0$ and $\mathrm{Mv}=0.08 / \mathrm{kPa}$ runs are in good agreement with the measured evaporation data for Layer 1. For Layer 1, the rate of evaporation remains at the potential rate during the entire 14-day period. In Layer 2, the $\mathrm{Mv}=0$ simulation is actually in better agreement with the experimental evaporation data compared to the $\mathrm{Mv}=0.08 / \mathrm{kPa}$ run, which remains well above the measured evaporation rate on Days 21 and 22.

In the Sealed Column test, the measured evaporation rate falls below the potential rate on Day 13 and 14 at the end of Layer 1 drying. Both the $\mathrm{Mv}=0$ and $\mathrm{Mv}=0.08 / \mathrm{kPa}$ give a reasonable prediction of the observed evaporation rate. On Day 13 and 14, the $\mathrm{Mv}=0$ run slightly under-predicts the observed evaporation while the $\mathrm{Mv}=0.08 / \mathrm{kPa}$ slightly over-predicts it. For Layer 2 , the $\mathrm{Mv}=0.08 / \mathrm{kPa}$ run over-predicted the rate of evaporation in the last days of the test while the $\mathrm{Mv}=0$ run slightly under-predicted it.

One significant difference between the Cracked and Sealed Columns was the sharp increase in the rate of evaporation after the placement of Layer 2 in the Cracked Column test. The length of the column was $60 \mathrm{~cm}$, half of which was full of tailings. The orientation of the fan above the column and the angle at which air was circulating into and out of the column was difficult to control. Because of this, the effective wind speed felt at the surface of Layer 2 during the Cracked Column was $60 \mathrm{~km} / \mathrm{h}$, while the effective wind speed felt at the tailings surface during the Sealed Column test was only $38 \mathrm{~km} / \mathrm{h}$, causing the jump in the rate of evaporation in the Cracked Column. 


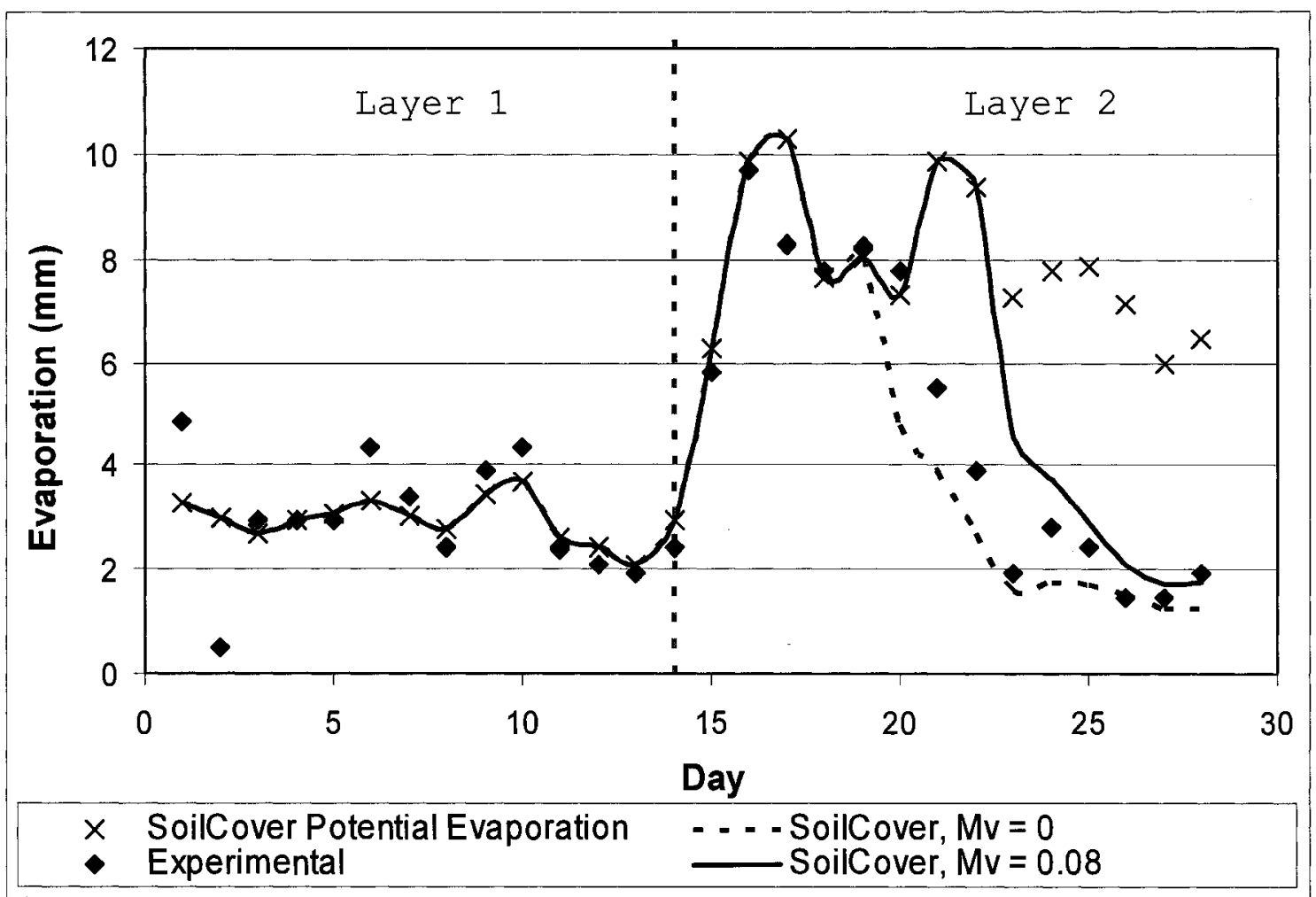

(a) Cracked Column

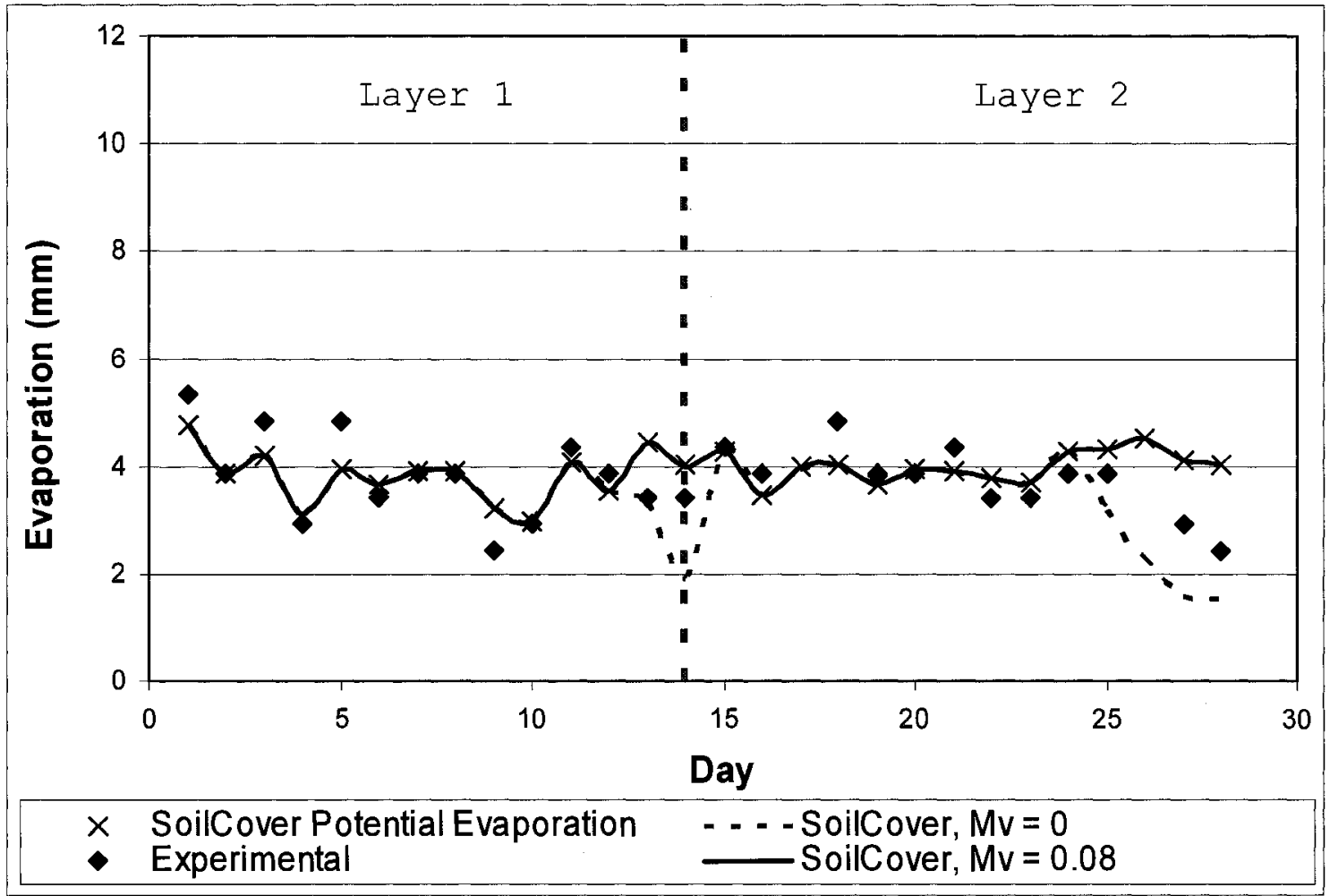

(b) Sealed Column

Figure 6.4 Measured (Experimental) and modelled (SoilCover $\mathrm{Mv}=0$ and $\mathrm{Mv}=0.08$ ) evaporation during (a) the Cracked Column test and (b) the Sealed Column test. 
The measured and modelled ("SC") matric suctions for the Cracked and Sealed Columns are given in Figure 6.5 and Figure 6.6.

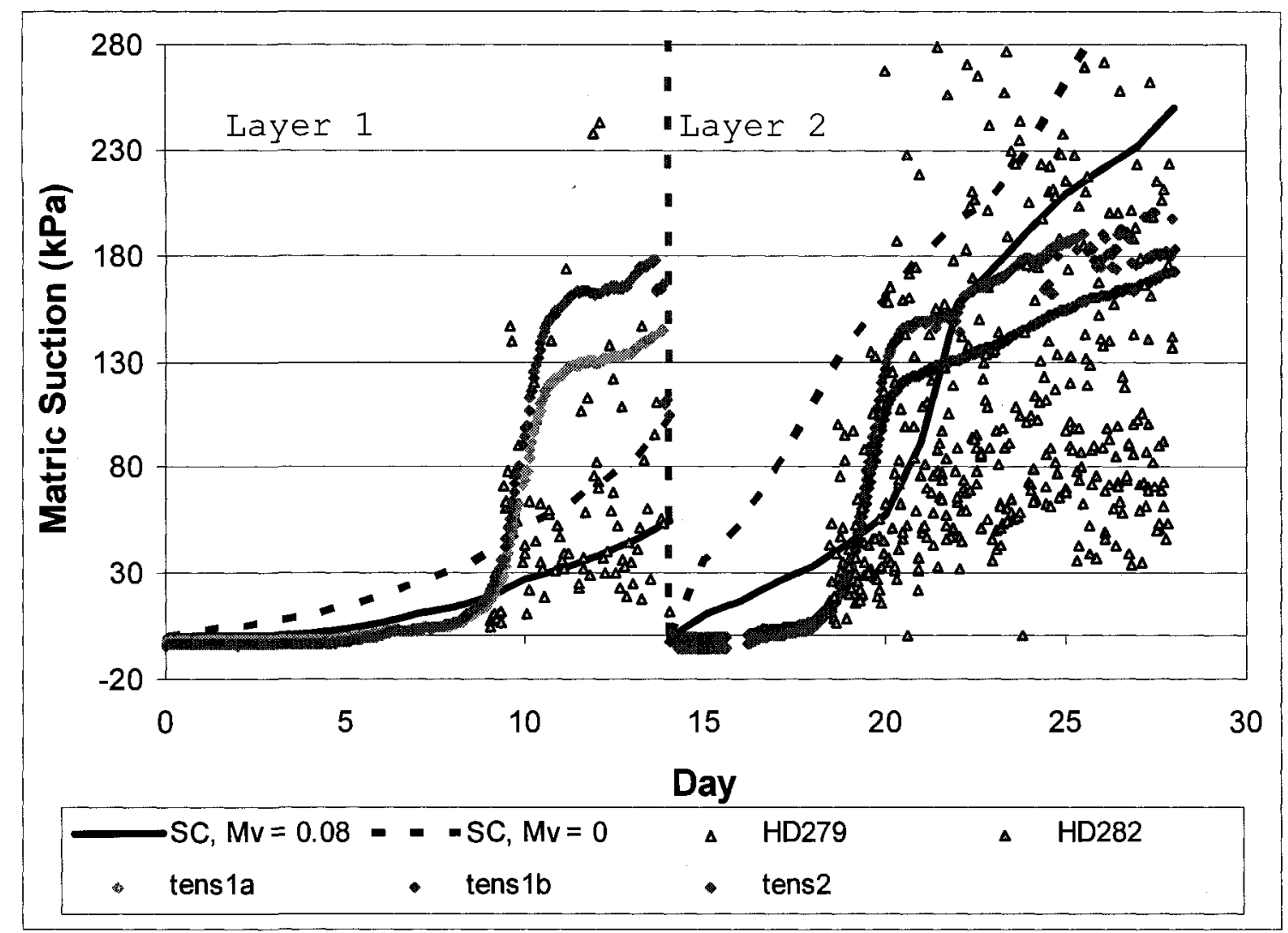

Figure 6.5 Measured and modelled matric suctions during the Cracked Column test. Matric suctions were measured by tensiometers and HD sensors located at the depths given in Table 6.1. SoilCover (SC) suctions were taken at a depth of $2 \mathrm{~cm}$ below the tailings surface. 


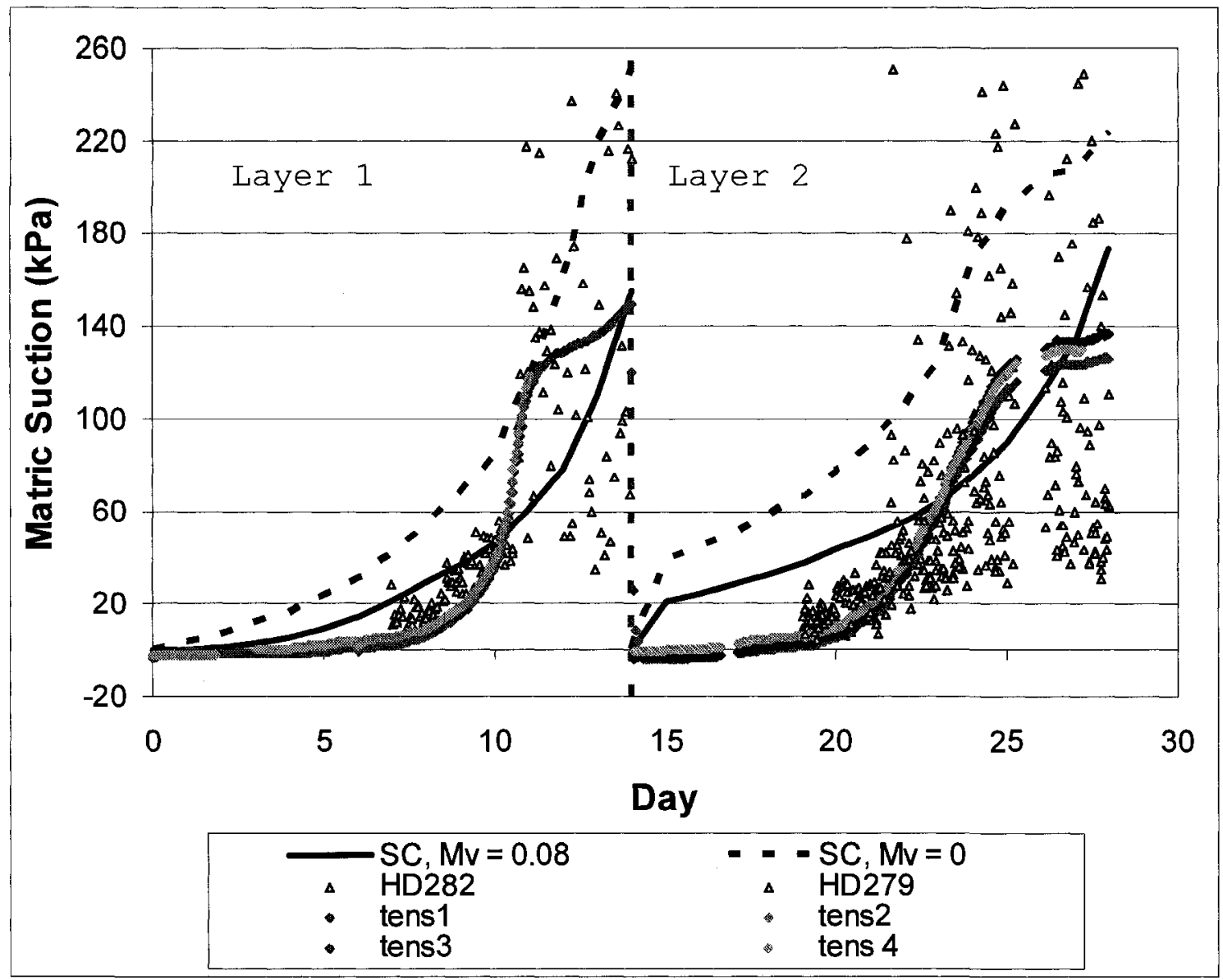

Figure 6.6 Measured and modelled matric suctions during the Sealed Column test. Matric suctions were measured by tensiometers and HD sensors located at the depths given in Table 6.1. SoilCover (SC) suctions were taken at a depth of $2 \mathrm{~cm}$ below the tailings surface. 
The measured and modelled oxygen sensor readings are compared in Figure 6.7. In the Cracked Column on Day 8 and again on Day 17 when larger cracks appeared, the reading from the oxygen sensors rose quickly from near-zero values to approximately $21 \% \mathrm{O}_{2}$, indicating that fresh air was circulating via the cracks to the oxygen sensors. The large size of the oxygen sensor (1" diameter, 3" length) likely induced crack formation.

In the Sealed Column on Day 10 and again on Day 18, the reading on the oxygen sensor buried in Layer 1 increased quickly from near-zero values to approximately $21 \%$ $\mathrm{O}_{2}$, indicating that fresh air was circulating down to the oxygen sensor despite efforts to seal the cracks. The reason for this was likely because the sensor was taped to the base of the column. A small separation between the tailings and the column would have allowed oxygen a direct route into the sensor, bypassing the slower route of diffusion through the tailings. In hindsight, the sensor in Layer 1 should not have been attached directly to the base of the column so that this channeling effect could have been avoided.

The sensor buried in Layer 2 appeared to have been affected on two occasions by fresh airflow (Day 21 and Day 24). However, the attempt at sealing those cracks appears to have been more successful in the end as the oxygen concentration of the Layer 2 sensor followed the predicted concentrations much more closely. 


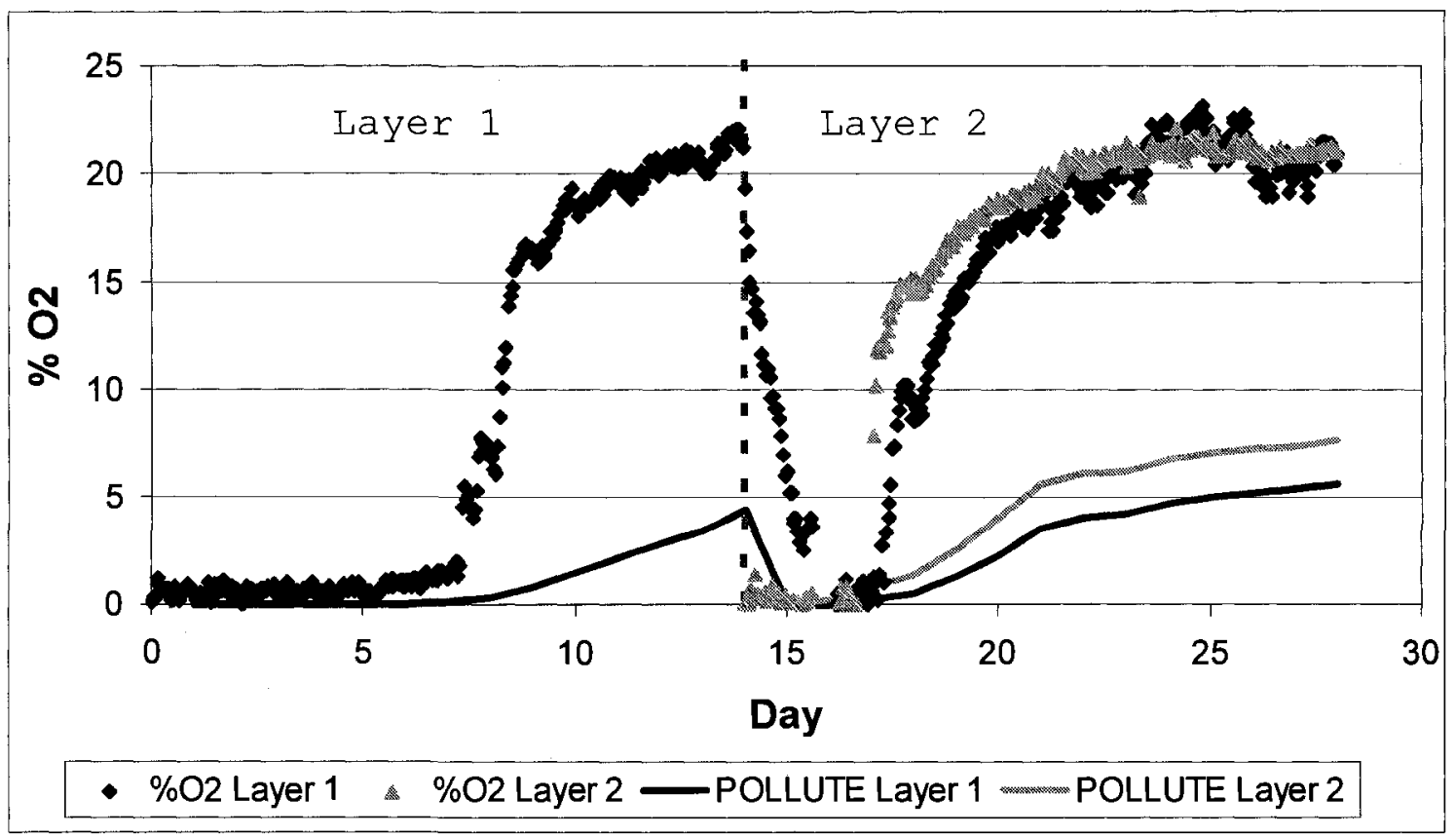

(a) Cracked Column

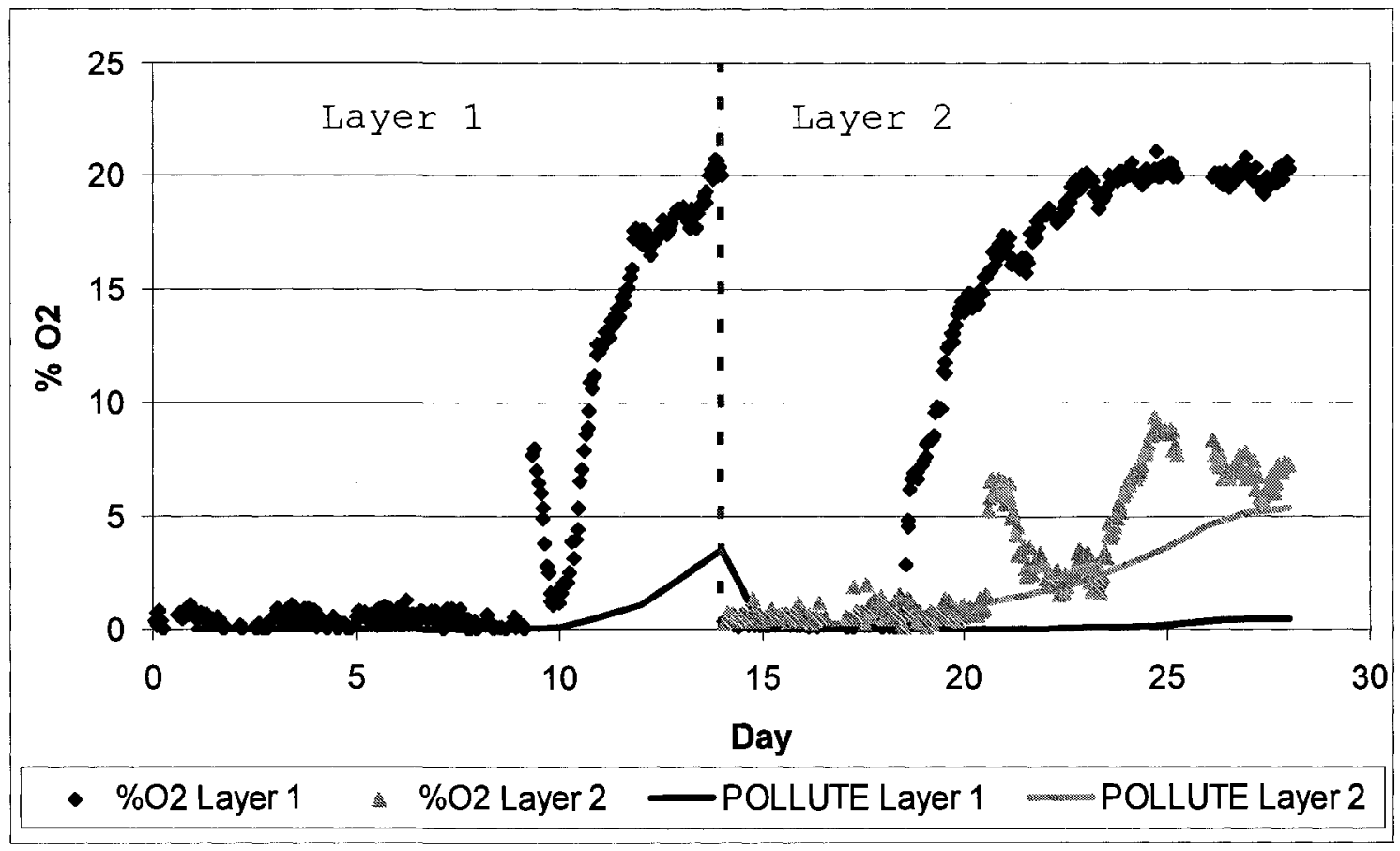

(b) Sealed Column

Figure 6.7 Measured (\%O2) and modelled (POLLUTE) gaseous oxygen concentrations during (a) the Cracked Column test and (b) the Sealed Column test. 
The measured and modelled sulphide concentration at the tailings surface is shown in Figure 6.8 for both columns. Modelling was again conducted using the nKc and Jerz and Rimstidt methods. The concentration profiles with depth on Day 28 are compared in Figure 6.9. Contrary to what one might expect, the cracks in the Cracked Column did not seem to affect the agreement between the measured and modelled sulphide concentrations with depth (Figure 6.9 a). However, the tailings samples were taken close to the centre of the column, where cracks might not affect the extent of oxidation. To determine whether there was any horizontal trend in sulphide content relative to a crack edge, an additional $7-\mathrm{cm}$ layer test was carried out. The methodology and results of the test are given in Appendix G. The results showed no significant variation across a horizontal profile in the tailings. 


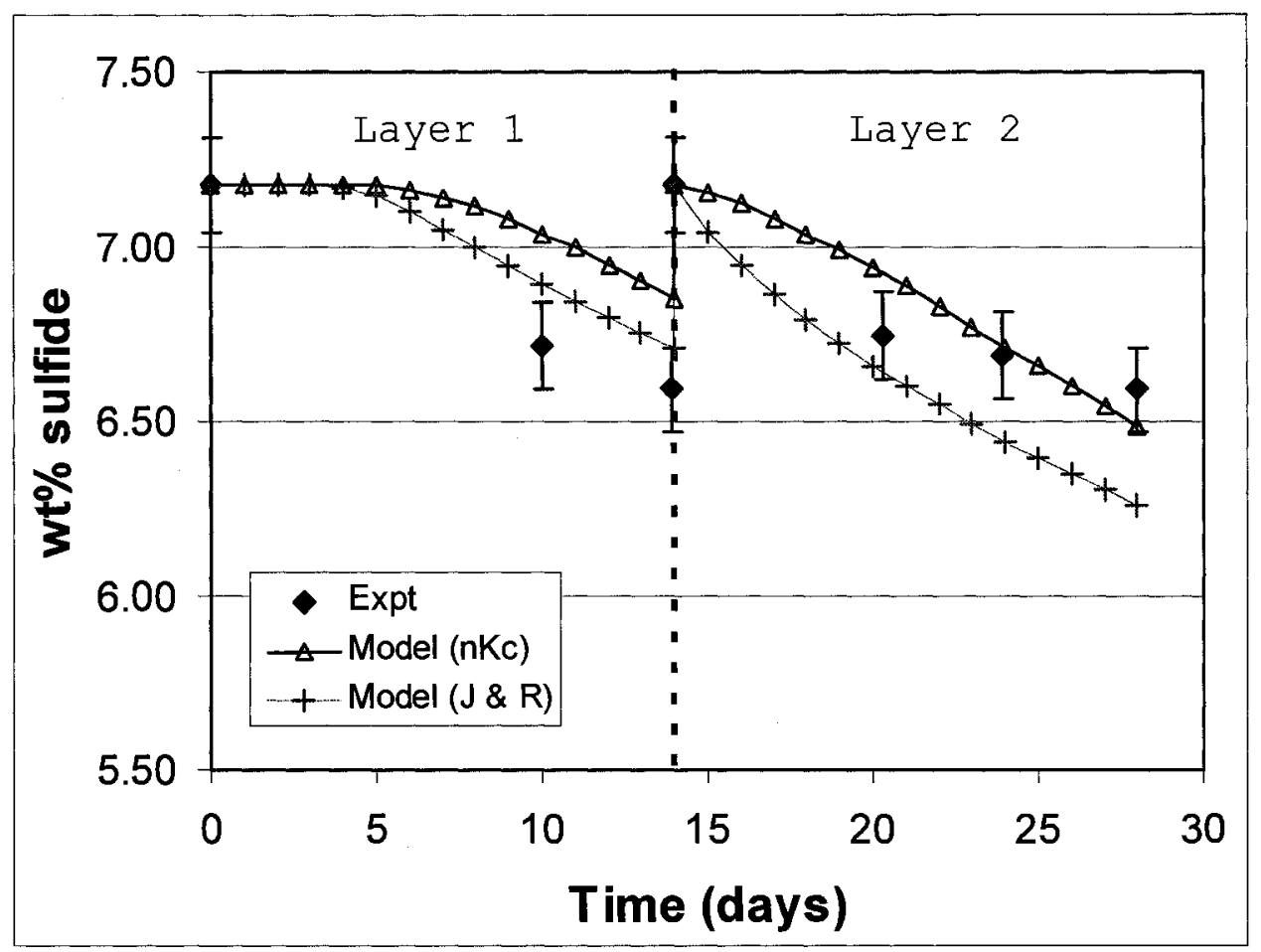

(a) Cracked Column

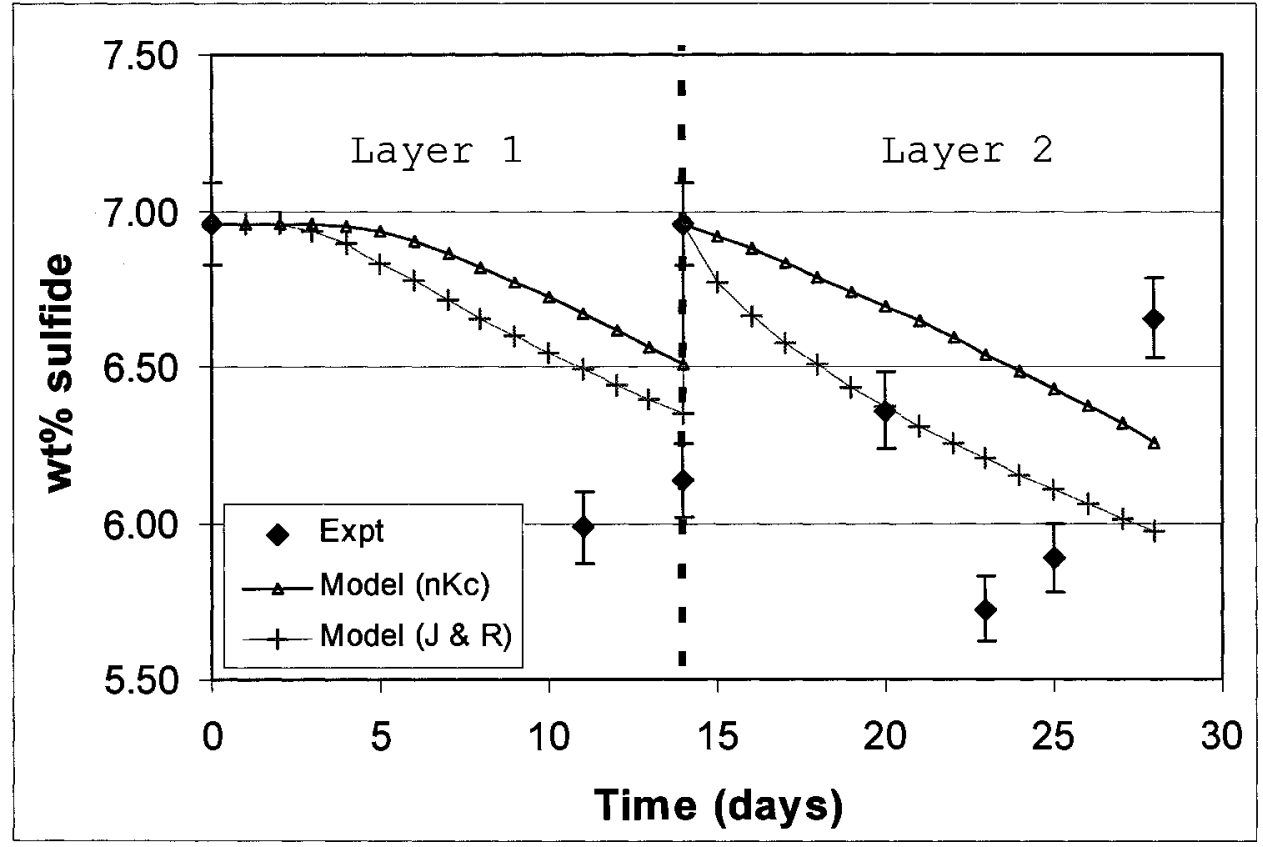

(b) Sealed Column

Figure 6.8 Measured (Expt) and modelled (by nKc method and by Jerz and Rimstidt ( $\mathrm{J} \& \mathrm{R}$ ) method) sulphide at the tailings surface for (a) the Cracked Column test and (b) the Sealed Column test. Error bars represent the standard deviation in the sulphide content measurements (see Appendix B). 


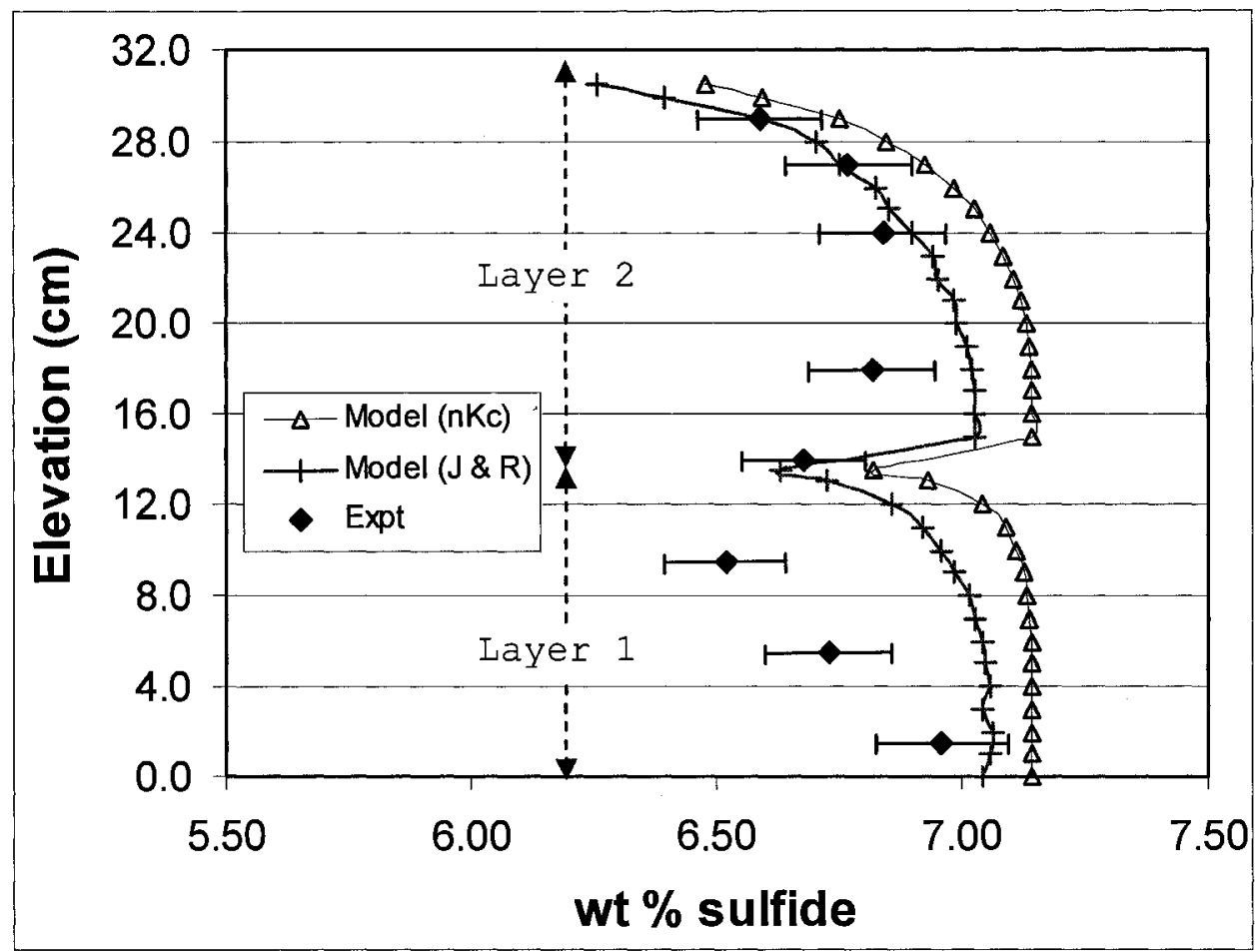

(a) Cracked Column

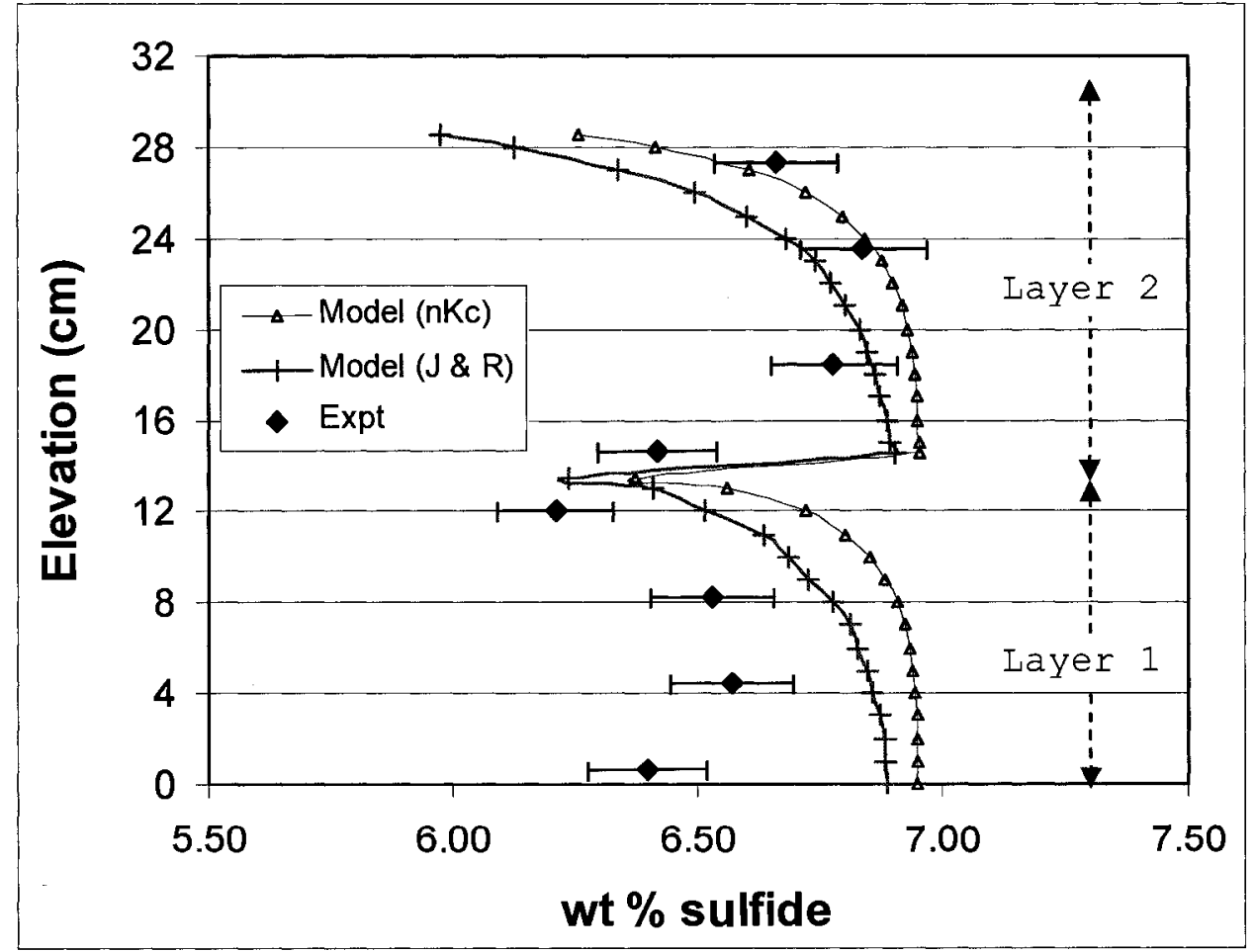

(b) Sealed Column

Figure 6.9 Measured (Expt) and modelled (by nKc method and by Jerz and Rimstidt (J \& R) method) sulphide concentration with depth on Day 28 of (a) the Cracked Column test and (b) the Sealed Column test. Error bars represent the standard deviation in the sulphide content measurements (see Appendix B). 
The change in pore water chemistry for both column tests is compared in Table 6.2. For both columns, the concentrations of metals/metalloids and sulphate increased significantly, $\mathrm{pH}$ dropped and the EC increased. The Sealed Column showed a slightly less pronounced change than the Cracked Column. The pore water samples were not filtered.

Table 6.2 Comparison of pore water quality before and after the column tests.

\begin{tabular}{l|r|rr|rr}
\hline & $\begin{array}{c}\text { Tresh } \\
\text { Tailings } \\
\text { Day 0 }\end{array}$ & \multicolumn{2}{|c|}{ Cracked Column Day 28 } & \multicolumn{2}{|c}{ Sealed Column Day 28 } \\
\cline { 3 - 6 } $\mathrm{SO}_{4}^{2-}$ & 2,140 & $\mathrm{mg} / \mathrm{L}$ & $\%$ change & $\mathrm{mg} / \mathrm{L}$ & $\%$ change \\
$\mathrm{Ca}$ & 545 & 2,520 & 17.8 & 2,450 & 14.5 \\
$\mathrm{Mg}$ & 125 & 576 & 5.7 & 544 & -0.2 \\
$\mathrm{~K}$ & 283 & 222 & 77.6 & 200 & 60 \\
$\mathrm{Al}$ & $<0.1$ & 18.0 & 382 & 35.0 \\
$\mathrm{Cu}$ & 0.07 & 42.6 & $>42,500$ & 38.7 & $>38,600$ \\
$\mathrm{Fe}$ & $<0.3$ & 5.35 & 7543 & 4.88 & 6871 \\
$\mathrm{~Pb}$ & $<0.01$ & 588 & $>195,900$ & 551 & $>183,567$ \\
$\mathrm{Mn}$ & 2.8 & 1.26 & $>12,500$ & 0.92 & $>9,100$ \\
$\mathrm{Si}$ & 5 & 21.7 & 657 & 21.0 & 650 \\
$\mathrm{Zn}$ & 0.8 & 22 & 340 & 19 & 280 \\
$\mathrm{pH}$ & 6.93 & 3.40 & 325 & 3.07 & 284 \\
$\mathrm{EC}$ & $4.25 \mathrm{mS} / \mathrm{cm}$ & $5.88 \mathrm{mS} / \mathrm{cm}$ & 38.4 & $5.22 \mathrm{mS} / \mathrm{cm}$ & 22.8 \\
\hline
\end{tabular}

\subsection{Discussion}

Overall, the effect of cracking was either very slight or undetectable. In terms of the evaporation rate, there was no noticeable effect whether the cracks were sealed or not. The variability in day-to-day evaporation masked any increase owing to crack formation. The suction profiles for both the Cracked and Sealed tests were similar (Figure 6.5 and Figure 6.6). The SoilCover predictions were somewhat off in both cases, however, the overall sulphide depletion profile is relatively insensitive to SoilCover suctions (as discussed in Section 4.4), and so this should not affect the end result. The oxygen sensors 
buried in the Cracked Column confirmed that oxygen was circulating into cracks. The sensor in the bottom layer of the Sealed Column was exposed to oxygen despite the attempt to seal off the crack spaces. This was likely caused by separation at the base of the column where the sensor had been taped down. The sensor buried in the second layer was sealed off reasonably well and results were in good agreement with the oxygen concentrations predicted by POLLUTE.

As was the case for the small-scale test, in terms of modelling the sulphide depletion, the Jerz and Rimstidt method gave results that were in better agreement with the measured sulphide concentrations than the nKc method (see Figure 6.8 and Figure 6.9). The MAE values between the modelled and experimental results are presented in Table 6.3.

Table 6.3 Mean absolute error (MAE) values between measured and modelled sulphide concentrations for the column tests. The two modelling methods were the nKc method and the Jerz and Rimstidt ( $\mathrm{J} \& \mathrm{R}$ ) method. The modelled and experimental values are shown in Figure 6.8 and Figure 6.9.

\begin{tabular}{lll}
\hline & \multicolumn{2}{c}{ MAE (wt\% S) } \\
& nKc & J \& R \\
\hline Cracked Column & & \\
At surface & 0.18 & 0.20 \\
With depth on Day 28 & 0.24 & 0.15 \\
\hline $\begin{array}{l}\text { Sealed Column } \\
\text { At surface }\end{array}$ & & \\
With depth on Day 28 & 0.52 & 0.35 \\
\hline
\end{tabular}

The MAE was less for the Jerz and Rimstidt method than for the nKc method; however, in all cases, the MAE between modelled and experimental values was more than the standard deviation between replicate samples (see Appendix B, standard deviation $=0.12 \mathrm{wt} \% \mathrm{~S}$ for nine samples from a well-mixed bucket of tailings). Therefore, there was some disagreement between the model predictions and actual 
measurements of sulphide content. The disagreement was more prominent in the bottom layer of tailings.

In general, the measured and modelled values show a similar trend except at the tailings surface for the Sealed Column test (Figure $6.8 \mathrm{~b}$ ). The reason for this disagreement is not known. One possibility is that the external lab testing the samples mixed up the samples and misreported the data; however, this was not confirmed. Whether the cracks were sealed or exposed did not significantly affect the final sulphide content prediction. In fact, there was better agreement between the measured and modelled values for the Cracked Column compared to the Sealed Column.

The pore water concentrations, $\mathrm{pH}$ and $\mathrm{EC}$ indicate that oxidation products were released into the pore water from both column tests. As expected, $\mathrm{Fe}$ and $\mathrm{SO}_{4}^{2-}$ increased due to pyrite oxidation. The measured Fe concentration was higher than expected for the circumneutral conditions in the pore water. This may have been because the water samples were unfiltered and contained some fine suspended particles. Acid digestion of these particles would have solubilized Fe(III) in the solid phase and increased the total $\mathrm{Fe}$ detected. The $\mathrm{Mg}^{2+}$ concentrations increased and the $\mathrm{pH}$ did not decrease significantly. This could have been due to carbonate dissolution. The precipitation and dissolution of gypsum is likely controlling $\mathrm{Ca}^{2+}$ and $\mathrm{SO}_{4}^{2-}$ concentrations in the pore water, which is why there were only slight changes in the concentrations of $\mathrm{Ca}^{2+}$ and $\mathrm{SO}_{4}^{2-}$. The increase in $\mathrm{EC}$ reflects the increase in the ionic strength of the pore water, primarily due to $\mathrm{Fe}, \mathrm{K}^{+}$, $\mathrm{SO}_{4}^{2-}$ and $\mathrm{Mg}^{2+}$. The concentrations of the trace metals $\mathrm{Pb}, \mathrm{Mn}, \mathrm{Zn}$ and $\mathrm{Cu}$ all increased in the pore water after 28 days of weathering. 
The most significant outcome from these column experiments was that the results indicate that the input parameters needed for sulphide oxidation modelling are not significantly affected by cracking. This in turn allows use of SoilCover and POLLUTE for the purpose of predicting sulphide oxidation in real surface disposal facilities without concern about the effects of cracking. However, the present study was conducted on a very small scale compared to that of the entire Bulyanhulu TSF. For comparison, crack measurements taken at Bulyanhulu's TSF found that the cracking pattern in a $60-\mathrm{cm}$ layer of tailings increased the total surface area by between $300 \%$ and $350 \%$ compared to an un-cracked surface (Golder, 2005). In their modelling, Golder (2005) assumed that these cracks would result in a corresponding 3 -fold increase in the rate of oxidation of sulphide minerals. The results of the laboratory-scale experiments in this study contradict Golder's assumption that the rate of sulphide oxidation would increase proportionately with the increase in exposed surface area due to cracking; however, the disagreement between the two studies could be a reflection of the differences in the scale of operation more than anything. For this reason, it would be useful to repeat a similar series of cracked versus sealed experiments at an operational scale. 


\section{Chapter 7: Application to Bulyanhulu}

The results of the small-scale test and the column tests show that SoilCover and POLLUTE are useful and reliable tools for predicting the extent of drying and oxygen ingress for layers of cracked or un-cracked paste tailings. In this chapter, the models are applied to predict the extent of sulphide depletion at Bulyanhulu and determine whether acid drainage conditions are likely to occur. The comparisons between the $\mathrm{nKc}$ method and the Jerz and Rimstidt method for predicting sulphide depletion (see Figure 4.10, Figure 6.8 and Figure 6.9) established that the Jerz and Rimstidt was the better of the two methods (i.e. Jerz and Rimstidt predictions were closer to actual measured values than nKc predictions). The Jerz and Rimstidt method also predicted greater oxidation than the nKC method and, therefore, it was used to develop a more reliable (as well as conservative) estimate of sulphide oxidation in the Bulyanhulu tailings.

Given the current deposition strategy at Bulyanhulu (10 to 30-cm layers deposited every 5 to 30 days), the worst-case scenario for sulphide oxidation would be to deposit 10-cm layers every 30 days. This deposition scheme would maximize the potential for drying and oxygen exposure of the tailings.

For SoilCover modelling, the potential evaporation rate at Bulyanhulu was adjusted to $10 \mathrm{~mm} /$ day (weather conditions given in Appendix D). This was the average potential evaporation rate calculated from weather data collected at the mine site in 2004 (Simms et al., 2007). The initial GWC of each layer was $40 \%$. The simulations consisted of 10-cm layers dried for 30 days.

The modelled daily evaporation is shown in Figure 7.1. Given the thinness of the layers and the high potential evaporation rate, it is not surprising that Stage III (residual) 
evaporation dominates. The amount of time spent in Stage I evaporation (in Stage I the actual evaporation rate equals the potential evaporation rate) decreases with each successive layer. Also, the residual evaporation rate increases slightly with each successive layer. Consider, for example, Days 1 through 30, when only Layer 1 is present. The potential rate of evaporation is maintained for 4 days before decreasing rapidly to the residual rate of $0.5 \mathrm{~mm} /$ day. Compare that to Days 120 through 150 , when Layer 5 has been added. The potential evaporation rate is only maintained for 1 day before falling to the residual rate of $0.9 \mathrm{~mm} /$ day.

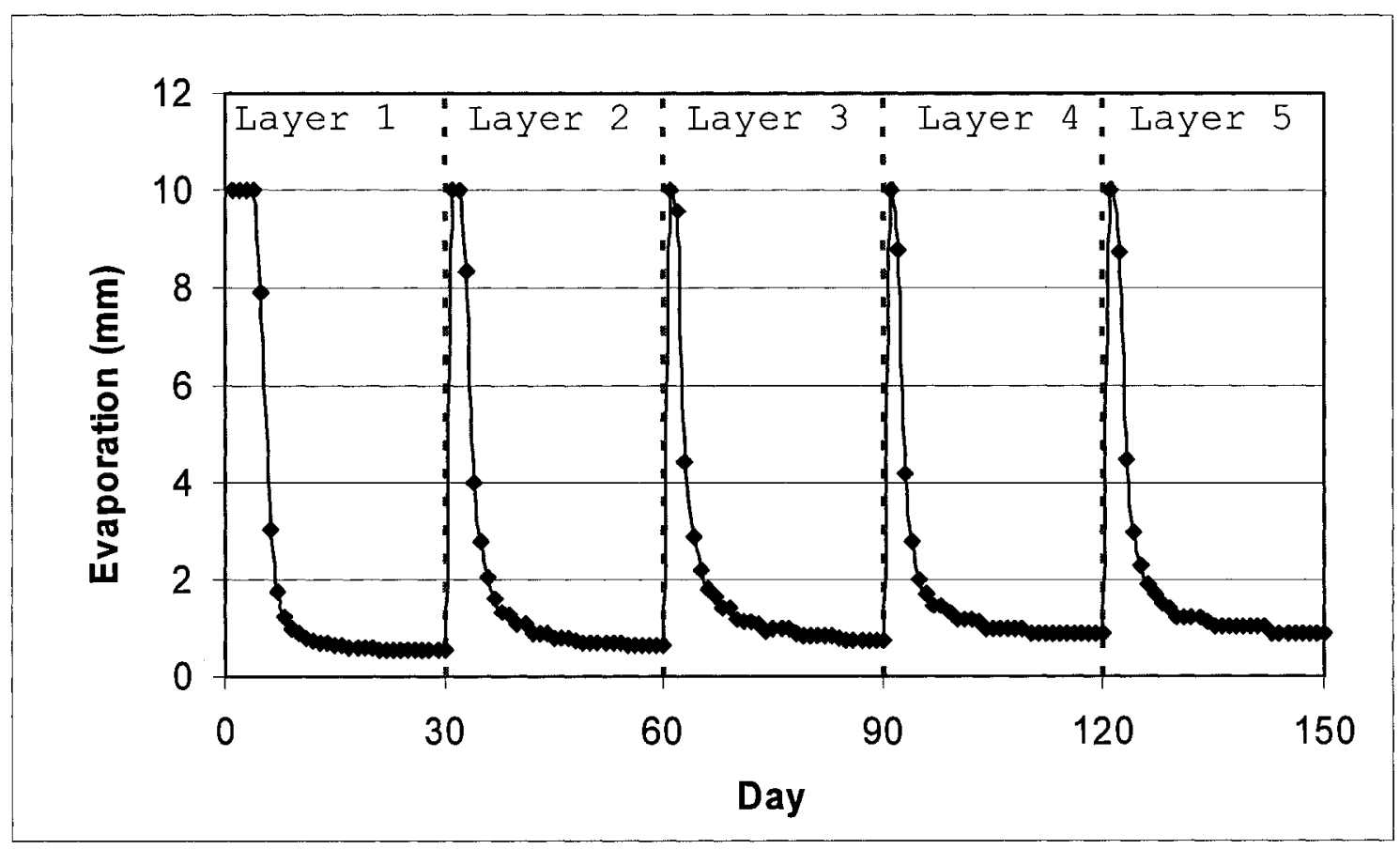

Figure 7.1 Evaporation during a 5-layer, 150-day simulation of paste deposition at Bulyanhulu. Potential evaporation rate was $10.0 \mathrm{~mm} /$ day.

These phenomena occur due to the downward movement of water from a freshlydeposited (saturated) layer into the underlying (dry) layer. In effect, the underlying layers acts as a sponge, absorbing the water provided by the newly-added surface layer. This causes a more rapid decline from the rate of potential evaporation because the surface of 
the tailings dries more quickly due to water loss to the underlying layers. It also allows a slightly higher residual evaporation rate to be maintained by gradual transport of water from the deeper, more saturated layers, to the tailings surface.

The modelled sulphide content with depth is shown in Figure 7.2. The initial sulphide content for all layers was $6.80 \mathrm{wt} \%$ (the average sulphide content of the tailings analyzed for the small-scale, large-scale and column tests). Only the results for five 10$\mathrm{cm}$ layers are shown. Once a layer is covered by two other layers, the sulphide oxidation becomes undetectable in that layer. Therefore, the sulphide concentration profile on Day 150 represents the maximum sulphide depletion that would occur in the paste tailings at Bulyanhulu.

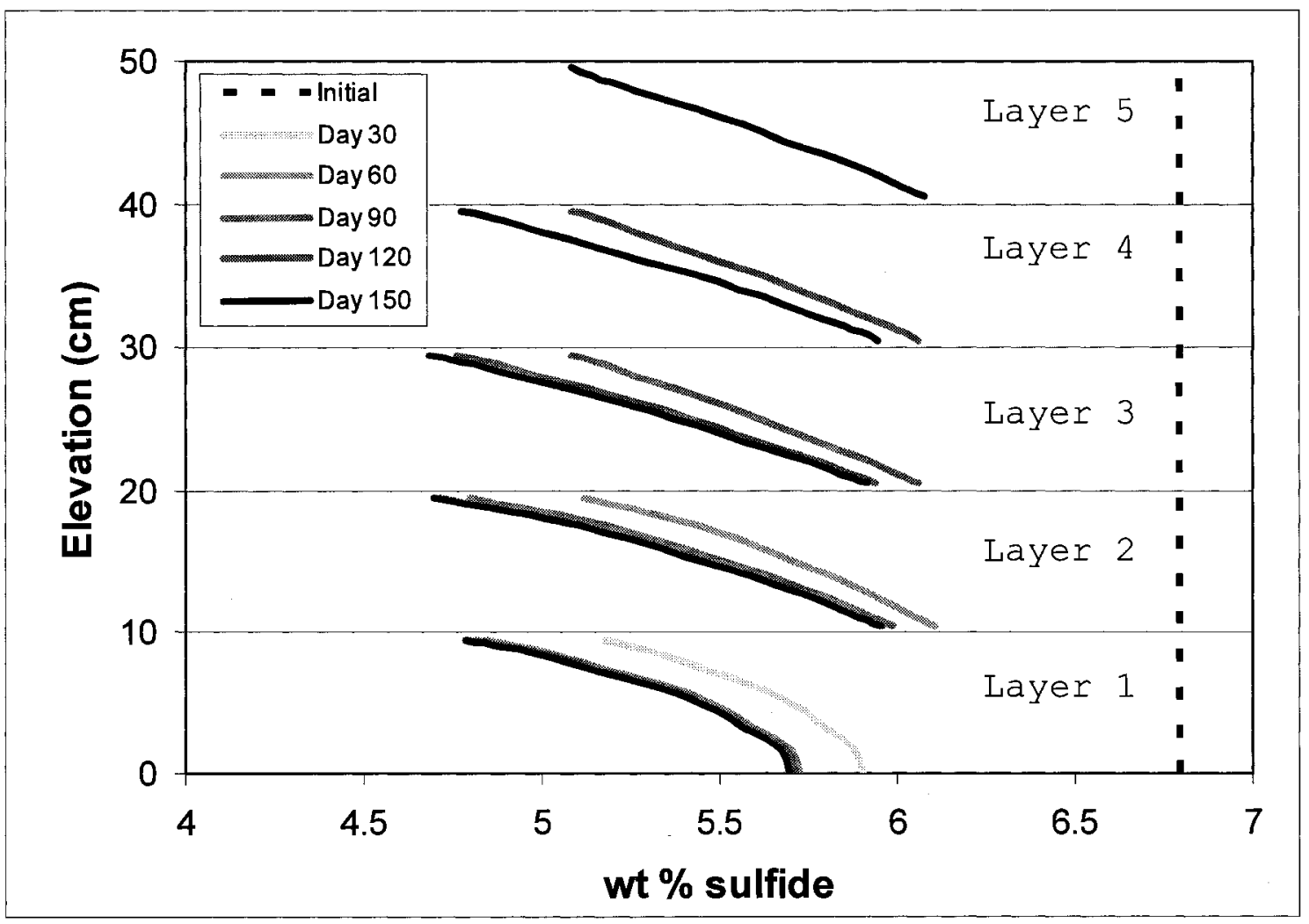

Figure 7.2 Sulphide depletion with depth during a 5-layer, 150-day simulation of paste deposition at Bulyanhulu. Initial sulphide content was $6.80 \mathrm{wt} \% \mathrm{~S}$. 
According to Reaction 6, there is a 2:1 molar ratio between sulphide consumption and proton release for circumneutral pyrite oxidation. According to Reaction 7, the molar ratio is also 2:1 for the consumption of protons by calcite. The carbonate content of Bulyanhulu tailings was $6.2 \%$ as $\mathrm{CaCO}_{3}$, or $620 \mathrm{mmol} \mathrm{CaCO}_{3} / \mathrm{kg}$ (Section 3.2). From Figure 7.2 , the highest sulphide consumption was from 6.80 to $4.69 \mathrm{wt} \% \mathrm{~S}$, or $660 \mathrm{mmol} \mathrm{S} / \mathrm{kg}$. Therefore, the neutralizing capacity of the carbonate minerals in the tailings would be insufficient to maintain a circumneutral $\mathrm{pH}$ and prevent acid drainage.

The scenario presented above assumes pyrite oxidation by molecular oxygen, which releases $4 \mathrm{H}^{+}$per pyrite molecule oxidized. Pyrite oxidation by $\mathrm{Fe}^{3+}$ produces 16 $\mathrm{H}^{+}$for every pyrite molecule oxidized and, if uncoupled from Reaction 2 (i.e. under acidic conditions or in acidic microenvironments surrounding pyrite grains), this would more rapidly consume the carbonate minerals and create acidic drainage. The assumption was also made that all carbon was present as calcite, which is unlikely. Ankerite may also be present, in which case the actual neutralizing capacity of the tailings would be less than $620 \mathrm{mmol} \mathrm{CaCO}_{3} / \mathrm{kg}$. The scenario further assumes that paste deposition at Bulyanhulu will indeed adhere to the planned deposition scheme. If paste layers were to be exposed for greater periods than the maximum intended 30 days and/or were to be thinner than the minimum intended $10 \mathrm{~cm}$, the potential for acid generation is greater. 


\section{Chapter 8: Conclusions}

Based on static tests, the Bulyanhulu tailings are considered acid generating. The acid potential is $176 \mathrm{~kg} \mathrm{CaCO}_{3} / \mathrm{t}$ and the neutralizing potential is $53 \mathrm{~kg} \mathrm{CaCO}_{3} / \mathrm{t}$. The tailings contain between $10.5 \%$ and $13.5 \%$ pyrite, $6.2 \%$ carbonate minerals $\left(\operatorname{as} \mathrm{CaCO}_{3}\right.$ ), $<1 \%$ chalcopyrite, and the remainder is silicate minerals.

The first-order removal constant for oxygen in the tailings as determined from laboratory testing is $K=0.8$ day $^{-1}$. However, a value of $K=100$ day $^{-1}$ was used in POLLUTE modelling since it gave the best agreement to measured sulphide contents in the tailings.

SoilCover is an effective means to predict the drying profile in multiple layers of tailings. The predicted and measured soil suctions are in good agreement, despite the formation of cracks on the tailings surface. Cracks do not significantly affect the ability of SoilCover to predict the saturation of a layer of paste. The effect of crack formation may prove to be more pronounced in a full-scale operation and it would be interesting to compare SoilCover results to an active tailings facility, where the cracks are larger and deeper than those formed during the experiments carried out in this study. Salt precipitation seems to have more of an effect, impeding evaporation by forming a cemented crust layer and by increasing total soil suction. A future study might focus on measuring the effect of salts and cementation on the rate of evaporation, effective diffusion coefficient of oxygen and overall sulphide oxidation.

SoilCover required manual correction for the effects of volume change. The height of the one-dimensional mesh had to be shrunk to reflect the shrinking of the soil. Also, the relative hydraulic conductivity function had to be calculated using the actual 
saturation vs. suction SWCC in order to maintain higher hydraulic conductivities and prevent the premature desaturation of the surface elements in the model simulations.

POLLUTE predictions of the oxygen concentration profile with time were difficult to confirm experimentally because of preferential cracking around the oxygen sensors. Nonetheless, one sensor in the second layer of the Sealed Column test was sealed off successfully and the measured oxygen concentrations were in good agreement with the POLLUTE predictions. POLLUTE results were found to be relatively insensitive to the removal constant $K$ (tested with $K=40,50,60$ day $^{-1}$ ).

The results of the experimental and modelling comparisons in Chapters 4, 5 and 6 indicate that SoilCover and POLLUTE combined with Jerz and Rimstidt's rate equation describing the abiotic oxidation of pyrite by oxygen at circumneutral $\mathrm{pH}$, can be combined to predict sulphide oxidation in layers of drying paste tailings without concerns about the two-dimensional effect of cracking.

The models were applied to determine whether the paste deposition strategy at Bulyanhulu might result in generation of acid drainage conditions. The conclusion, based on a 10-cm layer, 30-day cycle deposition scheme, was that oxidation of the Bulyanhulu paste tailings would likely lead to acid drainage conditions. The carbonate minerals in the tailings would not be sufficient to neutralize the oxidation products from pyrite oxidation.

The advantages of using SoilCover and POLLUTE are that they are simple, easy to use and do not require high computational power to get results quickly. The only inputs required are material properties that can be measured in the lab, site-specific weather conditions, and the deposition strategy being used (i.e. layer thickness and drying time). With these parameters, a reasonably accurate estimation of the extent of sulphide 
depletion in multilayer deposition schemes can be estimated. Using these tools, various deposition strategies can be compared to assess the best combination of layer thickness and drying time that will maximize drying and strength gain while minimizing or preventing acid drainage.

The simplicity of the models used in this study is a benefit but may also be a drawback. The analysis assumes a simple 2 to 1 molar ratio for proton release to sulphide oxidation and no competing reactions. In particular, they ignore the effects of solution chemistry and chemical reactions between solids and the aqueous solution for mineral phases, and the only chemical processes described include oxygen transport and its removal through sulphide oxidation. It will therefore be useful to compare the results to those from other reactive transport models that are more comprehensive in nature, such as MIN3P. 


\section{References}

Aachib, M., Mbonimpa, M., and Aubertin , M. (2004) Measurement and prediction of the oxygen diffusion coefficient in unsaturated media, with applications to soil covers. Water, Air and Soil Pollution. 156: 163-193.

Abedi-Koupai, J. and Mehdizadeh, H. (2008) Estimation of osmotic suction from electrical conductivity and water content measurements in unsaturated soils. Geotechnical Testing Journal. 31: 1-7.

Al, T.A. and Blowes, D.W. (1995) A geochemical, hydrogeological, and hydrological study of the tailings impoundment at the Falconbridge Limited, Kidd Creek Division Metallurgical Site, Timmins, Ontario. MEND (Mine Environment Neutral Drainage) Program Project 2.23.2d.

ASTM D422-63, (2007) Standard test method for particle-size analysis of soils. Annual Book of ASTM Standards. vol. 04.08.

Baczek, F. (2007) Paste thickener designs evolving to higher capacity and efficiencies. International Mining: Paste Tailings Management Supplement. pp. 2-4.

Blight, G.E. (2007) Wind erosion of tailings dams and mitigation of the dust nuisance. Journal of the South African Institute of Mining and Metallurgy. 107: 99-107.

Blowes, D.W. and Jambor, J.L. (1990) The pore-water geochemistry and the mineralogy of the vadose zone of sulphide tailings, Waite Amulet, Quebec, Canada. Appl. Geochem. 5: 327-346.

Blowes, D.W., Ptacek, C.J., and Jurjovec, J. (2003) Mill tailings: Hydrogeology and Geochemistry. In Environmental Aspects of Mine Wastes (J.L. Jambor, D.W. Blowes and A.I.M Ritchie, eds.) Mineral. Assoc. Can. Short Series Vol. 31: 95-116. 
Brackebusch, F.W. (1994) Basics of paste backfill systems. Mining Engineering. 296: $1175-1178$.

Bulut, R. and Leong, E.C. (2008) Indirect measurement of soil suction. Geotechnical and Geoogical Engineering. Online First publication available through SpringerLink. May 15, 2008. ISSN: 1573-1529 (Online).

Cabral, A.R., Tremblay, P., and Lefebvre, G. (2004) Determination of the diffusion coefficient of oxygen for a cover system including a pulp and paper by-product. Geotechnical Testing Journal. 27: 184-197.

Campbell Scientific (2006) Instruction Manual: 229 Heat Dissipation Matric Water Potential Sensor. Campbell Scientific Canada Corp., Edmonton Alberta, Canada.

Chandler, R.J. and Tosatti, G. (1995) The Stava tailings dams failure, Italy, July 1985. In Proceedings of the Institution of Civil Engineers Geotechnical Engineering. 113: $67-79$.

Chamberlain, C.M., Wilkinson, J.J., Herrington, R.J., and Boyce, A.J. (2003) The Bulyanhulu enigma: an atypical Archaean lode gold deposit - evidence for a pre-ore magmatic input. Transactions - Institution of Mining and Metallurgy. 112B: 112113.

Clark, C.S. (1965) The oxidation of coal mine pyrite. Ph.D Thesis, The Johns Hopkins University, Baltimore, MD, U.S.A.

Danielson, V. (2001) Grade is king: Bulyanhulu - the hub of Barrick's district development program in Tanzania. Canadian Mining Journal. 122: 26-29.

Davies, M.P. (2002) Tailings impoundment failures: Are geotechnical engineers listening? Geotechnical News. 20: 31-36. 
Deschamps, T., Benzaazoua, M., Bussière, B., Aubertin, M., and Belem, T. (2008) Microstructural and geochemical evolution of paste tailings in surface disposal conditions. Minerals Engineering. 21:341-353.

Elberling, B. (1996) Gas diffusion coefficient in cemented porous media. Journal of Hydrology. 178: 93-108.

Elberling, B. and Nicholson, R.V. (1996) Field determination of sulphide oxidation rates in mine tailings. Water Resour. Res. 32: 1773-1784.

Elberling, B., Nicholson, R.V., and Scharer, J.M. (1994) A combined kinetic and diffusion model for pyrite oxidation in tailings: a change in controls with time. $J$. Hydrol. 157: 47-60.

EPCOR (2008) Britannia Mine Water Treatment Plant. Available at: http://www.epcor.ca/en-ca/about-epcor/operations/operations-bcp-pnw/waterwastewater/britannia-mine/Pages/default.aspx. Accessed December 19, 2008.

Fisseha, B. (2008) Flow behavior in multilayer deposits of unsaturated paste tailings. M.A.Sc Thesis, Carleton University, Ottawa, Ontario, Canada.

Flint, A.L., Campbell, G.S., Ellett, K.M., and Calissendorff, C. (2002) Calibration and temperature correction of heat dissipation matric potential sensors. Soil Sci. Soc. Am. J. 66: 1439-1445.

Fredlund, D.G., Xing, A., and Huang, S. (1994) Predicting the permeability function for unsaturated soils using the soil-water characteristic curve. Can Geotech J. 31: 521532.

Fujiyasu, Y. (1997) Evaporation behavior of tailings. Ph.D Dissertation, University of Western Australia., Perth, Australia. 
Fujiyasu, Y., Fahey, M., and Newson, T. (2000) Field investigation of evaporation from freshwater tailings. Journal of Geotechnical and Geoenvironmental Engineering. 126: $556-567$.

Garrels, R.M. and Thompson, M.E. (1960) Oxidation of pyrite by iron sulphate solutions. Am. J. Sci. 258A: 57-67.

GAEA Technologies Ltd. (2004) User's Guide: POLLUTE Version 7. GAEA Technologies Limited, Whitby, Ontario, Canada.

Gerke, H.H., Molson, J.W., and Frind, E.O. (2001) Modelling the impact of physical and chemical heterogeneity on solute leaching in pyritic overburden mine spoils. Ecol. Eng. 17: 91-101.

Golder (2005) Report on Bulyanhulu gold mine tailings storage facility optimization of deposition. Report No. 5098/6586/5/S. Golder Associates Africa, Johannesburg, South Africa.

Henriquez, J. and Simms, P. (2008) Dynamic imaging and modelling of multilayer deposition of gold paste tailings. Minerals Engineering. In Press.

Howie, F.M. (1992) Pyrite and Marcasite. In The care and conservation of geological material: minerals, rocks, meteorites and lunar finds. (F.M. Howie, ed.) Butterworth-Heinemann Publishers, Guildford, U.K. pp. 70-84.

Hudson-Edwards, K.A., Macklin, M.G., Jamieson, H.E., Brewer, P.A., Coulthard, T.J., Howard, A.J., and Turner, J.N. (2003) The impact of tailings dam spills and cleanup operations on sediment and water quality in river systems: the Rios AgrioGuadiamas, Aznalcollar, Spain. Appl. Geochem. 18: 221-239. 
INAC (2008) Giant Mine Remediation Project. Government of Canada: Department of Indian and Northern Affairs. Available at: http://nwt-tno.inac-ainc.gc.ca/giant/ Accessed December 19, 2008.

Jambor, J.L. (1994) Mineralogy of sulphide-rich tailings and their alteration products. In The Environmental Geochemistry of Sulphide Mine-Wastes (J.L. Jambor and D.W. Blowes eds.) Mineral. Assoc. Can. Short Course Vol. 22: 59-102.

Jambor, J.L., Nordstrom, D.K., and Alpers, C.N. (2000) Metal-sulphate salts from sulphide-mineral oxidation. In Sulphate minerals: Crystallography, geochemistry, and environmental significance (C.N. Alpers, J.L. Jambor and D.K. Nordstrom, eds.) Rev. Mineral. 40: 303-350.

Jambor, J.L. (2003) Mine-waste mineralogy and mineralogical perspectives of acid-base accounting. In Environmental Aspects of Mine Wastes (J.L. Jambor, D.W. Blowes and A.I.M Ritchie, eds.) Mineral. Assoc. Can. Short Series Vol. 31: 117-145.

Jaynes, D.B., Rogowski, A.S.S., and Pionk, H.B. (1984) Acid mine drainage from reclaimed coal strip mines: 1. Model description. Water Resour. Res. 20: 233-242.

Jerz, J.K. and Rimstidt, J.D. (2004) Pyrite oxidation in moist air. Geochimica et Cosmochimica Acta. 68: 701-714.

Johansen, O. (1975) Thermal conductivity of soils. Ph.D Thesis, Norwegian University of Science and Technology, Trondheim, Norway.

Jurjovec, J., Ptacek, C.J., and Blowes, D.W. (2002) Acid neutralization mechanisms and metal release in mine tailings: A laboratory column experiment. Geochim. Cosmochim. Acta. 60: 367-385. 
Kendelewicz, T., Doyle, C.S., Bostick, B.C., and Brown, G.E.Jr. (2004) Initial oxidation of fractured surfaces of $\mathrm{FeS}_{2}\left(\begin{array}{lll}1 & 0 & 0\end{array}\right)$ by molecular oxygen, water vapor, and air. Surf. Sci. 558: 80-88.

Lichtner, P.C. (1996) Continuum formulation of multicomponent-multiphase reactive transport. In Reactive transport in porous media (P.C. Lichtner, C.I. Steefel and E.H. Oelkers, eds.) Rev. Mineral. 34: 1-81.

Linklater, C.M., Sinclair, D.J., and Brown, P.L. (2005) Coupled chemistry and transport modelling of sulphidic waste rock dumps at the Aitik mine site, Sweden. Applied Geochemistry. 20: 275-293.

Makinson, J.D., Lee, J.S., Magner, S.H., De Angelis, R.J., Weins, W.N., and Hieronymus, A.S. (2000) X-Ray diffraction signatures of defects in nanocrystalline materials. JCPDS-International Centre for Diffraction Data, Advances in X-ray Analysis. 42: 407-411.

Macklin, M.G., Brewer, P.A., Balteanu, D., Coulthard, T.J., Driga, B., Howard, A.J., and Zaharia, S. (2003) The long-term fate and environmental significance of contaminant metals released by the January and March 2000 mining tailings dam failures in Maramures County, upper Tisa Basin, Romania. Appl. Geochem. 18: 241-257.

Martin, V., Aubertin, M., and McMullen, J. (2006) Surface disposal of paste tailings. In Proceedings of the 5th ICEG Environmental Geotechnics: Opportunities, Challenges and Responsibilities for Environmental Geotechnics, Cardiff, UK, June, 26-30. 2: 1471-1478. 
Mayer, K.U., Frind, E.O., and Blowes, D.W. (2002) Multicomponent reactive transport modelling in variably saturated porous media using a generalized formulation for kinetically controlled reactions. Water Resour. Res. 38: 1174-1194.

Mbonimpa, M., Aubertin, M., and Bussière, B. (2006) Predicting the unsaturated hydraulic conductivity of granular soils from basic geotechnical properties using the modified Kovacs (MK) model and statistical models. Can. Geotech. J. 43: 773-787.

Meggyes, T. and Debreczeni, A. (2006) Paste technology for tailings management. Land Contamination and Reclamation.. 14: 815-827.

MEND (1991) Acid rock drainage prediction manual. MEND (Mine Environmental Neutral Drainage) Program Project 1.16.1b.

MEND (1997) Review of water cover sites and research projects. MEND (Mine Environment Neutral Drainage) Program Project 2.18.1.

MEND (2005) List of potential information requirements in metal leaching and acid rock drainage assessment and mitigation work. MEND (Mine Environment Neutral Drainage) Program Project 5.10E.

Mielke, R.E., Pace, D.L., Porter, T., and Southam, G. (2003) A critical stage in the formation of acid mine drainage: Colonization of pyrite by Acidithiobacillus ferrooxidans under pH-neutral conditions. Geobiology 1: 81-90.

Miller, S.D., Robertson, A., and Donohue, T. (1997) Advances in acid drainage prediction using the net acid generation (NAG) test. In Proceedings of the Fourth International Conference on Acid Rock Drainage, Vancouver, Canada, May 31 June 6. 2: 533-547. 
Mills, A.L. (1999) The role of bacteria in environmental geochemistry. In The Environmental Geochemistry of Mineral Deposits. Part A: Processes, Techniques and Health Issues (G.S. Plumlee and M.J. Logsdon, eds.) Rev. Econ. Geol. 6A: 125132.

Molson, J.W., Fala, O., Aubertin, M., and Bussière, B. (2005) Numerical simulations of pyrite oxidation and acid mine drainage in unsaturated waste rock piles. Journal of Contaminant Hydrology. 78: 343-371.

Moses, C.O. and Herman, J.S. (1991) Pyrite oxidation at circumneutral pH. Geochimica et Cosmochimica Acta. 55: 47 1-482.

Newman, P., White R., and Cadden, A. (2001) Paste - The Future of Tailings Disposal? In Proceedings of the International Conference on Mining and the Environment, The Swedish Mining Association, Skelleftea, Sweden, June 25-July 1. 2: 594-603. Newman, P. (2003) Paste, the answer to dam problems. Materials World. 11:24-26.

Nicholson, R.V., Gillham, R.W., and Reardon, E.J. (1988) Pyrite oxidation in carbonatebuffered solution: Experimental kinetics. Geochim. Cosmochim. Acta. 52: 10771085.

Nordstrom, D.K. (1982) Aqueous pyrite oxidation and the consequent formation of secondary minerals In: Acid Sulphate Weathering (J.A. Kittrick, D.S. Fanning and L.R. Hossner, eds.) Soil Society of America Special Publication. 10: 37-56.

Parkhurst, D.L. and Appelo, C.A.J. (1999) User's Guide to PHREEQC (Version 2) - A Computer Program for Speciation, Batch-Reaction, One-Dimensional Transport, and Inverse Geochemical Calculations, U.S. Geological Survey Water-Resources. 
Penman, H.L. (1948) Natural evaporation from open water, bare soil and grass. Proceedings of the Royal Society of London. Series A, 193: 120-145.

Price, W.A. (2003) Challenges posed by metal leaching and acid rock drainage, and approaches used to address them. In Environmental Aspects of Mine Wastes (J.L. Jambor, D.W. Blowes and A.I.M Ritchie, eds.) Mineral. Assoc. Can. Short Series Vol.31: 1-10.

Priestly, C.H.B. and Talyor, R.J. (1972) On the assessment of surface heat flux and evaporation using large-scale parameters. Monthly Weather Review. 100: 81-92.

Reedy, B.J., Beattie, J.K., and Lowson, R.T. (1991) A vibrational spectroscopic ${ }^{18} \mathrm{O}$ tracer study of pyrite oxidation. Geochim. Cosmochim. Acta. 55: 1609-1614.

Renken. K., Yanful, E.K., and Mchaina, D.M. (2005) Effective oxygen diffusion coefficient and field oxygen concentrations below a Geosynthetic Clay Liner (GCL) covering mine tailings. In Proceedings of the Geo-Frontiers 2005 Congress, Austin, Texas, January 24-26. (E.M. Rathje, ed.) (electronic)

Robb, G.A. and Robinson, J.D.F. (1995) Acid drainage from mines. The Geographical Journal. 161: 47-54.

Robinsky, E.I. (1999) Thickened tailings disposal in the mining industry. Robinsky Associates, Toronto, ON.

Rowe, R.K. and Booker, J.R. (1985) 1-D pollutant migration in soils of finite depth. $J$. Geotech. Eng. 111: 13-42.

Schippers, A., Jozsa, P., and Sand, W. (1996) Sulphur chemistry in bacterial leaching of pyrite. Applied and Environmental Microbiology. 62: 3424-3431. 
Shuttleworth, J.A., Thomson, B.J., and Wates, J.A. (2005) Surface paste disposal at Bulyanhulu - practical lessons learned. In Proceedings of the $6^{\text {th }}$ International Conference on Paste and Thickened Tailings, Santiago, Chile, April 20-22. (R. Jewel and S. Barerra, eds.) Australian Centre for Geomechanics, Perth, Australia, pp. 207-216.

Simms, P., Grabinsky, M.W., and Zhan, G. (2007) Modelling evaporation of paste tailings from the Bulyanhulu Mine. Can. Geotech. J. 44: 1417-1432.

Simms, P., Yanful, E.K., St-Arnaud, L., and Aubé, B. (2000) A laboratory evaluation of metal release and transport in flooded pre-oxidized mine tailings. Applied Geochemistry. 15: 1245-1263.

Sobek, A.A., Schuller, W.A., Freeman, J.R., and Smith, R.M. (1978) Field and laboratory methods applicable to overburdens and minesoils. U.S. Envrion. Protect. Agency EPA-600/2-78-054.

SoilCover (2000) Unsaturated Soils Group, Department of Civil Engineering, University of Saskatchewan, Saskatoon, Canada

Swanson, D.A., Barbour, S.L., Wilson, G.W., and O'Kane, M. (2003) Soil-atmosphere modelling of an engineered soil cover for acid generating mine waste in a humid, alpine climate. Can. Geotech. J. 40: 276-292.

Theriault, J., Frostiak, J., and Welch, D. (2003) Surface disposal of paste tailings at the Bulyanhulu Gold Mine, Tanzania. In Proceedings of Sudbury 2003, Mining and the Environment, Sudbury, ON, May 26-28. (G. Spiers, P. Beckett and H. Conroy, eds.) Laurentian University Centre for Continuing Education, Sudbury, ON pp. 265-269. 
Thornwaite, C.W. (1948) An approach toward a rational classification of climate.

Geographical Review. 38: 55-94.

UMS (2008) T5 Pressure transducer tensiometer user manual. UMS GmbH, Munich, Germany.

U.S. EPA (United States Environmental Protection Agency) Treatment for Acid Mine Drainage. Updated Jan. 10, 2008; Accessed Sept. 1, 2008 at: http://www.epa.gov/reg3wapd/nps/mining/treatment.htm

Van Genuchten, M.T. (1980) A closed-form equation for predicting the hydraulic conductivity of unsaturated soils. Soil. Sci. Soc. Am. J. 44: 892-898.

Verburg, R. (2001) Use of paste technology for tailings disposal: Potential environmental benefits and requirements for geochemical characterization. Presented at the International Mine Water Association Symposium, Belo Horizonte, Brazil.

Verburg, R., Johnson, B., Fordham, M., and Logsdon, M. (2003) A rapid and costeffective method for bench screening of geochemical performance and disposal options for high-sulphide tailings. Presented at the $6^{\text {th }}$ International Conference on Acid Rock Drainage, Cairns, Australia, July 12-18.

Verburg, R., Newman, P., and Fordham, M. (2006) Surface paste disposal of highsulphide tailings - Field cell monitoring and pilot plant testing. Presented at the 7th International Conference on Acid Rock Drainage (ICARD), St. Louis, MO, March 26-30.

Vick, S.G. (1990) Planning, design and analysis of tailings dams. BiTech Publishers, Limited, Vancouver, British Columbia, Canada. 
Walton-Day, K. (2003) Passive and active treatment of mine drainage. In Environmental Aspects of Mine Wastes (J.L. Jambor, D.W. Blowes and A.I.M Ritchie, eds.) Mineral. Assoc. Can. Short Series Vol. 31:335-359.

White, A.F. and Brantley, S.L. (1995) Chemical weathering rates of silicate minerals: An Overview. In Chemical Weathering Rates of Silicate Minerals (A.F. White and S.L. Brantley, eds.) Rev. Mineral. 31: 1-583.

Williamson, M.A. and Rimstidt, J.D. (1994) The kinetics and electrochemical ratedetermining step of aqueous pyrite oxidation. Geochim. Cosmochim. Acta. 58: $5443-5454$.

Wilson, G.W. (1990) Soil evaporative fluxes for geotechnical engineering problems. Ph.D Thesis, University of Saskatchewan, Saskatoon, Saskatchewan, Canada.

Wilson, G.W., Fredlund, D.G., and Barbour, S.L. (1997) The effect of soil suction on evaporative fluxes from soil surfaces. Can. Geotech. J. 34: 145-155.

Wunderly, M.D., Blowes, D.W., Frind, E.O., and Ptacek, C.J. (1996) A multicomponent model incorporating kinetically controlled pyrite oxidation. Water Resources Research. 32: 3173-3187.

Xu, T., White, S.P., Pruess, K., and Brimhall, G.H. (2000) Modelling of pyrite oxidation in saturated and unsaturated subsurface flow systems. Transport in Porous Media. 39: $25-56$.

Yanful, E.K., Mousavi, S.M., and De Souza, L. (2006) A numerical study of soil cover performance. Journal of Environmental Management. 81: 72-92. 
Yanful, E.K., Simms, P.H., and Payant, S.C. (1999) Soil covers for controlling acid generation in mine tailings: A laboratory evaluation of the physics and geochemistry. Water, Air and Soil Pollution. 114: 347-375.

Yilmaz, E., Kesimal, A., and Erçikdi, B. (2004) Evaluation of acid producing sulphidic mine tailings as a paste backfill. İstanbul Üniv. Müh. Fak. Yerbilimleri Dergisi. 17: 11-19.

Zagury, G.J., Neculita, C.M., and Bussière, B. (2005) Passive biological treatment of acid mine drainage: challenges of the 21 st century, 2e Symposium sur l'environnement et les mines organisé par l'ICM - Rouyn-Noranda, 15-18 Mai. 


\section{A. Effect of Shrinking Particle Diameter on Oxidation Rate}

The change in pyrite surface area (S) over a time interval, $t$, can be approximated by the removal rate of pyrite $\left(K_{p y}, \mathrm{~mol} \mathrm{FeS}_{2} /\right.$ day $)$ times the time step $(\Delta t)$ over the molar density, $D_{p y}\left(\mathrm{~mol} \mathrm{FeS}_{2} / \mathrm{m}^{3}\right)$ (Elberling et al., 1994). The following equation describes the reduction in pyrite surface area due to radial shrinkage:

$$
S_{t}=S_{t-1}-\frac{K_{p y} \Delta t}{D_{p y}}
$$

Sulphide depletion during the small-scale test was modelled in two ways: (1) accounting for the reduction in surface area due to particle shrinkage and (2) assuming the change in particle diameter does not affect the available surface area. The effect on surface area reduction due to particle shrinkage was found to be insignificant in the overall sulphide depletion results. Figure A.1 shows the reduction in surface area during the 26-day test and Figure A.2 shows the resulting sulphide depletion profiles using a constant surface area or the shrinking surface area. There is effectively no difference between the two because the reduction in particle size over the 26-day test makes very little difference in the total available surface area. 


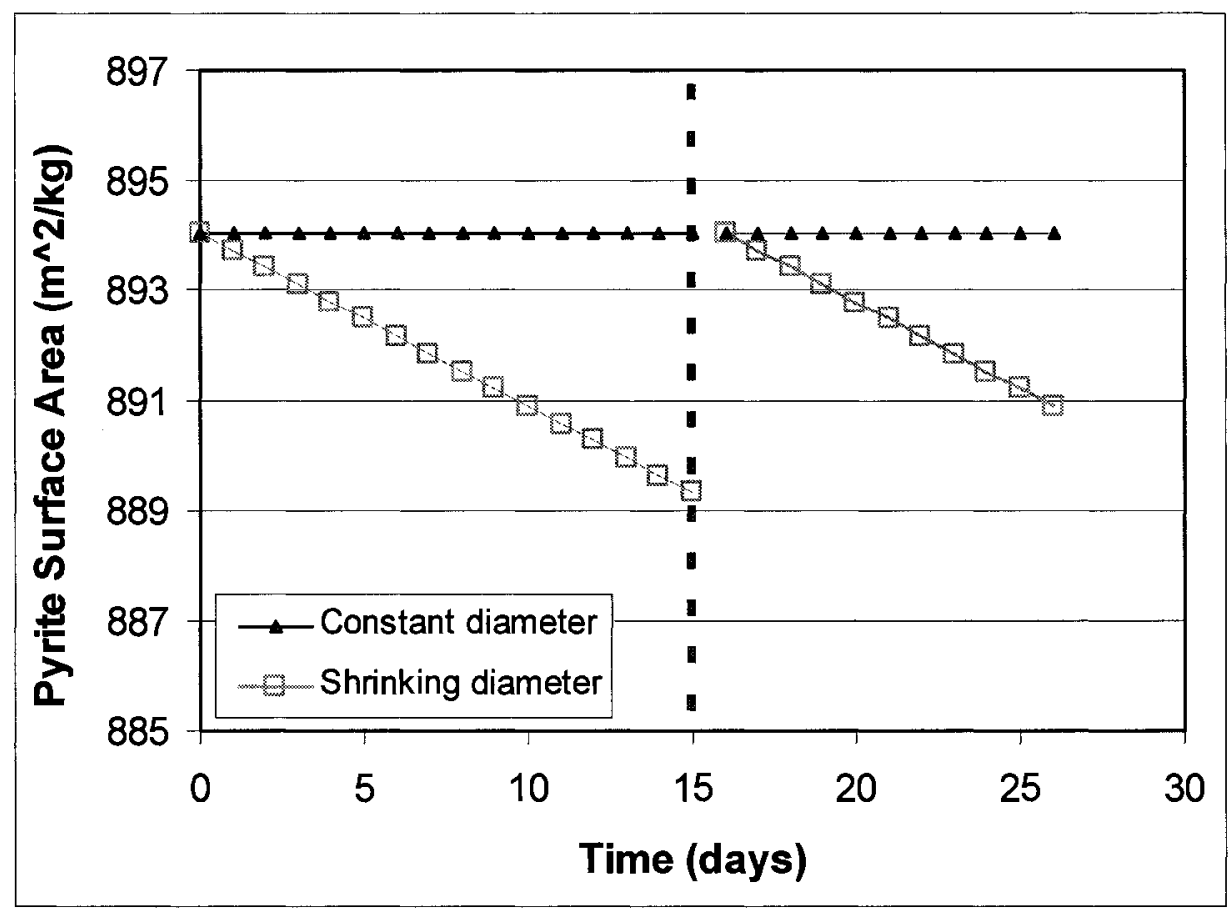

Figure A.1 Pyrite surface area with and without accounting for particle shrinkage due to oxidation.

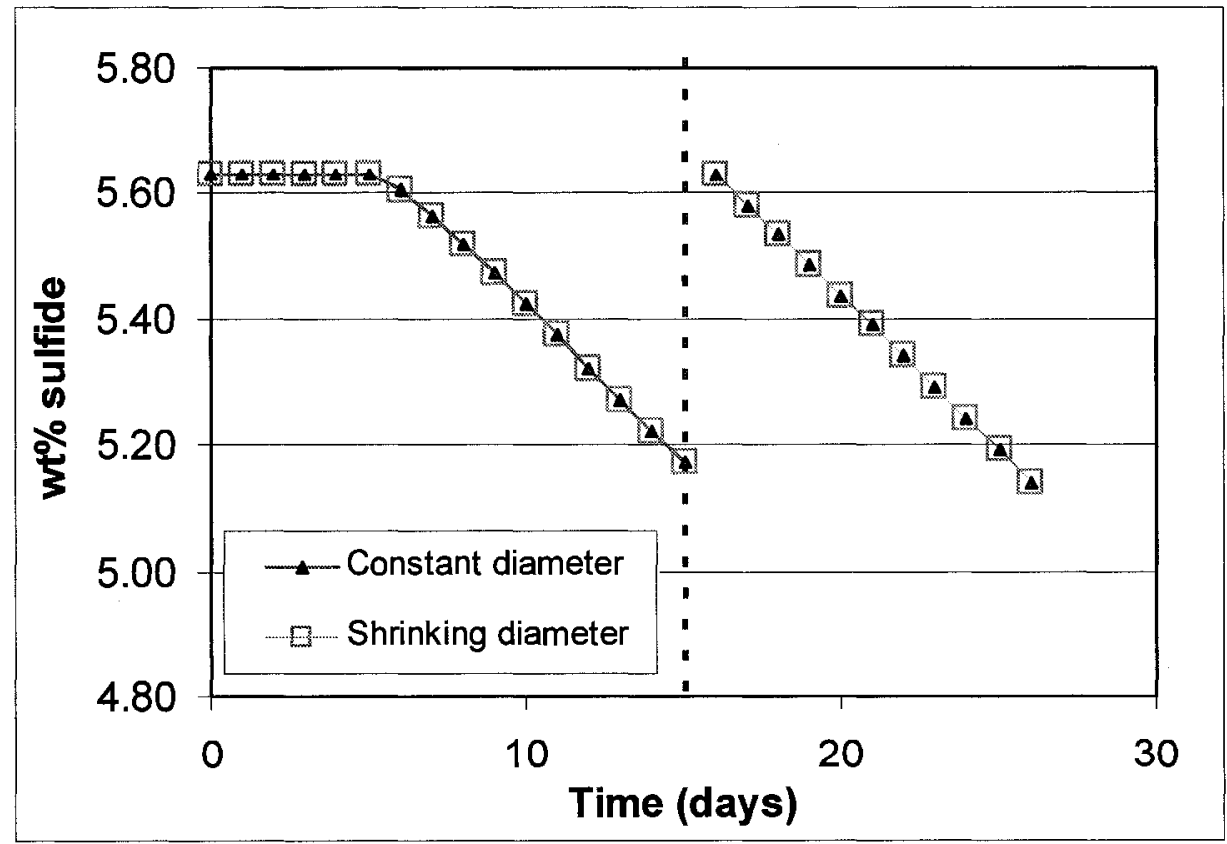

Figure A.2 Comparison of sulphide depletion for small-scale test with and without accounting for the reduction in particle size. 


\section{B. Bucket Homogeneity Test}

This test was done to validate the assumption that within a well-mixed bucket of fresh tailings the sulphide content was uniform. It was also used to determine the precision in the sulphide measurements.

A bucket of tailings was mixed thoroughly and ten samples were taken from different locations in the bucket. Each sample was analyzed for sulphide content in the solid phase with the following results:

Table B.1 Solid phase sulphide content of samples taken at random in a well-mixed bucket of unoxidized tailings.

\begin{tabular}{|r|r|}
\hline Sample & wt\% S \\
\hline 1 & 6.31 \\
\hline 2 & 6.26 \\
\hline 3 & 6.31 \\
\hline 4 & 4.56 \\
\hline 5 & 6.42 \\
\hline 6 & 6.41 \\
\hline 7 & 6.41 \\
\hline 8 & 6.38 \\
\hline 9 & 6.62 \\
\hline 10 & 6.62 \\
\hline
\end{tabular}

Sample 4 was removed from the dataset using a Q-test to identify and eliminate outlying points. For 10 observations, $\mathrm{Q}_{99 \%}=0.568$.

$$
Q=\frac{\text { gap }}{\text { range }}=\frac{(6.26-4.56)}{(6.62-4.56)}=0.83
$$

Since $\mathrm{Q}_{\text {calculated }}>\mathrm{Q}_{99 \%}$, we can reject sample 4 at $99 \%$ confidence.

The mean of the remaining 9 points is $6.42 \mathrm{wt} \% \mathrm{~S}$ and the standard deviation is $0.12 \mathrm{wt} \% \mathrm{~S}$. In terms of percentage, the standard deviation of the measurements was \pm $1.9 \%$ of the mean. This value was used to create the error bars shown on the sulphide depletion graphs in Figures 4.10, 4.11, 6.6, and 6.7. 


\section{Long-Term Rewetting Test: Rewetting and Sampling Dates}

Table C.1 Sampling and rewetting dates for the long-term rewetting test (Chapter 3).

\begin{tabular}{lcc}
\hline Date & Rewet & Sampled \\
\hline 26-Jan-08 & & $\mathrm{x}$ \\
10-Feb-08 & $\mathrm{x}$ & $\mathrm{x}$ \\
19-Feb-08 & $\mathrm{x}$ & $\mathrm{x}$ \\
12-Mar-08 & $\mathrm{x}$ & \\
19-Mar-08 & $\mathrm{x}$ & \\
21-Apr-08 & $\mathrm{x}$ & $\mathrm{x}$ \\
14-May-08 & $\mathrm{x}$ & \\
22-May-08 & & $\mathrm{x}$ \\
19-June-08 & & \\
\hline
\end{tabular}




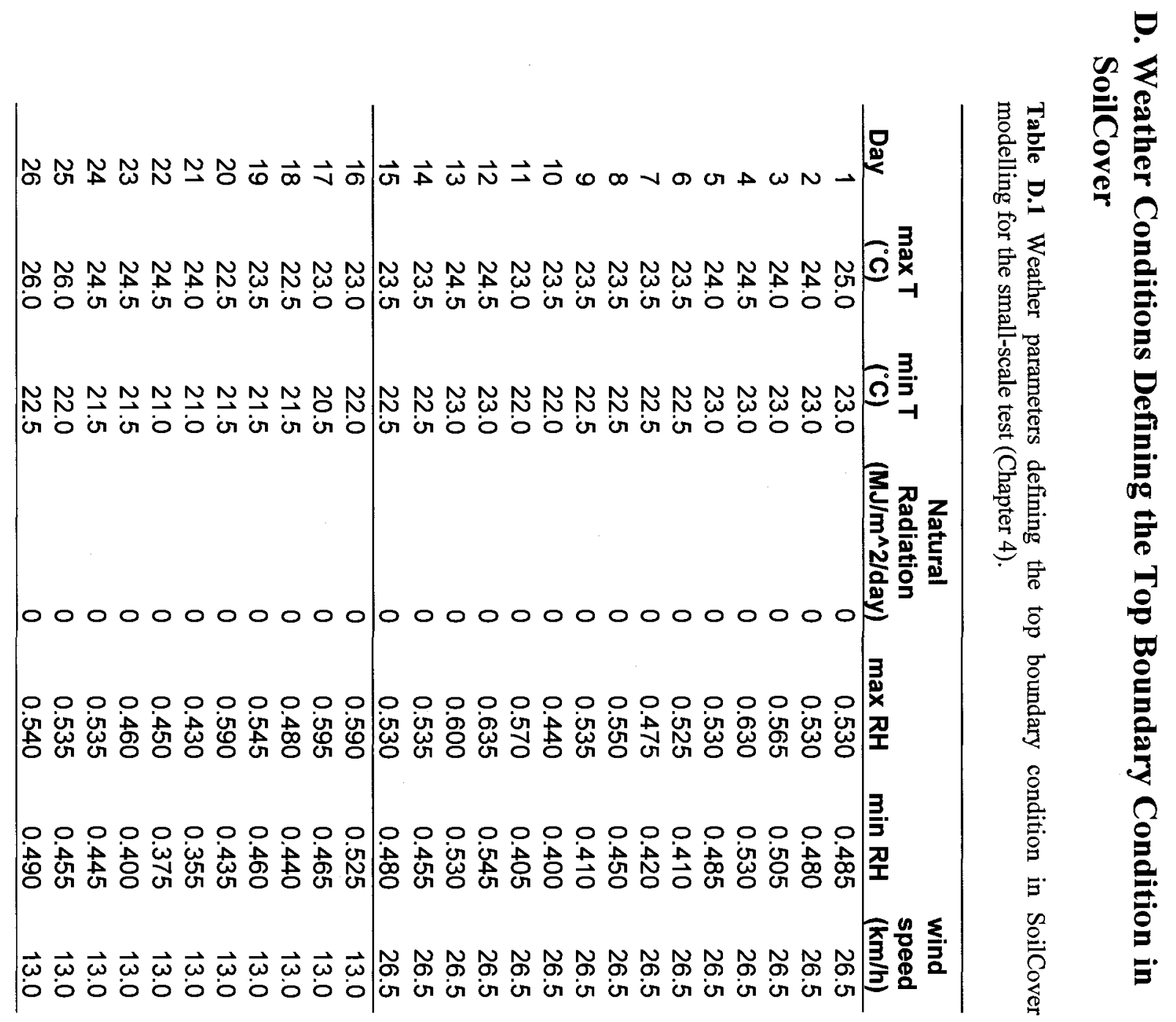




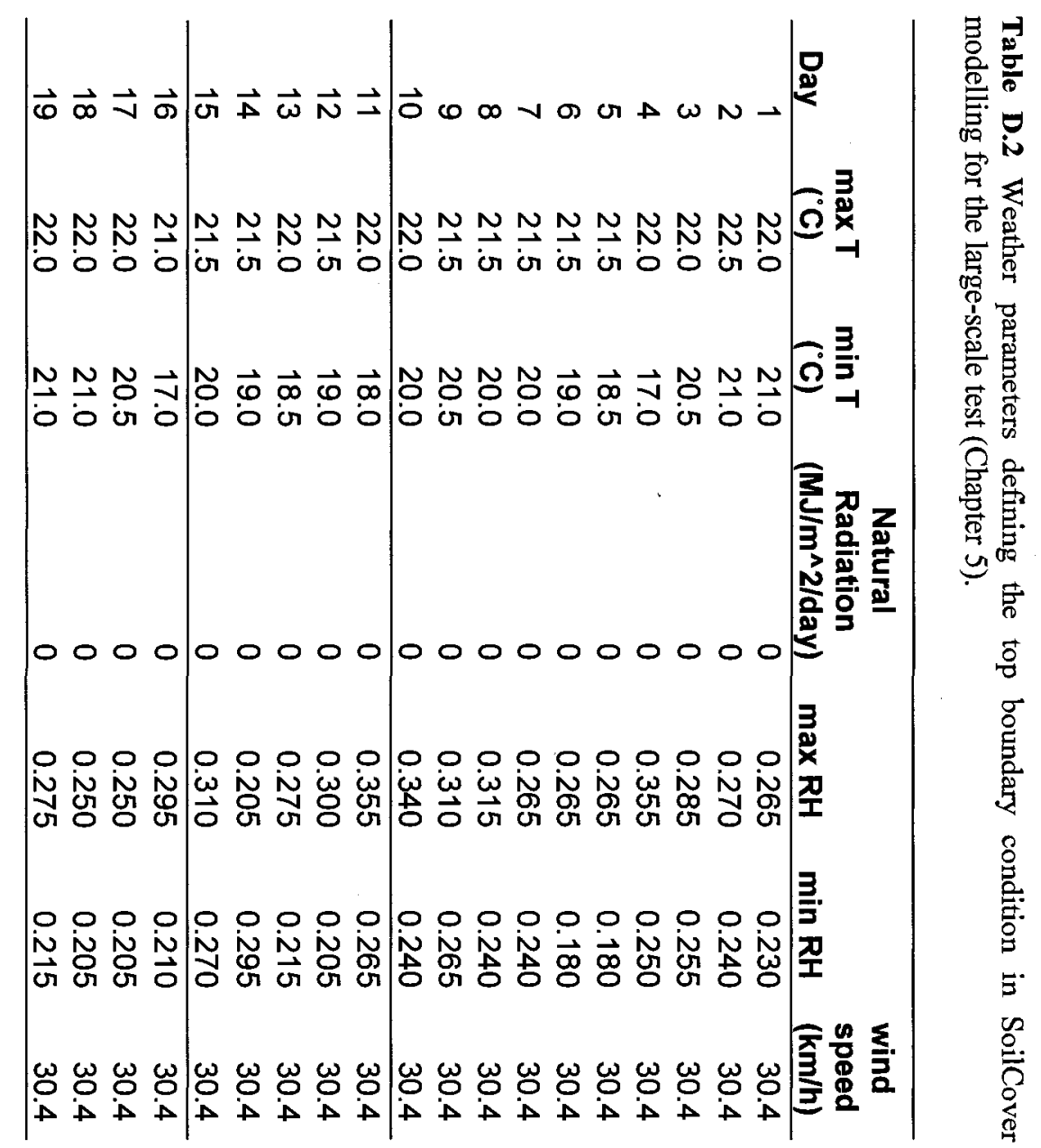




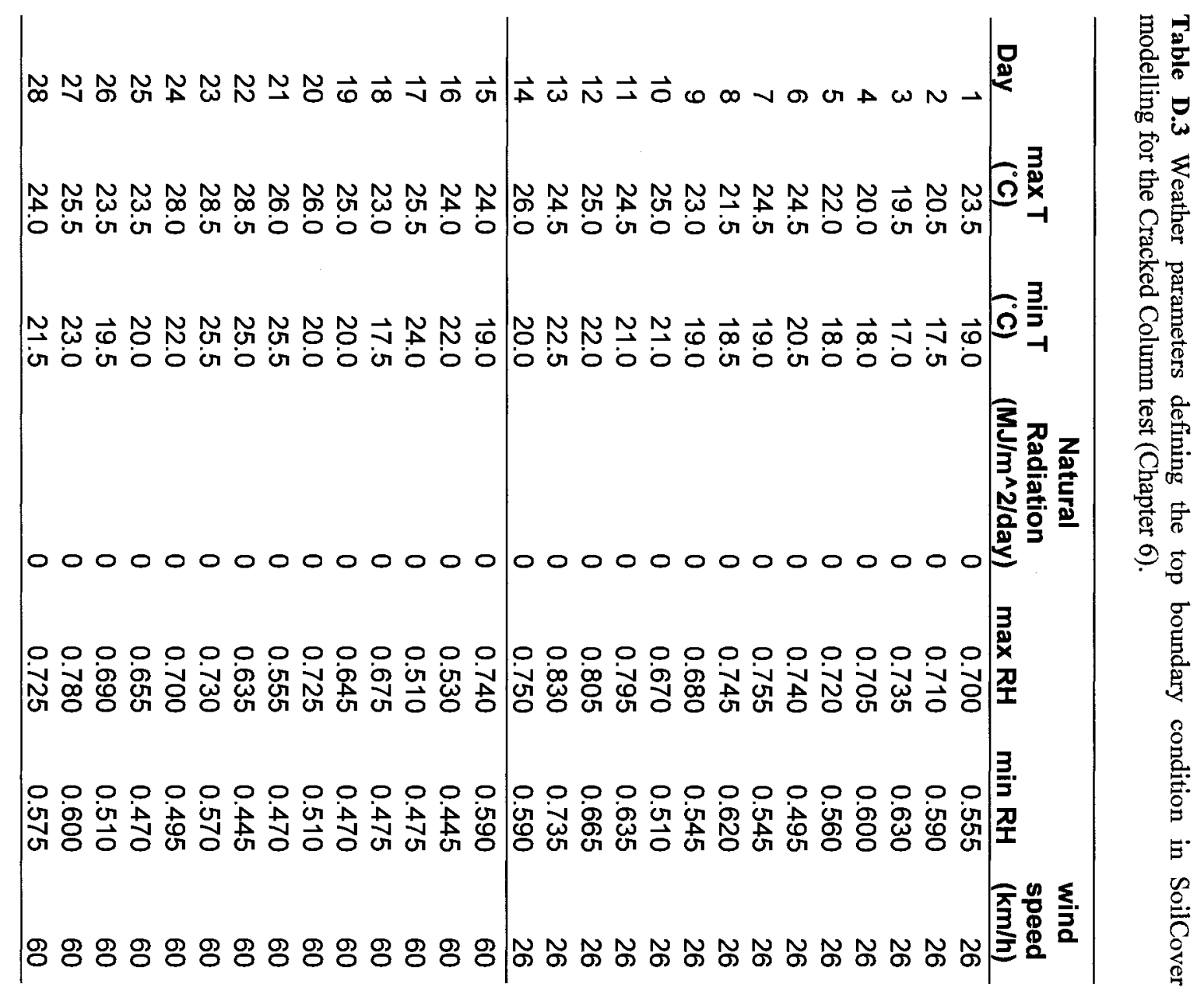


Table D.4 Weather parameters defining the top boundary condition in SoilCover modelling for the Sealed Column test (Chapter 6).

\begin{tabular}{|c|c|c|c|c|c|c|}
\hline Day & $\begin{array}{c}\max T \\
\left({ }^{\circ} \mathrm{C}\right)\end{array}$ & $\begin{array}{c}\min \mathrm{T} \\
\left({ }^{\circ} \mathrm{C}\right)\end{array}$ & $\begin{array}{c}\text { Natural } \\
\text { Radiation } \\
\text { (MJ/m^2/day) }\end{array}$ & $\max \mathbf{R H}$ & $\min R H$ & $\begin{array}{l}\text { wind } \\
\text { speed } \\
(\mathrm{km} / \mathrm{h})\end{array}$ \\
\hline 1 & 24.0 & 20.5 & 0 & 0.675 & 0.515 & 36 \\
\hline 2 & 24.5 & 21.0 & 0 & 0.740 & 0.625 & 36 \\
\hline 3 & 26.0 & 22.5 & 0 & 0.760 & 0.525 & 36 \\
\hline 4 & 24.5 & 22.5 & 0 & 0.805 & 0.700 & 36 \\
\hline 5 & 26.0 & 21.5 & 0 & 0.765 & 0.565 & 36 \\
\hline 6 & 24.5 & 21.0 & 0 & 0.745 & 0.655 & 36 \\
\hline 7 & 24.0 & 20.5 & 0 & 0.720 & 0.630 & 36 \\
\hline 8 & 24.0 & 21.0 & 0 & 0.730 & 0.615 & 36 \\
\hline 9 & 23.5 & 22.0 & 0 & 0.785 & 0.690 & 36 \\
\hline 10 & 23.0 & 20.5 & 0 & 0.795 & 0.720 & 36 \\
\hline 11 & 25.0 & 21.0 & 0 & 0.730 & 0.575 & 36 \\
\hline 12 & 23.5 & 20.5 & 0 & 0.750 & 0.675 & 36 \\
\hline 13 & 24.0 & 21.5 & 0 & 0.695 & 0.555 & 36 \\
\hline 14 & 24.5 & 21.0 & 0 & 0.725 & 0.620 & 36 \\
\hline 15 & 24.0 & 20.5 & 0 & 0.715 & 0.595 & 38 \\
\hline 16 & 23.5 & 21.5 & 0 & 0.785 & 0.675 & 38 \\
\hline 17 & 25.0 & 21.5 & 0 & 0.755 & 0.610 & 38 \\
\hline 18 & 24.5 & 21.0 & 0 & 0.745 & 0.605 & 38 \\
\hline 19 & 23.5 & 20.5 & 0 & 0.765 & 0.650 & 38 \\
\hline 20 & 24.5 & 21.0 & 0 & 0.745 & 0.625 & 38 \\
\hline 21 & 24.5 & 21.5 & 0 & 0.750 & 0.630 & 38 \\
\hline 22 & 25.5 & 21.5 & 0 & 0.760 & 0.645 & 38 \\
\hline 23 & 24.5 & 20.5 & 0 & 0.770 & 0.635 & 38 \\
\hline 24 & 25.0 & 20.5 & 0 & 0.735 & 0.575 & 38 \\
\hline 25 & 23.5 & 20.0 & 0 & 0.695 & 0.610 & 38 \\
\hline 26 & 23.5 & 19.5 & 0 & 0.720 & 0.525 & 38 \\
\hline 27 & 22.5 & 20.0 & 0 & 0.720 & 0.610 & 38 \\
\hline 28 & 23.5 & 20.5 & 0 & 0.740 & 0.605 & 38 \\
\hline
\end{tabular}

Table D.5 Weather parameters defining the top boundary condition in SoilCover modelling for the Bulyanhulu 10-cm layer simulation (Chapter 7).

\begin{tabular}{|c|c|c|c|c|c|c|}
\hline Day & $\begin{array}{c}\max T \\
\left({ }^{\circ} \mathrm{C}\right)\end{array}$ & $\begin{array}{c}\min T \\
\left({ }^{\circ} \mathrm{C}\right)\end{array}$ & $\begin{array}{c}\text { Natural } \\
\text { Radiation } \\
\text { (MJ/m^/2/day) }\end{array}$ & $\max R H$ & $\min R H$ & $\begin{array}{l}\text { wind } \\
\text { speed } \\
(\mathrm{km} / \mathrm{h})\end{array}$ \\
\hline $\mathrm{All}^{*}$ & 35 & 35 & 3 & 0.4 & 0.3 & 30 \\
\hline
\end{tabular}

*conditions were the same each day to give daily potential evaporation of $10.0 \mathrm{~mm}$ 


\section{E. Electrical Conductivity Calibration Curve}

Ten milliliters of $996 \mu \mathrm{S} / \mathrm{cm}$ solution was spiked with $100 \mu \mathrm{L}$ of sample with known EC to create the calibration curve in Figure E.1. The calibration curve was then used to determine the EC of the two unknown samples from Jan $30^{\text {th }}$ and Feb $7^{\text {th }}$.

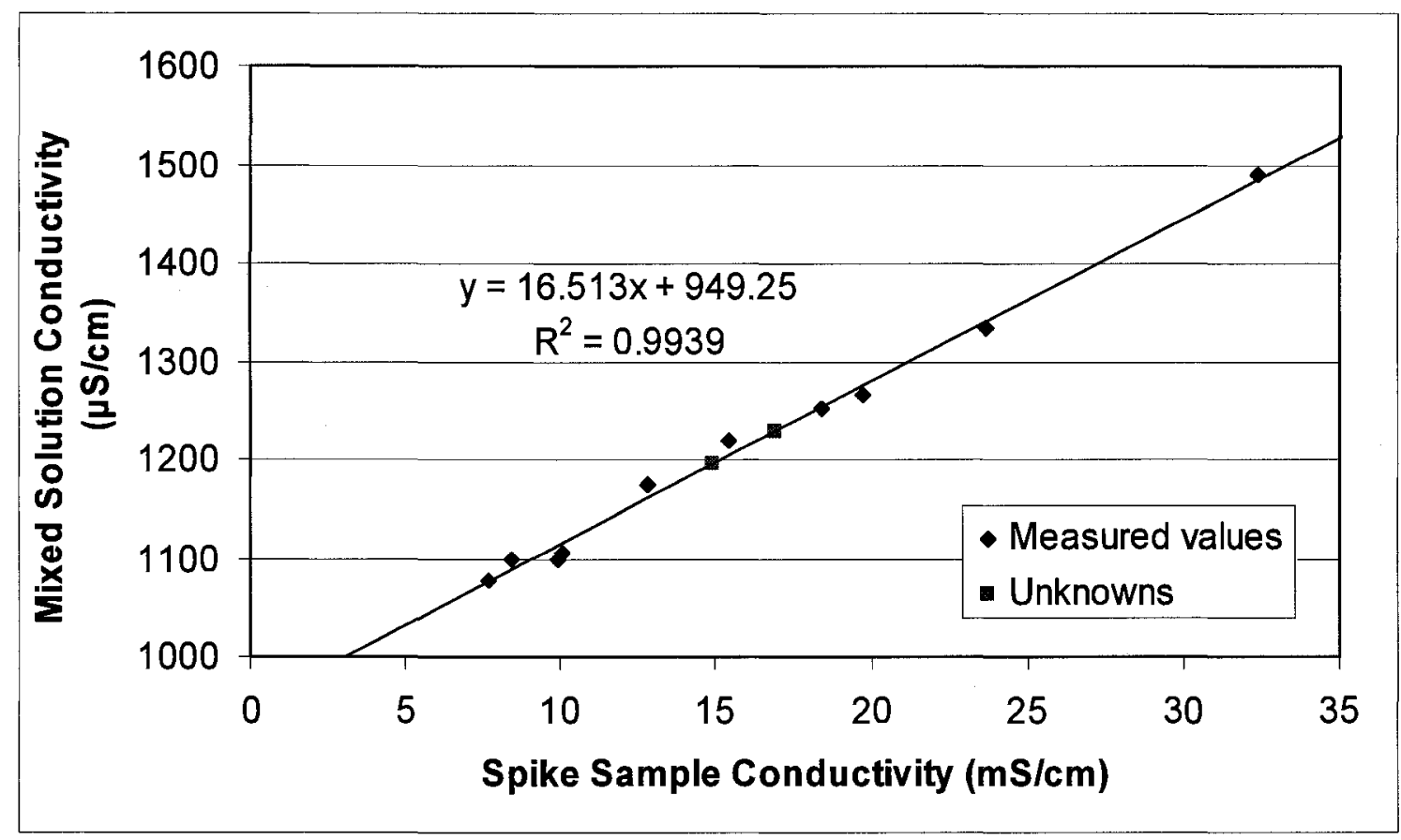

Figure E.1 Calibration curve for pore water electrical conductivity measurements.

Table E.1 Calibration curve and unknown measurements of electrical conductivity used in Figure E.1.

\begin{tabular}{ll}
\hline $\begin{array}{l}\text { Spike Sample } \\
\text { Conductivity } \\
(\mathrm{mS} / \mathrm{cm})\end{array}$ & $\begin{array}{l}\text { Mixed Solution } \\
\text { Conductivity } \\
(\mu \mathrm{S} / \mathrm{cm})\end{array}$ \\
\hline 7.65 & 1077 \\
8.43 & 1098 \\
9.93 & 1100 \\
10.06 & 1105 \\
12.81 & 1174 \\
15.45 & 1218 \\
18.40 & 1251 \\
19.74 & 1265 \\
23.70 & 1333 \\
32.40 & 1490 \\
14.88 & 1195 \\
16.88 & 1228 \\
\hline
\end{tabular}

Jan 30 unknown sample Feb 7 unknown sample 


\section{F. Large-Scale Test Sulphide Depletion Results}

The sulphide depletion profiles from the large-scale test showed poor agreement between experimental and modelled results. The only consistent profile is on Day 19 taken from the middle of a slab. The other experimental profiles do not even fit the type of shape that would be expected (i.e. higher sulphide depletion nearer the tailings surface). Also, the comparisons between Crack and Middle profiles on the same day did not show the expected trend that sulphide would be more depleted near the edge of a crack.

The reason for this was likely because the cracking pattern in Layer 1 and Layer 2 was not consistent (see Figure 5.3). As a result, a core sample taken at a crack edge for Layer 2 may not have been at a crack edge directly below in Layer 1. Likewise, what was a core sample taken far from a crack edge in Layer 2 might have been next to a crack in Layer 1. Because of this oversight, the depth profiles could be muddled with different oxygen exposures. 


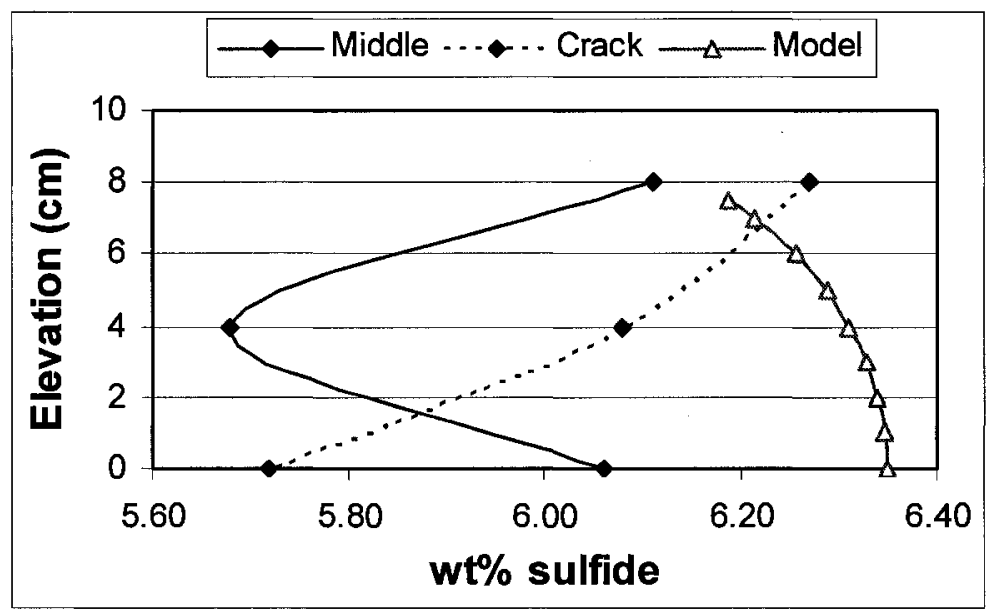

(a) Day 9

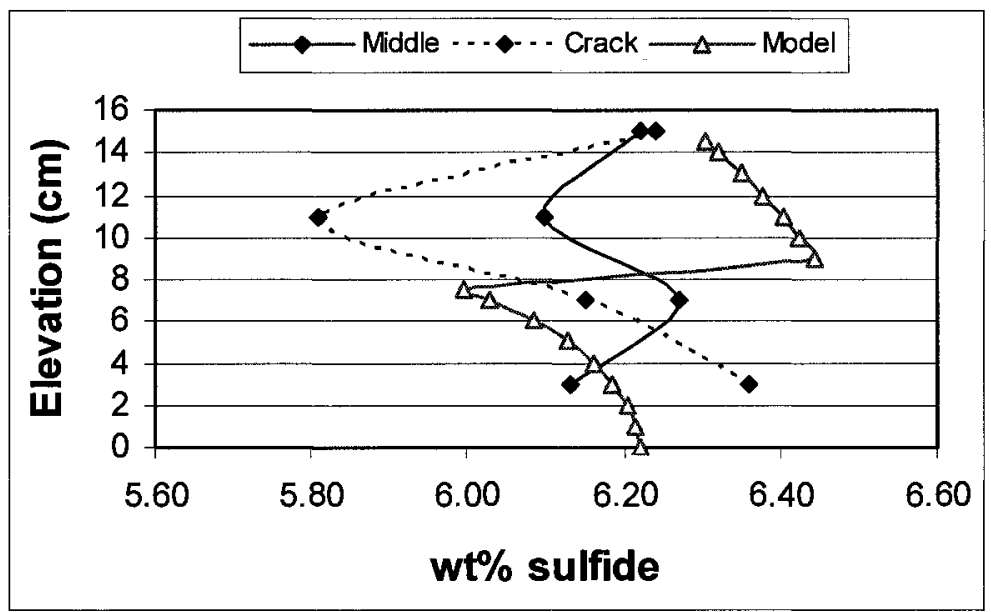

(b) Day 15

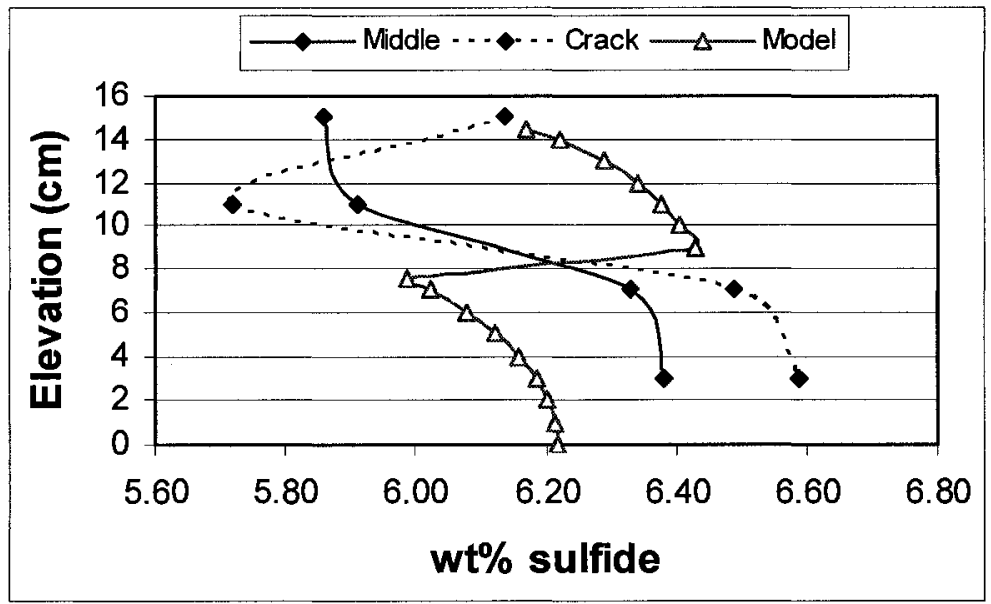

(c) Day 19

Figure F.1 Experimental and modelled sulphide content with depth during the large-scale test. Profiles were taken on (a) Day 9, (b) Day 15, and (c) Day 19 at either the edge of a crack (Crack) or in the middle of a slab of tailings (Middle). 


\section{G. Horizontal Profile of Sulphide Content}

There was no significant difference between the Cracked and Sealed Columns in terms of sulphide depletion with depth on Day 28. However, the profiles were taken close to the centre of the column where the effect of cracking may not have been felt. Therefore, an additional single layer test was done to try to determine whether there was any difference in sulphide content in a horizontal profile through the tailings.

A single layer of fresh tailings was poured at $40 \% \mathrm{GWC}$ and allowed to dry over a 12-day period. The tailings cracked and pulled away from the column edges by Day 8 . On Day 12, six samples were taken at the locations shown on the following schematic:

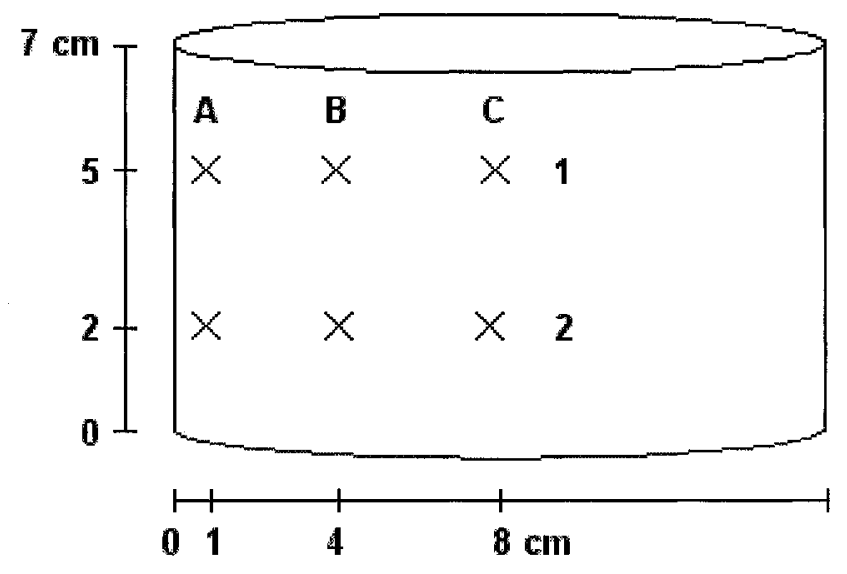

Figure G.1 Schematic of sampling to compare horizontal profile of sulphide content in cracked tailings. 
The initial sulphide content of the fresh tailings was $7.20 \mathrm{wt} \% \mathrm{~S}$. The six samples were analyzed for sulphide content in the solid phase with the following results:

Table G.1 Horizontal profile of sulphide content in the solid phase of a 7-cm layer of tailings. A1, A2, B1, B2, C1 and C2 correspond to the sampling locations shown in Figure G.1.

\begin{tabular}{llllll}
\hline & $w t \% ~ S$ & & $w t \% ~ S$ & & $w t \% ~ S$ \\
\hline A1 & 6.71 & B1 & 7.09 & C1 & 6.62 \\
A2 & 7.16 & B2 & 6.73 & C2 & 6.95 \\
\hline
\end{tabular}

There was no trend observed horizontally through the tailings. It appears that cracks do not significantly affect the extent of sulphide oxidation. These results imply that the saturation of the tailings does not change horizontally through the layer despite the formation of cracks; rather it is the vertical saturation profile that impacts the degree of oxidation. 